\title{
International Congress on the Breeding of Sheep and Goats
}

Sheep and Goat Breeding and Husbandry:

Potentials under Socio-Economic Conditions

World Conference Center Bonn, Germany 15-16 October 2020

\section{Collection of Abstracts}

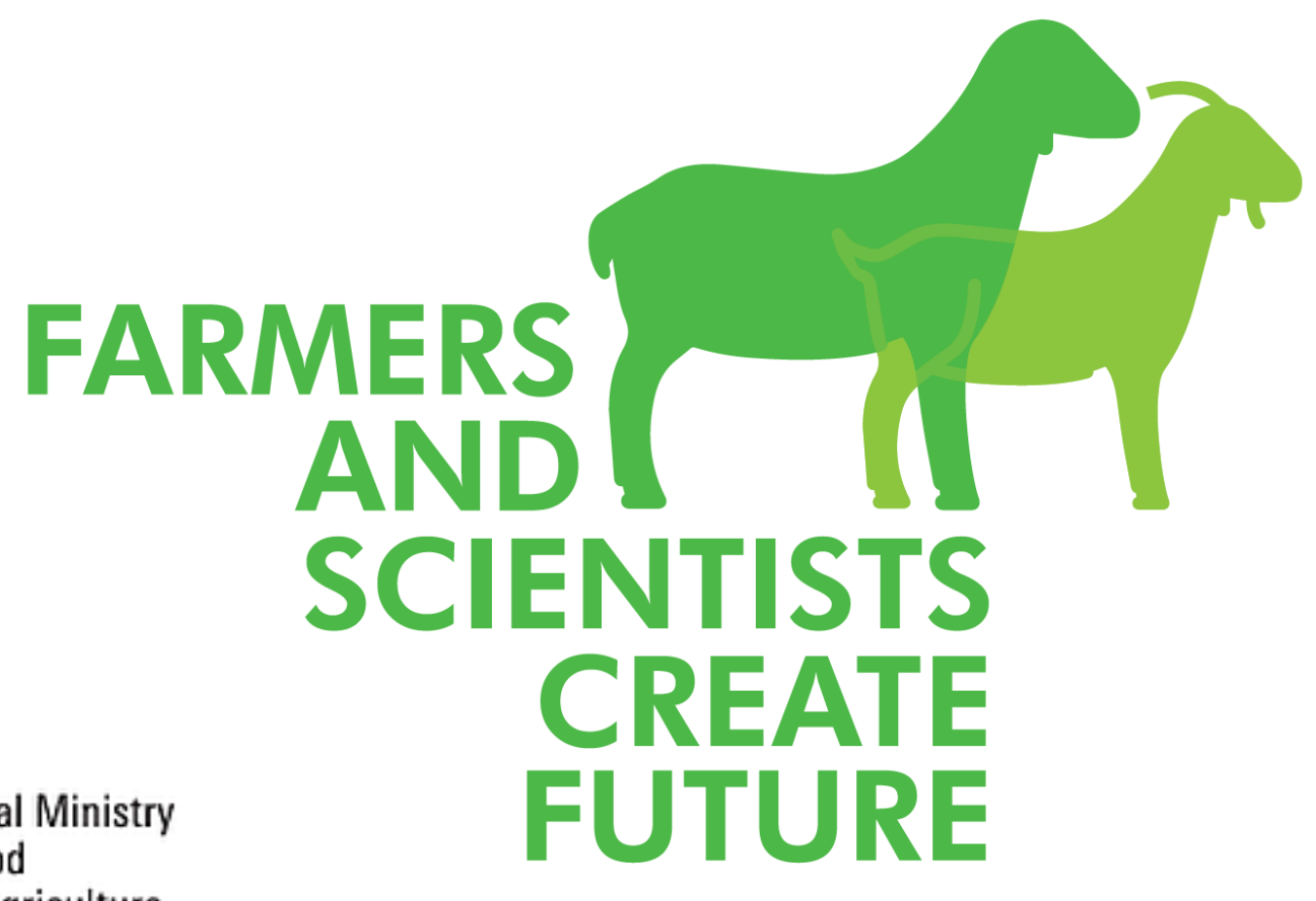

of Food

and Agriculture 


\section{Focus and Scope of Genetic Resources}

Genetic Resources is an open access journal disseminating global knowledge and tools used by the community of practitioners of plant, animal and forest genetic resources involved in monitoring, collecting, maintaining, conserving, characterizing and using genetic resources for food, agriculture and forestry. Genetic Resources publishes original research as well as methods, strategies, guidelines, case studies or reviews on a variety of topics of interest on the present and future use of genetic resources. These may include the documentation, conservation, management, assessment, characterization and evaluation of genetic resources and their link to broader biodiversity, socioeconomic practices, policy guidelines or similar, serving stakeholders within and across sectors. Occasionally, Genetic Resources publishes special issues with a focus on selected topics of interest for the genetic resources community. The journal welcomes contributions from all world regions.

\section{Special issue editorial team:}

\section{Organizer}

Christian Gerlinger (BMEL, Germany)

\section{Genetic Resources}

Etienne Verrier (AgroParisTech, France)

Sandra Goritschnig (ECPGR Secretariat, Italy)

\section{Editorial office:}

ECPGR Secretariat

c/o Bioversity International

Via dei Tre Denari 472A

00054 Maccarese (RM), Italy

Submissions to www.genresj.org

The designations employed, and the presentation of material in the periodical, and in maps which appear herein, do not imply the expression of any opinion whatsoever on the part of ECPGR or BMEL concerning the legal status of any country, territory, city or area or its authorities, or concerning the delimitation of its frontiers or boundaries. Similarly, the views expressed are those of the authors and do not necessarily reflect the views of ECPGR or BMEL.

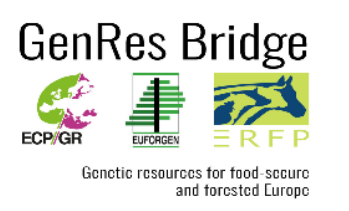

This special issue has been produced with the support of the Federal Ministry of Food and Agriculture (BMEL), Germany and in the frame of GenRes Bridge, a project which has received funding from the European Union's Horizon 2020 research and
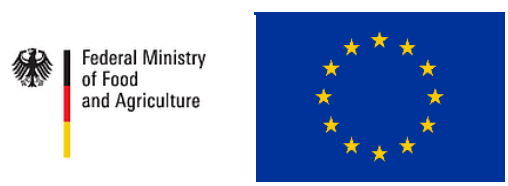
innovation programme under grant agreement No 817580 


\section{Table of contents}

Scientific Program Group

Editorial

Congress Summary

Abstracts:

Block 1+2: Animal breeding and genetics: What will sheep and goat breeding look like in the future?

Oral presentations

Poster abstracts

Block 3: Economy: How can the profitability of sheep and goat farming be improved?

Keynote presentation

Oral presentations

Poster presentations

Block 4: Environmental performance and climate change: What do sheep and goats contribute to climate change mitigation?

Oral presentations

Block 5: Animal genetic resources: Diversity and characterization

Keynote presentation

Oral presentations

Poster presentations

Block 6: Animal genetic resources: Implementation of policies and support

Oral presentations

Block 7: Management and animal welfare:

Keynote presentation

Oral presentations

Poster presentations 
Block 8: Other topics

Keynote presentation $\quad \underline{68}$

Oral presentations $\underline{69}$

Poster presentations $\quad \underline{72}$

Block 9: Animal health: Parasitology

Oral presentations $\quad \underline{78}$

Block 10: Animal health: Locomotive apparatus and monitoring

Oral presentations $\quad \underline{83}$

Block 11: Animal health: Reproduction

Oral presentations $\quad \underline{89}$

Poster presentations (all Animal health subtopics) 94

Block 12: Structures of and prospects for sheep and goat farming, sustainability

Oral presentations $\quad \underline{105}$

Poster presentations $\quad \underline{109}$ 


\section{Head of program group}

Dr. Bernhard Polten (Bundesministerium für Ernährung und Landwirtschaft, BMEL)

\section{Animal breeding and genetics}

Prof. Dr. Gesine Lühken (Justus-Liebig-Universität Giessen)

Dr. Christian Mendel (Bayerische Landesanstalt für Landwirtschaft)

\section{Economy}

Prof. Dr. Stanislaus von Korn (Hochschule für Wirtschaft und Umwelt Nürtingen Geislingen)

Janine Bruser (Landesverband Schleswig-Holsteiner Schaf- und Ziegenzüchter e.V.)

Fides Marie Lenz (Schafzuchtverband Nordrhein-Westfalen e.V.)

\section{Environmental performance and climate change}

Prof. Dr. Thomas Döring (Universität Bonn)

Michael Gertenbach (Landwirtschaftskammer Niedersachsen)

\section{Animal genetic resources}

Dr. Roswitha Baumung (Food and Agriculture Organization of the United Nations, FAO)

Christian Gerlinger (Bundesministerium für Ernährung und Landwirtschaft, BMEL)

\section{Management and animal welfare}

Dr. Heiko Georg (Thünen Institut)

PD Dr. Pera Herold (Landesamt für Geoinformation und Landentwicklung Baden-

Württemberg)

Gerhard Schuh (Thüringer Landesamt für Landwirtschaft und Ländlichen Raum)

\section{Other topics}

Prof. Dr. Claudia Klein (Friedrich-Loeffler-Institut, FLI)

Dr. Bettina Bongartz (Deutsche Gesellschaft für Züchtungskunde e.V., DGfZ)

\section{Animal health}

Prof. Dr. Martin Ganter (Stiftung Tierärztliche Hochschule Hannover)

PD Dr. Esther Humann-Ziehank (LABVETCON)

Dr. Henrik Wagner (Universität Gießen)

\section{Structures of and prospects for sheep and goat farming, sustainability}

Dr. Reinhard Reents (Vereinigte Informationssysteme Tierhaltung w.V., vit)

Dr. Jens Wilkens (Vereinigte Informationssysteme Tierhaltung w.V., vit)

Session summaries and results

Prof. Dr. Bernt Guldbrandtsen (Universität Bonn) 


\section{The future of a sustainable sheep and goat breeding}

\section{Bernhard Polten}

Federal Ministry for Food and Agriculture (BMEL), Rochusstr. 1, 53123 Bonn, Germany

Due to their manifold possible uses, sheep and goats are among the oldest domestic animals. There are plenty of good reasons to keep sheep and goats. Approximately one billion sheep and 600 million goats are kept worldwide. They are used for landscape management purposes, e.g.: to keep heathlands open or to maintain the dykes along coasts and rivers. Sheep and goats thus also contribute to the maintenance of biotopes. They promote biodiversity and sustainability. With the help of sheep and goats, valuable products can be gained from grass and, in the case of goats, also from leaves in grassland areas: milk, meat and wool. They therefore contribute to the income of sheep and goat keepers.

Sheep and goats can adapt to changing environments. Yet, greater adaptive capacity is more important now than ever before. Infectious diseases can spread quickly throughout the world. Environmental changes are often perceived as a result of climate change with different manifestations.

This International Congress on the Breeding of Sheep and Goats intends, for example,

- to give an impression of sheep and goat keeping at global level,

- to translate new research results into practice,

- to identify the real-world need for research, and

- to contribute to networking.

The global COVID-19 pandemic has posed great challenges to all parties involved in the congress. Until only a few months ago, the congress had been planned as a pure face-to-face event. But due to the coronavirus, the congress had to be re-organised as a hybrid event at short notice. This has called for a great amount of extra time and technical efforts from all actors.

But we - and especially the organisation team, the programme group and the scientific programme group, all people involved on and off stage, as well as all participants in this event - hope that all those efforts will be rewarded by an interesting congress and many new contacts and that the new technologies used may be able to outweigh at least some of the disadvantages caused by the coronavirus crisis. 
Abridged press release on the "International Congress on the Breeding of Sheep and Goats" at the WCCB in Bonn on 15 and 16 October 2020, published in German in: Züchtungskunde, 92, (6) pp. 452-459, 2020, ISSN 0044-5401, Verlag Eugen Ulmer, Stuttgart

\title{
Sheep and goat keepers worldwide discussed the future of breeding and husbandry
}

\author{
Bettina Bongartz ${ }^{1}$ and Christian Gerlinger ${ }^{2}$ \\ ${ }^{1}$ Deutsche Gesellschaft für Züchtungskunde e.V. (DGfZ - German Society for Animal Production), \\ Adenauerallee 174, D-53113 Bonn \\ ${ }^{2}$ Bundesministerium für Ernährung und Landwirtschaft (BMEL - German Federal Ministry of Food and \\ Agriculture), Rochusstraße 1, D-53123 Bonn
}

Contact: [Deutsche Gesellschaft für Züchtungskunde e.V. (DGfZ), Adenauerallee 174, 53113 Bonn, info@dgfz-bonn.de]

The "International Congress on the Breeding of Sheep and Goats", held in Bonn from 1516 October 2020 as a hybrid event, brought together researchers and professionals from the sheep and goat breeding sector across all borders.

The Federal Ministry of Food and Agriculture (BMEL) invited experts to the first International Congress on the Breeding of Sheep and Goats in Bonn on 15 and 16 October 2020 under the title "Farmers and Scientists create Future". The conference provided a platform for researchers, professional associations, practitioners and non-governmental organisations to deepen their exchange on topical issues of sheep and goat breeding and husbandry.

They discussed different current issues ranging from climate change to resilience with regard to animal breeding. More than 300 participants from all around the world joined the congress online or on site. The state-of-the-art World Conference Center Bonn (WCCB) provided the perfect framework for hosting a safe event in times of COVID-19.

Nearly 150 contributions from approximately 40 countries were submitted, which made for a particularly interesting international programme. Experts delivered more than 60 presentations, mainly in English, which were translated simultaneously into German. During the breaks and the evening event, the participants had the opportunity to talk to and network with other experts. Throughout the entire conference, all participants had the chance to contemplate more than 50 posters. Exhibitors were present in the foyer to round off the congress. The German Society for Animal Production (DGfZ) also provided information on their responsibilities, activities and services in English and German.

Due to the COVID-19 pandemic, the event took place in a hybrid set-up, which involved considerable technical and organisational effort. The presentations were live-streamed and the posters were made available online, allowing all virtual participants to take part and join the discussion at all times. What an experience! Even some facilitators successfully ran their sessions via live stream. Impressed by what is possible thanks to technology, both speakers and 


\section{Congress Summary}

participants on site clearly enjoyed coming together after a six month conference break. "I am truly delighted to see you face-to-face again after such a long time," said one speaker before delivering his presentation.

While planning the event, all relevant parties met regularly to coordinate it together, assessing the ever-changing conditions and regulations in place regarding the feasibility of an international congress. At the same time, different technical options as well as the participant management had to be evaluated and considered against the backdrop of strict hygiene measures. The DGfZ provided crucial assistance with their experience in event management. Dr Bettina Bongartz, Managing Director of the DGfZ, provided her full support in the preparations of the event. She is also a member of the scientific programme group. The BMEL took a courageous decision by hosting a hybrid event and hence two events running simultaneously. This also meant double the amount of work and a budget twice as high.

The kick-off event and the plenary meeting took place in the venerable plenary hall of the former German Bundestag. State Secretary Hans-Joachim Fuchtel delivered an address outlining both the challenges and the achievements of the joint commitment by the Federal Government, the Länder and the sheep and goat farmers. He also urged all participants to remain aware of their key responsibility for biodiversity conservation and climate stewardship. "This congress is to make a contribution to this end. It aims to take stock of sheep and goat breeding at global level and to communicate the outcomes, while also translating new research results into practice, identifying where global research is actually necessary and contributing to the exchange of ideas." Mr Alfons Gimber and Mr Bernd Merscher, the respective chairs of the Confederation of German Sheep Breeding Associations (VDL) and the Federation of German Goat Breeders (BDZ), would not want to miss out on the opportunity to also deliver an address to the audience. "It is key that we recognise the global importance of sheep and goats as well as their economic relevance and their services to society," said both of them.

To kick off the plenary session, Prof. Dr. Susanne Crewell from the Institute of Geophysics and Meteorology at the University of Cologne and Prof. Dr. Daniela Jacob, Director of the Climate Service Center Germany (GERICS), showed impressive scenarios and research outcomes regarding climate change, which will also severely affect animal husbandry. Impressive timelapse videos and expected changes showed the participants how urgently necessary global action is. Mohammed Bengoumi from the FAO Subregional Office for North Africa then gave a presentation on the role of small ruminants in poverty reduction and rural development, outlining the major positive impacts of optimising the breeding and husbandry of sheep and goats in Africa. His presentation took the audience to another world, which faces different challenges and conditions. He gave an insight into the types of husbandry systems on different continents as well as the people, the specific needs they have and requirements they face.

Dr Joanne Conington from Scotland's Rural College in Edinburgh gave a presentation on the genomic selection in sheep and goats, which has already been carried out and outlined the differences compared to other animal species. As in bovine and porcine animals, the application of genomic selection results in an increased progress in breeding also in small ruminants. 
However, genomic selection has not yet achieved a breakthrough success in sheep and goat breeding due to structures which are different from the ones in cattle breeding. Nonetheless, researchers and practitioners have made solid progress over the past years in order to reap the full potential of this breeding method in the stocks, as Dr. Conington explained.

The diverse topics covered by the congress were grouped into eight fields, which were presented in three parallel sessions:

- Animal breeding and genetics

- Animal genetic resources

- Animal health

- Economy

- Management and animal welfare

- Environmental performance and climate change

- Other topics

- Structures of and prospects for sheep and goat farming, sustainability

The issues of breeding, economy, management and animal genetic resources were of particular concern to the participants, resulting in diverse debates that even continued in the breaks.

As for the economic dimension, examples from goat milk production were used to illustrate the economic variables in the output and cost estimation which are relevant to farmers, to what extent these variables are economically viable and what could be improved. Another speaker presented an analysis of the current assessment of viability in sheep farming which is representative for the whole of Germany.

An impressive keynote address in the session on "other topics" proposed an entirely new way of earning money with sheep while at the same time improving the reputation of sheep farming. Coaches and pastoralists can help conduct hands-on training courses for managers and teambuilding seminars for small and large companies. One training session can last between 3 and 4 hours. However, certain criteria need to be fulfilled. Pastoralists, for instance, must have a minimum stock of 500 sheep and goats in an attractive landscape. Examples like this prove that it is always worth thinking outside the box and exploring different opportunities to create an additional source of income.

Breeding plays a special role in developing sustainable sheep and goat farming as it critically paves the way for economic success. Solid data collection, storage and processing play a key role here.

Animal genetic resources are of utmost significance for countries in Asia and Africa. The conference gave participants the opportunity to listen to various presentations and to contemplate numerous posters from various countries. But in Germany, too, there are commitments and strategies for the conservation and use of animal genetic resources (AnGR). The National Programme for the Conservation and Sustainable Use of Animal Genetic Resources in Germany has proven to be advantageous in order to increase or at least maintain 


\section{Congress Summary}

the breeding stocks for endangered breeds and thereby maintain AnGR as the basis for adaptability in livestock production.

"We fully achieved our common goal to further strengthen networks of experts and practitioners working in the area of sheep and goat breeding, to foster the exchange on latest research findings, and to promote the communication on innovations," explained Dr. Bettina Bongartz, Managing Director of the DGfZ. The President of the DGfZ, Dr. Erwin Hasenpusch, was equally delighted about the conference, though it took place under such trying circumstances. "The Federal Ministry has demonstrated that it is possible to host events like this which are safe for all those involved. I am truly impressed by the commitment of everyone involved." "Congratulations to all parties involved and in particular to Dr. Bernhard Polten, head of the Division for Animals and Technology, for the great success that this congress has been, under difficult conditions due to COVID-19. Mr Christian Gerlinger (BMEL) deserves many thanks for taking care of the very complex organisational and technical arrangements of the event. This unique conference in such trying times has showcased the considerable importance animal breeding has for the sustainable development of livestock farming and thereby for agriculture across the globe," said the DGfZ.

The international congress delivered valuable information, incentives and insights thanks to the distinguished speakers and the very dedicated audience. The international line-up of the event, in particular, highlighted the multi-faceted importance of small ruminants across the world. Those involved agreed that work on open questions and the food for thought provided should be continued and that the dialogue should be upheld in order to make headway regarding the burning issues in the field of breeding, animal welfare and environmental affairs together with a view to the practical implementation. 


\section{Central information processing in German sheep and goat breeding}

\section{Jens Wilkens}

Vereinigte Informationssysteme Tierhaltung w.V., Heinrich-Schröder-Weg 1, 27283 Verden / Aller, Germany

Contact: jens.wilkens@vit.de

\section{Abstract:}

German sheep and goat breeding has a distinctive federal structure. The breed societies work closely together under the umbrella of VDL/BDZ. Information processing with serv.it OVICAP (https://service.vit.de/ovicap/) in the field of herd bookkeeping was established with vit (Vereinigte Informationssysteme Tierhaltung) as the VDL service partner. serv.it OVICAP has been an integral part of breeding work in Germany for 10 years now. By working together in a central information system, synergy effects can be used, which contribute to cost reduction and optimization of functionality and data quality.

The breed societies in the association are effectively enabled to functionally administer information on the identification of sheep and goats as well as their pedigrees and breeding relevant characteristics. This consolidated information base (4.884.539 animals in total, 1.104.314 animals registered in herdbook, 61.705 farmer adresses) is the basis for nationwide population analyses and breeding value estimations.

Use by the breeding farms is directly integrated into serv.it OVICAP. 70\% of active farms (2.900 breeders) use serv.it OVICAP to retrieve information about animals and make recordings (e.g. lambing - e.g. 64.774 lambings in 2019). A breeding planner can be used by the breeding farmers to estimate inbreeding degrees in mating decisions. The nationwide pedigree is essential for calculating the inbreeding degrees.

For breeders of all sheep and goat breeds, serv.it OVICAP is the information medium for their own breeding work. Working together with and on serv.it OVICAP is an essential contribution to the maintenance and further development of sheep and goat breeding. With regard to future developments, a good, expandable basis has been created i.a. in the area of advancing digitalization and implementation of genomic methods of animal breeding. 


\section{Genetic evaluation for sheep in Germany}

\section{Dr. Wolfgang Ruten and Dr. Dierck Segelke}

IT-Solutions for Animal Production, Verden, Germany

Contact: Heinrich-Schröder-Weg 1, 27283 Verden, Wolfgang.Ruten@vit.de

\section{Abstract:}

The VDL (Vereinigung Deutscher Landesschafzuchtverbände e. V.), as the umbrella organization of the German state sheep breeding associations, is the client for the sheep breeding value assessment. A consolidation of the pedigree and performance data during the development of the common herd book system at vit (serv.it Ovicap) allowed the establishment and introduction of a nationwide breeding value estimation for sheep. Since 2014 routine evaluation is executed once a year in July for 25 different sheep breeds. All known pedigree and performance data from the field test (fertility, fattening and slaughter performance characteristics, exterior assessment for herd book recording or licensing as well as maternity or mammalian performance) are taken into account for the breeding value estimation.

Table 1 shows the number of animals across all breeds in performance and in pedigree data:

\begin{tabular}{|l|c|c|c|}
\hline trait block & $\begin{array}{c}\text { number of records } \\
\text { performance data* }\end{array}$ & $\begin{array}{c}\text { number of animals } \\
\text { performance data }\end{array}$ & $\begin{array}{c}\text { number of animals } \\
\text { pedigree data }\end{array}$ \\
\hline fertility & 1.565 .899 & 392.961 & 490.617 \\
exteriorassessment & - & 363.236 & 499.885 \\
$\begin{array}{l}\text { fatteningand slaugher } \\
\text { performance characteristics }\end{array}$ & - & 262.927 & 426.272 \\
mammalian performance & 27.943 & 7.532 & 16.538 \\
* repeated performance & & &
\end{tabular}

A total of 772.772 sheep received breeding values in the run 2020/07.

Various statistical models are used within the individual trait complexes: A BLUP single-trait repeatability model is used for fertility, and BLUP multi-trait models are used for all other feature complexes. The breeding values are expressed as relative breeding values with an average of 100 points and a genetic standard deviation of 20 points.

With the introduction and establishment of the nationwide breeding value estimation for sheep, breeders and also the regional breeding associations have access to an innovative tool for breeding selection. Furthermore, the objective breeding values are comparable across the regions. By using this source of information consistently, the breeding value estimation can and will contribute to productivity increase in sheep breeding. 
Animal breeding and genetics

What will sheep and goat breeding

look like in the future?

\section{MoBPS for sheep and goats - an innovative tool to design and optimize breeding programs}

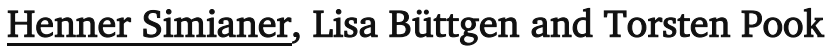

Animal Breeding and Genetics Group, Center for Integrated Breeding Research, University of Goettingen, Germany

Contact: Henner Simianer, Animal Breeding and Genetics Group, Center for Integrated Breeding Research, Albrecht-Thaer-Weg 3, 37075 Goettingen, Germany, hsimian@gwdg.de

\section{Abstract:}

Designing efficient breeding programs with the objective of generating maximum genetic progress in a cost-efficient way while maintaining genetic diversity, sustainability and animal welfare is a major challenge. We have developed an R-package termed Modular Breeding Program Simulator (MoBPS; Pook et al. 2020) allowing a flexible representation and a powerful simulation of current-time breeding programs. The basic conceptual assumption is that any breeding program can be represented by a network of nodes (typically cohorts of animals) and edges (typically breeding activities like selection or reproduction). A web-based graphical user interface (www.mobps.de) offers an intuitive approach to design breeding programs in a most flexible way. Once such a breeding program is entered, it can be simulated with the R-package, providing predictions for the genetic trend in all traits as well as the development of inbreeding rate. By comparing alternative designs the tool can be used to optimize the breeding program.

We will illustrate the usefulness and the functionality of the MoBPS package with various applications from sheep and goat breeding. It will also be demonstrated to what extent innovative technologies like gene-editing could potentially affect practical breeding in small ruminants. Templates will be provided for major breeding program designs in sheep and goat breeding, including sensible pre-settings of genetic parameters and links to widely used resources, like the major species-specific SNP genotyping arrays available.

Both the R-package and the web interface are free to use and provide a platform for the improvement of sheep and goat breeding programs worldwide.

\section{References:}

Pook, T., M. Schlather, and H. Simianer. 2020. MoBPS - Modular Breeding Program Simulator. G3; Genes $\mid$ Genomes $\mid$ Genetics 10 (6): 1915-18. https://doi.org/10.1534/g3.120.401193 


\title{
Early data from a community-based breeding program indicates opportunity for genetic gain in Black Bengal goats owned by underprivileged rural women in Bihar State of India
}

\author{
Chanda Nimbkar ${ }^{1}$, Tinni Sawhney ${ }^{2}$, Rubab Azam $^{2}$, Rumani Chakraborty ${ }^{2}$ and Peter Amer ${ }^{3}$ \\ ${ }^{1}$ Nimbkar Agricultural Research Institute (NARI), Phaltan, India \\ ${ }^{2}$ Aga Khan Foundation (AKF), New Delhi, India \\ ${ }^{3}$ AbacusBio Ltd., Dunedin, New Zealand
}

Contact: NARI Animal Husbandry Division, Phaltan-Lonand Road, Phaltan 415 523, Dist. Satara, Maharashtra, India, chanda.nimbkar@gmail.com

\section{Abstract:}

Supported by the Gates Foundation, AKF implemented a programme in Muzaffarpur district of Bihar State, India to transform the lives of rural poor through improving local Black Bengal breed goat production. Project Mesha strives to promote better goat management practices through trained women community workers. With advisory support from NARI and AbacusBio, a pilot breeding programme was established in four villages ( $~ 2000$ goats) in 2018 for withinbreed genetic improvement by selection of male kids for breeding. Based on discussions with rearers, twinning (but not litter sizes larger than twins) and early fast growth (weight at 100 days of age) were decided as selection criteria. Data from October 2018 to March 2020 was analysed using the Echidna Software. The average daily gains (ADG) of kids that were weighed $\geq$ three times up to the age of 120 days, were estimated with a regression of weight on age for each kid. Fixed models were fitted to analyse kid weights (59, 119 and 38 records for birth, 3 and 6 months' weights respectively) and ADG (199 records). There were 11\% singles, 46\% twins, 37\% triplets and 6\% quadruplets. Birth type was significant for birth, 3 month weights and ADG. Sex was significant for birth weight. Village was significant for 3 and 6 months' weights and ADG. The least squares mean (lsm) birth, 3 and 6 months' weights were $1.7 \pm 0.1$ $\mathrm{kg}, 5.9 \pm 0.2 \mathrm{~kg}$ and $11.0 \pm 0.5 \mathrm{~kg}$ respectively while $1 \mathrm{sm}$ ADG was $48.9 \pm 1.9 \mathrm{~g}$. Substantial variation in analysed traits indicates the opportunity to achieve genetic gain. 


\title{
Development of a sustainable breeding programme in German sheep farming by using multi-live cover (MuNaSch)
}

\author{
Nina Ossowski ${ }^{1,2}$, Jens Wilkens ${ }^{3}$, Christian $\mathrm{Mendel}^{4}$, Ingolf $\mathrm{Ru} \AA^{5}$, Henrik Wagner ${ }^{2}$, Axel \\ Wehrend $^{2}$ and Georg Thaller ${ }^{1}$ \\ ${ }^{1}$ Institute of Animal Breeding and Husbandry - Christian-Albrechts-University, Kiel, Germany \\ ${ }^{2}$ Clinic for Obstetrics, Gynaecology and Andrology of Large and Small Animals with Veterinary Ambulance \\ - Justus-Liebig-University, Giessen, Germany \\ ${ }^{3}$ United livestock information systems, Verden/Aller, Germany \\ ${ }^{4}$ Institute of Animal Breeding, Bavarian State Research Center for Agriculture, Poing-Grub \\ ${ }^{5}$ Tierzuchtforschung e.V., München, Germany
}

Contact: Nina Ossowski, Institute of Animal Breeding and Husbandry, Christian-Albrechts-University Kiel, nossowski@tierzucht.uni-kiel.de

\section{Abstract:}

The project MuNaSch ('Multi-Natursprung Schaf') launched to address scientific questions when using more than three rams contemporarily within mating seasons. Eartag-tissue-samples from one complete lambing season were collected from 17 herdbook-breeders located in Bavaria, Baden-Wuerttemberg and Thuringia including the breeds Merinoland-, Merinolangwoll-, Rhoen- and Dorperschaf. The results of paternity testing based on 19 microsatellite-markers were registered in the central data base serv.it OVICAP (German herdbook-system for sheep). According to the mating register and the corresponding lambing list the most likely father among the potential candidates was assigned.

Major aims of this innovative project were: (1) Determining the preference for particular rams, (2) effects on fertility at herd level, (3) performance of breeding animals and lambs, (4) impact on genetic variability, (5) improvement of breeding value estimation, (6) reduction of birth losses due to shortened lambing seasons.

First analysis of 150 Merinolandschaf ewes bred to three rams mated for four weeks verified the hypothesis of a ram-dominance. Half of the lambs born stemmed from ram A, whereas only $40 \%$ descended from ram B and 10\% from ram C. Regarding the multiples, by half of the siblings had more than one father within a litter. Currently, the maker-set gets reduced by regarding allele frequency, polymorphic information content, expected and observed heterozygosity to ensure financial efficiency.

The shepherds' feedback was unexceptional positive. With the help of this project, the profitability of herdbook-breeders should increase in spite of the tensed situation and help to withstand the current difficulties. 


\section{Animal breeding and genetics \\ What will sheep and goat breeding \\ look like in the future? \\ Oral presentations}

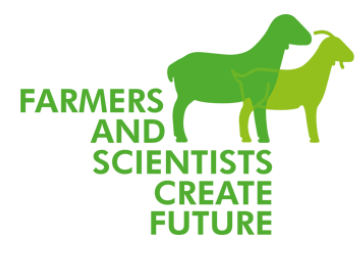

\section{Genomics to breed sheep resistant to footrot}

\section{Monia Lara Budnik, Julia Storms, Anna Wirth and Ottmar Distl}

University of Veterinary Medicine Hannover, Institute of Animal Breeding \& Genetics, Hannover, Germany Contact:monia.budnik@tiho-hannover.de, ottmar.distl@tiho-hannover.de

\section{Abstract:}

Ovine footrot is a complex disease caused by Dichelobacter nodosus and clinically characterized by interdigital dermatitis and under-running footrot. The objectives of our research project are to elucidate genomics of resistence to footrot within and across sheep breeds. In a large number of flocks in Germany, we recorded prevalences of footrot using clinical data and the load of benign and virulent strains of $D$. nodosus. On farm data recording in more than 200 flocks comprising $>30,000$ sheep was done using a mobile electronic hand-held system for individual animal ear tags and data input. We employed qRT-PCR to differentiate benign and virulent $D$. nodosus strains for classification of the footrot status of flocks. Based on these data, we were able to distinguish resistant, tolerant and susceptible animals. Genotyping was done for approximately 4000 sheep on ovine SNP50 and ovine infinium HD SNP beadchips in Merinos, Leine, Suffolk and East Friesian for 250-650 animals each and across several breeds for at least 50-100 animals including Bentheim, Dorper, Grey Heath, Forest sheep, Romney Marsh, Texel, White $\mathrm{P} / \mathrm{H}$ Heath and Pomeranian coarsewool. We found heritabilities for resistance to footrot using mixed models with genomic relationship matrices at $\mathrm{h} 2=0.4-0.7$ for the different breeds. Genome wide association studies with mixed models showed significant associated regions within breeds. Whole genome sequencing data from 120 individuals were employed to filter for highly associated variants. On whole genome sequences, imputed genotype data allowed us to validate highly associated regions and variants within and across breeds. 


\title{
High-resolution analysis of a QTL influencing sheep resistance to gastrointestinal nematode infection through whole-genome resequencing of a segregating trio
}

\author{
Beatriz Gutiérrez-Gil ${ }^{1}$, Praveen K. Chitneedi ${ }^{1,2}$, C. Esteban-Blanco ${ }^{1}$ and Juan-José Arranz ${ }^{1}$ \\ ${ }^{1}$ Universidad de León, León, Spain \\ ${ }^{2}$ Leibniz Institute for Farm Animal Biology, Dummerstorf, Germany
}

Contact: Dpto. Animal Production, Faculty of Veterinary Sciences, Campus de Vegazana, Universidad de León, 24071, León, Spain, beatriz.gutierrez@unileon.es

\section{Abstract:}

Gastrointestinal nematode (GIN) infections are one of the major health issues for grazing sheep populations. In the present study, we have used the imputed 50K-chip to high density (HD) chip (600K) genotypes obtained in a commercial population of 532 Churra adult ewes to refine QTL previously identified in this population for two indicator traits of GIN resistance (Atlija et al. 2016). For the most promising QTL region previously reported on chromosome 6 (OAR6) for faecal egg count (LFEC), we selected a segregating trio including the Qq sire and two daughters with extremely divergent phenotypes for the FEC trait in concordance with their QTL inferred genotypes, QQ and qq. The trio DNA samples were subjected to Whole Genome Resequencing (WGR) using the paired-end Illumina technology. After applying a variant calling bioinformatic workflow, the variants identified within the refined confidence interval of the LFEC OAR6 QTL were filtered for concordance with the QTL segregation pattern. Based on a variant functional annotation analysis, we identified a list of variants that based on their biological impact and their harboring gene could be considered as potential candidate causal variants of the QTL under study. Future research efforts should confirm the role of the candidate genes and mutations highlighted by this study. This study represents a new forward step towards increasing our knowledge on the genetic basis of genetic resistance to gastrointestinal nematodes in sheep and goat commercial populations.

\section{References:}

Atlija, M., Arranz, J.J., Martinez-Valladares, M., Gutiérrez-Gil, B. (2016). Detection and replication of QTL underlying resistance to gastrointestinal nematodes in adult sheep using the ovine 50K SNP array. Genet Sel Evol. 48, 4. doi: 10.1186/s12711-016$0182-4$ 


\title{
No doubt anymore: a simple genetic test to facilitate breeding for polledness in goats
}

\author{
$\underline{\text { R. Simon }}{ }^{1}$, C. Drögemüller ${ }^{2}$ and G. Lühken ${ }^{1}$ \\ ${ }^{1}$ Institute of Animal Breeding and Genetics, Justus Liebig University, Giessen 35390, Germany \\ 2 Institute of Genetics, Vetsuisse Faculty, University of Bern, Bern 3012, Switzerland \\ Contact: Rebecca Simon, Institute of Animal Breeding and Genetics, Justus Liebig University Giessen, \\ Giessen 35390,Germany, Rebecca.Simon@agrar.uni-giessen.de
}

\section{Abstract:}

Breeding for polledness in goats is more complicated than in cattle as polledness in goats is associated with disorders in sexual development. The incidence is also known as polled intersex syndrome. It is characterized by homozygous polled and genetically female (XX) individuals being infertile due to phenotypically diverse intersexuality. External genitals in affected intersexual goats range from true female to apparently male and all possible intermediate stages. This makes the identification of such cases in practice difficult and points the breeding on polledness in goats into its limits. Previously, a large deletion was postulated as the causal variant for PIS (Pailhoux et al. 2001). However, so far the development of genetic testing for the polled genotypes was not successful. Resequencing of the whole genomes of two genetically female (XX) goats, one PIS-affected and a horned control revealed an additional complex structural variant, which is combined with the already published variant (Simon et al. 2020). Our data allowed the development of a diagnostic PCR to proof both, the individual horn genotype and the genetic sex of goats simultaneously, for the first time. The genetic test was validated with more than 1000 goats of different breeds confirming that all analyzed PISsuspicious goats were homozygous polled and indeed female (XX). Thereby, the identification of phenotypically questionable intersexes is possible now. The new genetic testing offers a tool to facilitate breeding for polledness in goats.

\section{References:}

Simon, R., Lischer, H.E.L., Pieńkowska-Schelling, A., Keller, I., Häfliger, I.M., Letko, A., Schelling, C., Lühken, G., Drögemüller, C. (2020) New genomic features of the polled intersex syndrome variant in goats unraveled by long-read whole-genome sequencing. Anim Genet. 2020 Feb 14. doi: 10.1111/age.12918. [Epub ahead of print].

Pailhoux, E., Vigier, B., Chaffaux, S., Servel, N., Taourit, S., Furet, J.P., Fellous, M., Grosclaude, F., Cribiu, E.P., Cotinot, C., Vaiman, D. (2001) A 11.7-kb deletion triggers intersexuality and polledness in goats. Nat Genet. 29(4), 453-458. Doi:10.1038/ng769. 


\title{
Analysis of candidate genes for growth and milk performance traits in the Egyptian Barki sheep
}

\author{
Ibrahim Abousoliman ${ }^{1,2}$, Henry Reyer ${ }^{1}$, Michael Oster ${ }^{1}$, Eduard Muráni $^{1}$, Mosaad Mourad ${ }^{3}$, \\ Mohamed Abdel-Salam Rashed ${ }^{3}$, Ismail Mohamed $^{2}$ and Klaus Wimmers ${ }^{1,4}$ \\ ${ }^{1}$ Leibniz Institute for Farm Animal Biology (FBN), Dummerstorf, Germany \\ ${ }^{2}$ Desert Research Center, Cairo, Egypt \\ ${ }^{3}$ Ain Shams University, Cairo, Egypt \\ ${ }^{4}$ University of Rostock, Rostock, Germany \\ Contact: Abou-soliman@fbn-dummerstorf.de
}

\section{Abstract:}

Indigenous sheep breeds in Egypt, including Ossimi, Rahmani, and Barki, are of great importance for meat production. The Barki sheep is well adapted to desert hard condition like high temperature and shortage of food and water. Animal growth traits like birth weight (BW), weaning weight (WW) and average daily gain (ADG) are important traits due to their impacts on the viability of livestock raised for meat production. Milk production has a very important role in ensuring adequate supplies of new-born lambs and ultimately reducing the mortality rate due to starvation. In this study, data from 251 Barki ewes and lambs were used to investigate the association between genotypes at eight genes (LEP, IGF1, DGAT1, STAT5A, PRL, CSN1S2, GHR, and GHRHR) and production phenotypes. For each gene, one representative single nucleotide polymorphism (SNP) located in the coding region was selected for genotyping using kompetitive allele specific PCR. LEP (rs420693815) was significantly associated with weaning weight and average daily gain $(\mathrm{p}<0.1)$. Homozygous carriers of the TT genotype had a lower weaning weight and a lower average daily gain compared to the other genotypes. In ewes, significant effects on milk yield and composition were obtained for LEP (rs420693815) (milk yield, fat \%), STAT5A (rs161082816) (lactose \%), PRL (rs422713690) (MILK YIELD), and GHRHR (rs414991449) (protein\%, total solids \%), while IGF1, DGAT1, CSN1S2, and GHR genes showed no significant associations. The results indicated that LEP, STAT5A, PRL, and GHRHR genes might be considered as interesting candidates to improve growth and milk performance in Barki sheep.

\section{References:}

Abousoliman, I., Reyer, H., Oster, M., Muráni, E., Mourad, M., Abdel-Salam Rashed, M., Mohamed, I., Wimmers, K. (2020). Analysis of Candidate Genes for Growth and Milk Performance Traits in the Egyptian Barki Sheep. Animals 10, 197.

Sallam, A.M., Galal, S., Rashed, M.A., Alsheikh, S.M. (2012). Genetic diversity in Barki sheep breed in its native tract in Egypt. Egyp. J. Anim. Prod. 49, 19-28. 


\section{Assisted reproductive techniques in sheep and goats - chances and limits of alternative ways in breeding}

\section{Johanna Maria Meilwes and Martin Ganter}

Clinic for Swine, Small Ruminants and Forensic Medicine and Ambulatory Service, University of Veterinary

Medicine Hannover, Foundation; Hannover, Germany

Contact: Johanna Maria Meilwes, Clinic for Swine, Small Ruminants and Forensic Medicine and

Ambulatory Service, University of Veterinary Medicine Hannover, Foundation, Bischofsholer Damm 15,

30173 Hannover

Johanna.Maria.Meilwes@tiho-hannover.de

\section{Abstract:}

Aim of this contribution is to give an overview about the opportunities of assisted reproductive techniques in small ruminants and their use and situation in Germany.

Unlike in other countries, artificial reproductive medicine like artificial insemination (AI) and embryo transfer (ET) in sheep and goats is not common in Germany. There are no official data about the use of reproductive techniques in these species.

Compared to cattle, requirements for artificial techniques are much more complex.

Two Breeding Centers for semen collecting in small ruminants are registered in Germany.

In addition to research activities, the federal Research Institute for Animal Health, the Friedrich-Löffler-Institute (FLI) in Mariensee is keeping genetic reserves of different sheep and goat breeds as "German gene bank for farm animals".

At the Insemination center of Clinic for Small Ruminants, University of Veterinary Medicine Hannover semen of different sheep breeds is collected, stored and available. AI is performed but due to a low demand by sheep breeders rarely carried out.

To expand and offer opportunities that could improve sheep breeding, a national and international exchange of knowledge, experience and not least genetic material is necessary. There is an international request for German sheep genetic resources, for example East Frisian Milk Sheep, which could give the chance to an international exchange.

$\mathrm{AI}$ and ET could be a chance to improve the genetic diversity and breeding values. Flock health status could be improved by genetic and health tested animals. Many breeds are defined as rare breeds. Genetic reserves can ensure future preservation. 


\title{
The use of homologous seminal plasma before and during deep vaginal timed artificial insemination in sheep monitored by thermography and electrical impedance of vaginal mucous.
}

\author{
${\text { Beste } \text { Cil }^{1}}^{1}$ Koray Tekin ${ }^{1}$, Kumsal Duzgun ${ }^{1}$ and Calogero Stelletta ${ }^{1,2}$ \\ ${ }^{1}$ Department of Animal Reproduction and Artificial Insemination, Faculty of Veterinary Medicine, Ankara \\ University, Turkey \\ ${ }^{2}$ Department of Animal Medicine, Production and Health, University of Padova, Italy \\ Contact: Beste Cil, Department of Animal Reproduction and Artificial Insemination, Faculty of Veterinary \\ Medicine, Ankara University, Turkey, +90 555 7318338, email: cil.beste@gmail.com
}

\section{Abstract:}

Artificial insemination in sheep is an intriguing technique because the species-specific cervix conformation does not allow intrauterine deposit and consequently, the inseminating doses are not yet optimized. The variability of the ovulation time following the estrous synchronization remains the main constraint to increase the accuracy and precision of the technique regarding the success rate. The aim of this work was to apply a timed artificial insemination (TAI) protocol considering a deep vaginal deposition of inseminating doses, testing the effects of homologous seminal plasma (SP) and to simulate the application of "on-field" monitoring system based on thermography (IRT) and vaginal electrical impedance (VEI). A total of 109 young ewes were synchronized with 9-11 days of progestogen releasing device (P) and $300 \mathrm{IU}$ of ECG at P removal in non-breeding season. Ewes were divided into three groups: $1^{\text {st }}$ as control (C), deep vaginally inseminated with $3.2 \mathrm{ml}$ of chilled semen dosed as $100 \times 10^{6}$ motile sperm $/ \mathrm{ml}, 2^{\text {nd }}$ treated with seminal plasma $(0.4 \mathrm{ml} \mathrm{SP})$ before TAI (SP24h) and $3^{\text {rd }}$ treated with SP at TAI (SPTAI). IRT and VEI were applied at the time of P removal and the TAI. Lamb rates were 33.33\% (10/31), 32.36\% (16/48) and 36.67\% (11/30) for C, SP24h and SPTAI respectively. The monitoring system showed a significant $(\mathrm{P}<0.05)$ drop of vulvar temperature and vaginal electrical impedance in pregnant SP24h. IRT and VEI give the possibility to identify the timing of insemination and the animals answering to the hormonal synchronization. SP seems to synchronize the fertilization time and influence vaginal and thermal patterns.

\section{References:}

Cil, B., and Akcay, E. (2017). The importance of seminal plasma proteins in bulls in terms of cryopreservation and fertility. Lalahan Hayvancilik Arastirma Enstitusu Dergisi, 57, 118-126.

Stelletta, C., Tekin, K., Tirpan, M. B., Alemdar, H., Cil, B., Stelletta, F. O., Olgac, K. T., Inanc, M. E., Daskin, A. (2017). Vulvar thermal pattern following synchronization of estrus is linked to fertility after timed artificial insemination in goat. Theriogenology, 103, 137-142. doi: 10.1016/j.theriogenology.2017.07.038

Juyena, N. S., and Stelletta, C. (2012). Seminal plasma: an essential attribute to spermatozoa. Journal of Andrology, 33, 536551. doi: 10.2164/jandrol.110.012583 


\section{Blood levels of progesterone and cortisol in Murciano Granadina goats after artificial insemination}

\section{Begoña Peinado, Laura Almela, Ángel Poto and Sonia Galián}

Murcian Institute for Agricultural and Food Research and Development (IMIDA), La Alberca-Murcia, SPAIN

Contact: Begoña Peinado, Murcian Institute for Agricultural and Food Research and Development (IMIDA), La

Alberca-Murcia, SPAIN, email: begona.peinado@carm.es, Telephone: +34 968366756

\section{Abstract:}

Cortisol is used to assess stress. Early pregnancy detection by blood progesterone determination is

important in reproductive programs. In a group of 11 adult Murciano Granadina goats wich underwent artificial insemination, a study has been carried out to determine blood levels of progesterone and cortisol as possible biomarkers for early prediction of gestation diagnosis.

Three measurements were taken to determine progesterone levels and two for cortisol. The frecuency of sampling was 21 days, with one measurement coinciding with the day of the artificial insemination. An automatic immunofluorescence analyser was used to measure both parameters. Statgraphics Centurion program was used for the statistical analysis.

Among the results obtained, we highlight that for pregnant females $(n=4)$ the average progesterone values obtained, on the day of artificial insemination and 21 days later, were always higher compared to females that were not pregnant $(\mathrm{n}=7): 12.63 \pm 1.59 \mathrm{ng} / \mathrm{ml}$ and $15.26 \pm 2.3 \mathrm{ng} / \mathrm{ml}$ respectively, and compared to $8.63 \pm 1.66 \mathrm{ng} / \mathrm{ml}$ and $10.74 \pm 2.55 \mathrm{ng}$ $/ \mathrm{ml}$ respectively. Similar results were obtained for the average cortisol values, obtaining 58.74 $\pm 31.06 \mathrm{nmol} / \mathrm{L}$ on the day of the artificial insemination in the females that became pregnant, compared to $90.08 \pm 44.40 \mathrm{nmol} / \mathrm{L}$ in the females that did not become pregnant. These results indicate the usefulness of measuring blood progesterone and cortisol values as an early indicator of expected fertility after artificial insemination. 


\title{
Transcript abundance of candidate genes in different body tissues of Egyptian Barki sheep as an indicator of growth performance
}

\author{
Nasser Ghanem ${ }^{1}$, Mohamed Zayed ${ }^{2}$, Mohamed Radwan ${ }^{1}$, Mona Mohmady ${ }^{2}$ and Mohamed \\ Shehata $^{2}$
}

${ }^{1}$ Animal Production Department, Faculty of Agriculture, Cairo University, Giza, Egypt

${ }^{2}$ Animal and Poultry Division, Desert Research Center, Cairo, Egypt

Contact: Faculty of Agriculture, Cairo University, El-Gamaa Street, 12613 Giza, Egypt, nassergo@agr.cu.edu.eg

\section{Abstract:}

Sheep is considered one of the main animal genetic resources in Egypt as contributing in meat production while surviving harsh desert conditions and consuming low quality of forage. The aim of this study was to link the expression profile of selected candidate genes with growth performance of Egyptian Barki sheep. Barki sheep lambs $(n=26)$ were kept and fed individually after weaning. Growth performance traits as well as carcass characteristics were recorded after slaughtering. Samples from different body tissues (muscle, liver, fat) were taken and stored in RNA latter until RNA isolation. Real-time PCR was used to profile selected candidate genes (RPL7, CTP1, FABP4, ADIPOQ and CAPN3) and GAPDH was used as a housekeeping gene. Our data indicated that, heavier final body weight in the fast growing sheep lambs $(52.4 \mathrm{Kg})$ than both medium (41.4 Kg) and slow growing animals $(31.7 \mathrm{Kg}) 6$ months after weaning. Genes involved in protein biosynthesis (RPL7), fatty acid oxidation (CPT1) and lipolysis (FABP4) were up-regulated in fast and medium growing animals in all studied tissues. While, gene regulating lipogenesis (ADIPOQ) was expressed similarly in fat and liver tissues but increased its expression in muscle of fast and medium growing sheep. Expression of CAPN3 was increased in fast and medium growing compared to slow growing animals. This study clearly indicated the transcriptional profile of CPT1, FABP4 RPL7 and CAPN3 is linked with growth performance of sheep lambs, providing an evidence for the importance of these genes. 


\section{Usefulness of the genetic variant TMEM154 E35K for breeding against maedi visna susceptibility in the German sheep population}

\section{Gesine Lühken}

Institute of Animal Breeding and Genetics, Justus Liebig University, Giessen, Germany

Contact: Gesine Lühken, Institute of Animal Breeding and Genetics, Justus Liebig University Giessen, Giessen 35390,Germany, Gesine.Luehken@agrar.uni-giessen.de

\section{Abstract:}

Maedi visna, a disease caused by small ruminant lentiviruses, is present in sheep populations of many countries. The disease ends always fatal and cannot be prevented by vaccination. Developed eradication programs including testing and culling may be helpful but are neither cost-effective nor sustainable. Breeding against maedi visna susceptibility could solve or at least reduce these problems. At first in North American sheep populations, an amino acid substitution (E $>\mathrm{K})$ at position 35 of the transmembrane protein 154 (TMEM154) was observed to be associated with susceptibility to maedi visna.

In our study, we tested this association in 21 maedi visna-affected sheep flocks with different breed background and from different regions in Germany. For this purpose, sheep aged three years or older were tested serologically for maedi visna status by ELISA and genotyped for E35K. Secondly, we determined the E35K allele and genotype frequencies in unrelated sheep of 12 breeds kept in Germany in order to estimate their genetic maedi visna susceptibility status.

In most of the analyzed maedi visna-affected flocks, the 35E allele was significantly associated with seropositivity. However, an association was missing in two Merinoland sheep flocks, therefore other, maybe breed-specific factors may additionally influence maedi visna antibody titers. Frequencies of the susceptible 35E allele ranged among the 12 analyzed breeds from 2 $\%$ (German Grey Heath) to $93 \%$ (Cameroonian sheep), reflecting their genetic susceptibility status and different starting situations for potential breeding programs. 


\title{
Antibody titer after vaccination as potential phenotype for breeding against footrot in sheep: first results
}

\author{
Annabell Amend, O. O. Adeniyi and Gesine Lühken
}

Institute of Animal Breeding and Genetics, Justus Liebig University, Giessen, Germany

Contact: Gesine Lühken, Institute of Animal Breeding and Genetics, Justus Liebig University Giessen, Giessen 35390, Germany, Gesine.Luehken@agrar.uni-giessen.de

\section{$\underline{\text { Abstract: }}$}

Footrot is a highly contagious disease causing lameness and occurs worldwide mainly in sheep and goats. The causal agent is the bacterium Dichelobacter nodosus. In some few countries, selection against footrot susceptibility based on footrot scores is in progress or already established. However, footrot scores are difficult to collect as well as to interpret, and heavily influenced by weather and ground conditions.

Therefore, the aim of the current project was to establish and validate another method for phenotyping footrot susceptibility, which is the reaction of the animal's immune response after contact with antigens of the pathogen. An enzyme-linked immunosorbent assay (ELISA) including $D$. nodosus antigens extracted from a commercial vaccine was developed. With this ELISA, antibody titers were measured in blood samples collected at several time points after vaccination from female Merinoland and Rhoen sheep. The animals were vaccinated with 5-8 months of age and a second time 4 weeks later. Antibody titer data from 202 Merinoland sheep, belonging to 7 half-sib groups, were included in the presented preliminary analyses.

In all sheep, antibody titers increased after vaccination to a peak at week 6 , followed by a slower decrease. Between some half-sib groups, antibody titers were significantly different for several time points after vaccination. Estimated heritabilities for antibody titers, e.g. at 4 months after vaccination (animal model: 0.22; sire model: 0.42 ) are promising for a potential use of this phenotype for breeding towards lower footrot susceptibility and/or better effect of vaccination. 


\title{
Efficiency of estrus synchronization protocols and artificial insemination technologies in Abergelle goat at station and on farm conditions of Waghemira zone, Ethiopia
}

\author{
Bekahegn Wondim $^{1,2}$, Mengistie Taye ${ }^{1,3}$, Kefyalew Alemayehu ${ }^{1}$, Aynalem Haile ${ }^{4}$ and Mourad \\ Rekik $^{5}$ \\ ${ }^{1}$ Animal Production and Technology department, College of Agriculture and Environmental Science, Bahir \\ Dar University, PO. Box 5501, Bahir Dar, Ethiopia \\ ${ }^{2}$ Sekota Dryland Agriculture Research Center (SDARC), PO. Box 62, Sekota, Ethiopia \\ ${ }^{3}$ Biotechnology Research Institute, Bahir Dar University, POBOx 79, Bahir Dar, Ethiopia \\ ${ }^{4}$ International Center for Agricultural Research in Dry Areas (ICARDA), PO.Box 5689, Addis Ababa, \\ Ethiopia \\ ${ }^{5}$ International Center for Agricultural Research in Dry Areas (ICARDA), PO.Box 950764, Aman, Jordan \\ Contact: bewondim23@gmail.com
}

\section{$\underline{\text { Abstract }}$}

Reproductive biotechnological tools are important to suit kidding time with better forage availability and accelerate improved genetics in the goat breeding programs. The study was conducted during 2019/2020 to investigate the effect of different estrus synchronization protocols on estrus response and conception rate of Abergelle goats following fixed time artificial insemination. Three estrus synchronization protocols: 1) Pregnant mare serum gonadatropins with Enzaprost ${ }^{\circledR}$ as separate injection, 2) single injection of prostaglandin, and 3 ) double injection of prostaglandin were evaluated during the experiment. A total of 278 does for the treatment group and 57 does were used as control group. For semen collection, 23 bucks were used. For the first treatment groups, progesterone impregnated vaginal sponge was inserted at day1 and stayed for 11 days inside, 48 hour before sponge removal, $1 \mathrm{ml}$ (600IU) gonadatropins followed by $1 \mathrm{ml}$ Enzaprost ${ }^{\circledR}$ were administered. For the second treatment groups, $1 \mathrm{ml}$ of Enzaprost ${ }^{\circledR}$ was administered at day 1 . For the third treatment groups, $1 \mathrm{ml}$ of Enzaprost ${ }^{\circledR}$ was administered at day 1 followed by the second $1 \mathrm{ml}$ injection of Enzaprost ${ }^{\circledR}$ at day 11. Insemination was performed after 48 hours of estrus follow up. The control groups were allowed to mate as usual. The study revealed, that overall estrus response of $87.6 \%$, $61.4 \%$ and 53\% were investigated from first, second and last treatments, respectively. Relatively higher proportion of the conception rate $(\mathrm{p}<0.05)$ resulted from double injection of prostaglandin F2 $\alpha$ (78.8\%). It was concluded that double injection of prostaglandin F2 $\alpha$ was selected as the best protocol for its efficiency. 
Wool fiber density and other characteristics from birth to weaning in Junin lambs

\author{
E.C. Quispe ${ }^{1,2}$, W.H. Grabiel ${ }^{3}$, J. Aliaga ${ }^{1}$, M.D. Quispe ${ }^{4}$ and R. Quispe ${ }^{3}$ \\ ${ }^{1}$ Animal Production Department, Universidad Nacional Agraria La Molina, Lima, Perú, \\ jaliaga@lamolina.edu.pe \\ ${ }^{2}$ Laboratory of Animal Fibers, Natural Fiber's Tech SAC. Lima, Perú, edgarquispe62@gmail.com \\ ${ }^{3}$ Animal Production Department, Universidad Nacional del Centro del Perú, Huancayo, Perú, rolando- \\ quispe@outlook.com \\ ${ }^{4}$ Engineering Department, Maxcorp Technologies SAC. Lima, Perú, maxdavid22@gmail.com \\ Contact: edgarquispe62@gmail.com
}

\title{
Abstract:
}

This research had the objectives to evaluate the body weight and some characteristics of the skin and wool fibers of Junín lambs monthly from birth to weaning (120 days) and to analyze relationships between them in order to assess the potential of fiber and duct density as a new selection criterion for improving wool quality. Data on live weight, skin surface, monthly fiber growth (MFG), fiber density (FibDen), ducts density (DuctDen), FibDen/initially tattooed area (ITA), DuctDen/ITA, belonging to 24 Junin lambs, were considered. Additionally, the percentage of ducts with one, two, three, or four fibers (PD1F, PD2F, PD3F or PD4F, respectively) and average fiber diameter were considered also. Live weight and surface skin were recorded with weight scale and graduated ruler, respectively. FibDen and DuctDen were objectively determined using the device and methodology called FIBER DEN. AFD was measured with FIBER EC instrument. It was found that the FibDen and DuctDen increase monthly almost in proportion to the increase of the skin surface from birth to 120 days, with averages of 34.5 and 31.01 fibers and ducts per $\mathrm{mm}^{2}$. The direct relationship between AFD and the number of cuts (shearing) of the fiber, and FibDen with MFG into the period of study were found. Besides, the indirect relationship between AFD and FibDen and DuctDen was also found, with sufficient statistical evidence. It is concluded that FibDen and DuctDen could be considered as novel selection criteria for simultaneous improvement of wool quality and quantity because FibDen and DuctDen have a relation with quality and quantity characteristics. 


\section{Relationship between seminal vesicles echogenicity and semen quality in rams of endangered Venetian sheep breeds}

\section{Calogero Stelletta}

Department of animal medicine, production and health, University of Padova

Contact: Prof. Calogero Stelletta, Department of animal medicine, production and health, University of

Padova, Viale dell'Universita 16, 35020, Legnaro (PD), Italy, Email: calogero.stelletta@unipd.it

\section{Abstract:}

Seminal vesicles are the main producers of seminal plasma (SP) in rams. Their secretions can greatly influence the quality of sperm suspended on them. Sheep endangered breeds (SEB) need more attention on semen treatment after collection because the genetic materials should be maintained efficiently to enhance the biodiversity sustainability. Aim of this work was to investigate the relationship among testosteronemia under $\mathrm{GnRH}$ challenge test (T), echogenicity of seminal vesicles (low, medium, high) and testicles (Vencato et al., 2014), SP composition (P, Ca, Mg, PT, ALP, LDH, cholesterol, triglycerides) and spermatic post-thawed kinetic parameters (total motility, progressive motility, VAP, VSL, VCL, ALH, BCF, STR, LIN) in 4 Venetian SEB (Alpagota, Brogna, Foza, Lamon). A total of 22 rams ( $N=5$, Brogna, $N=7$ Lamon, $\mathrm{N}=5$ Foza e $\mathrm{N}=5$ Alpagota), 1-5 years old, were used as breeders submitted to a preservation program for extinction threatened breeds and collected two times with electroejaculator. Data analysis showed significant relationships among scrotal circumference, $\mathrm{T}$ and semen kinetic parameters. Negative correlations indices $(\mathrm{P}<0.05)$ resulted between testicular parenchymal echogenicity and semen volume as well as among seminal vesicles echogenicity, semen volume (-0.76) and seminal plasma total proteins (-0.82). Moreover, lower levels of calcium $(2.15 \pm 0.3 \mathrm{mg} / \mathrm{dl})$ and cholesterol $(28.83 \pm 3.37 \mathrm{mg} / \mathrm{dl})$ concentrations than reference levels (Juyena and Stelletta, 2012) were revealed in all breeds. Clinical biochemistry can be considered routinely to check the quality of the SP helping the eventual make-up of the extenders for chilled or frozen inseminating doses.

\section{References:}

Juyena, N.S., Stelletta, C. (2012) Seminal plasma: an essential attribute to spermatozoa. Journal of Andrology, 33, 536-551. doi: 10.2164/jandrol.110.012583

Vencato, J., Romagnoli, S., Stelletta, C. (2014) Trans-scrotal ultrasonography and testicular fine-needle aspiration cytology in the evaluation of ram sperm production. Small Ruminant Research, 120, 112-115. doi: 10.1016/j.smallrumres.2014.05.005 
Animal breeding and genetics

What will sheep and goat breeding

look like in the future?

Poster presentations

\section{Echotexture characterization of accessory glands in buck}

\section{Calogero Stelletta ${ }^{1,2}$ and Koray Tekin ${ }^{2}$}

${ }^{1}$ Department of animal medicine, production and health, University of Padova, Italy

${ }^{2}$ Department of animal reproduction and artificial insemination, Faculty of veterinary medicine, Ankara University, Turkey

Contact: Prof. Calogero Stelletta, Department of animal medicine, production and health, University of Padova, Viale dell'Universita 16, 35020, Legnaro (PD), Italy, Email: calogero.stelletta@unipd.it

\section{Abstract:}

Accessory glands (AGs) are the producers of seminal plasma (SP) which have strong influence on the quality of the ejaculates and the suspension of spermatozoa in it. AGs can be classified in epididymis, deferential ampullas, seminal vesicles, prostate and bulbo-urethral glands. Each AG is able to give specific compounds that are extremely important for the functionality of sperm within the female reproductive tract, other than the regulation of the resistance to chilling or freezing procedures. AGs high resolute ultrasonography (US $-10 \mathrm{MHz}$ ) can be considered as a monitoring tool to optimize the accuracy and precision of small ruminant male evaluation, thanks to the possibility of pixel grey intensity (PGI) calculation of regions of interest (ROIs) of US images. The aim of this work was to evaluate the variability of difference among the PGI accessory glands US images in buck. Twenty adult and fertile bucks were used to measure the PGI of accessory glands by using an image analysis software (Image $\mathrm{J}$ ). Epididymal tails presented the lower PGI $(62.13 \pm 20.67)$ with highest variability due to the presence of anechoic areas within the ROI. Deferential ampullas, seminal vesicles and bulbourethral glands showed different echotextures with $141.2 \pm 14.4,141.11 \pm 19.26$ and 171.7 \pm 12.68 PGI respectively. Echotexture index of accessory glands can give useful indications of edematous parenchyma and/or sclerotic glandular conditions and it could be used as tool for male health and reproductive management. 


\section{Animal breeding and genetics}

What will sheep and goat breeding

look like in the future?

\section{Genetic polymorphism in the TLR4 gene and its association with milk traits in Egyptian sheep}

\section{Ahmed M. Sallam}

Animal and Poultry Production Division, Desert Research Center, Cairo, Egypt

Contact: ${ }^{\text {st }}$ Mathaf El-Mataryia, 11735, Cairo, Egypt, ahmedsallam2@gmail.com

\section{Abstract:}

The Egyptian dairy production industry is predominantly based on cows and buffalos, with little care for sheep and goats. However, sheep contributes about $5 \%$ of the total whole milk produced annually in Egypt and contributes a substantial part of their livelihood of a large proportion of the Egyptians. Information available regarding the genetics of sheep milk is scarce in the Egyptian breeds. The objective of this study was to identify genetic variants in the TLR4 gene for milk traits in Barki sheep as one of the three major sheep breeds in Egypt. Records were available for about 300 ewes and were genotyped using polymerase chain reaction (PCR)single strand conformation polymorphism (SSCP) protocol. Two distinctive conformation patterns (named $\mathrm{G}$ and $\mathrm{T}$ ) were observed in the investigated region. The genotypic frequencies were $44.6 \%, 35.7 \%$ and $19.7 \%$ for GG, GT and TT genotypes, respectively. The direct sequencing identified a missense mutation located in the coding sequence of exon 3 of the gene (c.1710C $>$ A), which changes the amino acid sequence of the resulted protein (p.Asn570Lys). The association analyses suggested that the identified polymorphism had a significant effect (p-value $<0.05$ ) on the daily milk yield, fat percentage and protein percentage. Summarizing, the TLR4 is suggested as candidate gene to improve milk traits in the Egyptian sheep. 
Animal breeding and genetics

What will sheep and goat breeding

look like in the future?

Poster presentations

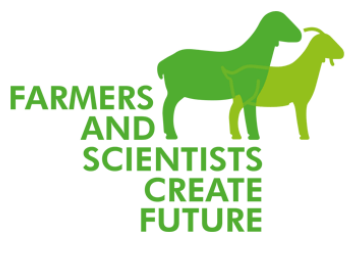

Influence of lipoprotein lipase (LPL) gene polymorphism on production traits in dairy goats

\author{
Evaldas Šlyžius ${ }^{1}$, Birutė Šlyžiené ${ }^{1}$ and Renata Bižiené ${ }^{2}$ \\ ${ }^{1}$ Lithuanian University of Health Sciences, Department of Animal Breeding, Kaunas, Lithuania \\ ${ }^{2}$ Lithuanian University of Health Sciences, Institute of Biology Systems and Genetics, Kaunas, Lithuania
}

Contact: Evaldas Šlyžius, Lithuanian University of Health Sciences, Department of Animal Breeding, Kaunas, Lithuania, email: Evaldas.slyzius@lsmuni.lt

\title{
Abstract:
}

The objective of this study was to investigate the influence of LPL gene polymorphism on production traits in dairy goats.

The polymorphism of the goat was analysed in 272 unrelated individuals belonging to three pure goat breeds (Saanen, $n=104$; Anglo Nubian, $n=88$ and Alpine, $n=80$ ) in Lithuania. The statistical characteristics were calculated using IBM SPSS Statistics, version 20.

In the examined herd, the genotype CC of LPL gene was present in $24.3 \%$ of goats, $19.9 \%$ of goats had heterozygotic CG genotype and $55.8 \%$ of goats had GG genotype. The results showed that goat LPL gene with CC genotype has a higher milk yield $(0.14 \mathrm{~kg}$ higher compared to GG and $0.72 \mathrm{~kg}$ higher compared to CG genotype, $\mathrm{P}<0.01$ ). The goats with GG genotype have a higher fat content $(0.09 \%$ higher compared to CC, $0.23 \%$ higher compared to CG genotype, $\mathrm{P}<0.05)$, while the protein content was higher in goats with CG genotype $(0.06 \%$ higher compared to CC, $0.03 \%$ higher compared to GG genotype, $\mathrm{P}<0.05$ ). We also estimated, that goats with CC genotype had higher lactose (4.29 \%) and lower SCC $\log 10$ (4.506) value $(\mathrm{P}<0.01)$. The analysis of the goat milk production parameters showed the significant mean differences between the breeds $(\mathrm{P}<0.01)$. The highest milk yield was estimated in Alpine goats, while the lowest SCC and the highest milk fat and protein content in Anglo Nubian goats $(\mathrm{P}<0.01)$.

The results of our research show that examined LPL gene polymorphisms seem to be the valuable biomarkers of the goat selection process. 


\section{The Nolana project - breeding high-performance hair sheep for Germany}

\section{Rolf Minhorst}

Nolana-Netzwerk Deutschland e.V., registered association, 56745 Weibern, Germany, https://www.nolana-schafe.de

Contact: Dr. Rolf Minhorst, Eichertstr. 48, 56745 Weibern, Germany, Tel: ++48-(0)2655-962912 rolf.minhorst@t-online.de

\section{Abstract:}

The price of raw wool in Germany has been falling since the end of World War II. Today, the production costs of wool far exceed the gross income from the sale of wool. In view of this precarious situation, the author proposed in 1997 to breed a new synthetic hair breed called Nolana. The project immediately enjoyed broad approval from many sheep breeders, some research institutions and animal husbandry administration.

Due to the EU import restrictions, no genetic material could be imported from overseas. So it was decided to follow the example of the synthetic or composite breeds that are widespread in the United States, relying only on the rules of quantitative genetics. It was supposed to be an open breeding program in which new breeds could be included at any time without a predetermined percentage of genes. The flocks present in the participating farms, primarily the Merino landrace, Suffolk or German Blackhead, served as mother base.

The Wiltshire Horn breed was used as the sire line. In later years, Dorper and Barbados rams were added. It was worked through simple back-crossing up to $\mathrm{R}_{2}$ and subsequent genetic consolidation. The 15th fattening and slaughter performance test for sheep in the Köllitsch testing station in 2010, demonstrated that the performance parameters of the new Nolana breed are in the good average of the existing dual-purpose breeds.

The project was taken up by many breeders and supported by the sheep breeding associations of the federal states by setting up herd books. Two new synthetic hair breeds have emerged from the Nolana project: The white Nolana meat sheep (NOL) and the brown hair sheep (BHS), both of which were officially recognized by the VDL on November 01, 2018. Actually, the Nolana-Network has 86 Members. The Nolana herdbook-stock includes 52 rams and 745 ewes, The Brown Hairsheep herdbook-stock includes 41 rams and 401 ewes. Besides that, there is also an unknown number of breeders and animals that are not listed in the herdbook. A conservative estimate, for example on the basis of Facebook ads, would result in at least five times the number of Nolana and Brown Hairsheep existing at present in Germany. 


\section{New genomic tools for sheep breeding in Germany}

\section{Monia Budnik, Julia Storms, Anna Wirth, Ann-Kathrin Struck and Ottmar Distl}

University of Veterinary Medicine Hannover, Institute of Animal Breeding \& Genetics, Hannover, Germany Contact: monia.budnik@tiho-hannover.de,ottmar.distl@tiho-hannover.de

\section{Abstract:}

New genomic tools became available through ovine genome projects and the development of genome-wide single nucleotide polymorphisms (SNP) arrays. We employed the newly developed ovine GGP $50 \mathrm{~K}$ beadchip for $>3000$ sheep in a wide spectrum of sheep breeds in Germany. The objectives were to test the suitability of this new tool for genotyping Mendelian traits including haplotypes for scrapie resistance, genetic variants for muscularity, fecundity, microphthalmia, entropion, susceptibility for maedi-visna, parentage testing, determination of sex and genomic evaluations for quantitative traits. For genotyping, we used EDTA-blood samples on FTA cards. All samples passed quality checks with a genotyping rate of $98 \%$. Most Mendelian genotypes were accurately genotyped. We found alleles associated with spider lamb, microphthalmia and yellow fat phenotype in very few cases. The TMEM154 K/K genotype associated with lower risk to maedi-visna showed a frequency of $46 \%$. The myostatin allele causing muscular hypertrophy (MSTN:g. $6223 \mathrm{G}>\mathrm{A}$ ) was at a frequency of 0.16 . More than $60 \%$ of the sheep were homozygous for the ARR haplotype. We employed genome-wide SNP genotypes to estimate heritabilities for growth traits recorded in field and stationary tests. In addition, we estimated genomic diversity measures for management the endangerment of particular breeds. Size of training sets and blending of breeds were tested to determine increase in prediction accuracies under different scenarios for German sheep breeds. Imputation of genotyping data on whole genome sequencing data seems to be advantageous for QTL detection. Single-step methods should improve accuracy of prediction by $15-35 \%$ compared with other methods. 


\title{
Aortic connective tissue abnormalities resembling Marfan syndrome in goats
}

\author{
Karianne Lievaart-Peterson ${ }^{1}$, Liesbeth Harkema ${ }^{1}$, Rene van den Brom ${ }^{1}$, Reinie Dijkman ${ }^{1}$, \\ Eveline Dijkstra $^{1}$, Mark van der Heijden ${ }^{2}$ and Piet Vellema ${ }^{1}$
}

${ }^{1}$ Royal GD, Deventer, the Netherlands

${ }^{2}$ Universitaire Landbouwhuisdieren Praktijk, Harmelen, the Netherlands

Contact: Karianne Lievaart-Peterson, Royal GD, Po BOX 9, 7400 AA Deventer, The Netherlands Telephone+31 (0)570-660478, k.lievaart-peterson@gdanimalhealth.com

\section{Abstract:}

Three cases of sudden death in adult dairy goats revealed a hemoabdomen due to rupture of the cranial abdominal aorta or cranial mesenteric artery at post mortem examination. Histologically, there was evidence of impaired vessel wall architecture with loss and fragmentation of elastin fibres, proliferation of the lamina intima and fibrosis. Similar microscopic lesions have been described in Marfan syndrome. Marfan syndrome is a genetic (autosomal dominant) disorder that affects the connective tissue, named after French paediatrician Antoine Marfan, who first described it in 1896 in children. Clinical manifestations involve the cardiovascular, ocular and skeletal system. It is caused by mutations in the gene encoding fibrillin-1, the major component of extracellular microfibrils that support elastin fibre deposition (Coelho and Almeida, 2020). Marfan-like syndrome has since been suggested or described in dogs, cattle (Hirano et al. 2012), sheep, and horses. Multiple connective tissue disorders in man and animals are caused by heritable genetic defects and may share similar features.

A genetic defect cannot be ruled out since the Dutch dairy goat population share a small genetic background. Occasionally rupture of the uterine artery is observed, but without similar vessel wall lesions. There is a need for further research including larger numbers of cases, further typing of vessel wall lesions as well as genetic typing.

To the best of our knowledge, this is the first description of morphologic connective tissue abnormalities resembling features of Marfan syndrome in goats.

\section{References:}

Coelho, S. G., Almeida, A. G. (2020). Marfan syndrome revisited: From genetics to the clinic. Rev Port Cardiol, 39(4), 215-226. doi:10.1016/j.repc.2019.09.008

Hirano, T., Matsuhashi, T., Kobayashi, N., Watanabe, T., Sugimoto, Y. (2012). Identification of an FBN1 mutation in bovine Marfan syndrome-like disease. Anim Genet, 43(1), 11-17. doi:10.1111/j.1365-2052.2011.02209.x 


\title{
Prion protein gene (PRNP) polymorphism in Latvian native breed goats
}

\author{
Kristine Piliena $^{1}$, Lasma Zelca ${ }^{2}$ and Daina Jonkus ${ }^{2}$ \\ ${ }^{1}$ Latvian Goat Breeding Association, Talsi region, Latvia \\ ${ }^{2}$ Latvia University of Life Sciences and Technologies, Jelgava, Latvia \\ Contact: Berzi, Vandzene, Vandzenes municipal, Talsi region, Latvia, piliena@inbox.lv
}

\section{Abstract:}

Scrapie is a lethal, neurodegenerative disease that is affecting sheep and goats. It is a disease that belongs to the group of transmissible spongiform encephalopathies (TSEs). This disease causes economic loss to herds, where animals are affected by it. The classical scrapie in sheep and goats has been affected by prion protein (PRNP) gene polymorphisms (Goldmann et al., 2011). The disease is hereditary and can be limited or eliminated by a thoughtful animal breeding by the selection of scrapie-resistant animals. Latvian native breed goats are dairy goats and their population is small. The aim of the study was to explain the polymorphism of the Latvian native goat breed population according to codons 146 and 222 of the PRNP gene. Genetic analyzes were performed in a laboratory by Eurofins Medigenomix GmbH. In total 397 samples were analyzed. It has been found, that in Latvia bred goats, the NN146 genotype is dominated after the codon 146 . The frequency of NN146 genotype was $97.7 \%$. The genotype NS146 of heterozygous animals was only $2.3 \%$. Only 9 animals or $1.1 \%$ are found with the resistant S146 allele. A larger polymorphism was observed at codon 222, where the frequency of the resistant K222 allele was 11.5\%. The homozygotes KK222 genotype was in 3 animals or $1.0 \%$, the heterozygotes QK222 genotype was in $21.2 \%$ and the QQ222 genotype was in $77.8 \%$. Although the number of animals with resistant alleles is small, in further breeding process it is crucial to increase the number of animals with necessary genotypes.

\section{Acknowledgements:}

Research was conducted with support from LR Ministry of Agriculture. Contract number 20-100-20-1.8.000011.

\section{References:}

Goldmann W, Ryan K, Stewart P, Parnham D, Xicohtencatl R, Fernandez N, Foster J. (2011). Caprine prion gene polymorphisms are associated with decreased incidence of classical scrapie in goat herds in the United Kingdom. Veterinary

Research 42(1):110. Doi.org/10.1186/1297-9716-42-110 


\section{Economics:}

How can the profitability of sheep and goat

farming be improved?

Genetic Resources

Keynote presentation

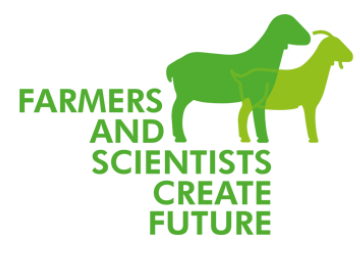

\section{Sheep and goats in the world and the importance of economy}

\section{$\underline{\text { Stanislaus von Korn }}$}

Hochschule für Wirtschaft und Umwelt Nürtingen-Geislingen (HfWU), Germany

Contact: Prof. Dr. Stanislaus von Korn, Institut für Angewandte Agrarforschung (IAAF), Hochschule für

Wirtschaft und Umwelt Nürtingen-Geislingen, 72622 Nürtingen, stanislaus.korn@hfwu.de

\section{Abstract:}

With the increasing number of sheep and goats in the world, the importance of small ruminants grew over the past 18 years. Such increases can be observed especially in Africa and Asia, while sheep stocks in Americas, Europe and Oceania had declined.

Sheep and goats mainly contribute to food and income security by producing of food goods. The small ruminants fulfill these functions in different systems in accordance with the respective site conditions: in subsistence farming, e.g. in Africa and Asia, as well as in profitoriented farms, e.g. in Europe. Favoured und less favoured areas are used, which often have no alternative use.

However, prerequisites for sensible sheep and goat husbandry are adequate biological performance (good productivity in subsistence farming) or adequate profitability through the production of marketable products.

Both parameters (productivity and profitability) always determine the importance of small ruminants. In this context, it is the goal of the Session Economy to analyze positive as well as negative influencing factors. 
Economics:

How can the profitability of sheep and goat

farming be improved?

Oral presentations

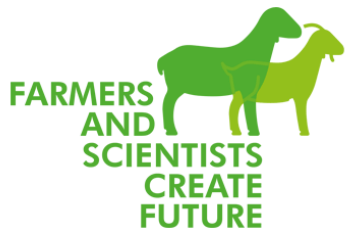

Assessment of the production of goat milk by means of performance cost
accounting in terms of economic efficiency and influence of stock size

Isabel Sand $^{1}$, Christina Gaio ${ }^{1}$, Wilfried Hartmann ${ }^{1}$, Fides Marie Lenz ${ }^{2}$ and Yvonne Kranch ${ }^{3}$

${ }^{1}$ Kuratorium für Technik und Bauwesen in der Landwirtschaft (KTBL), Darmstadt, Germany

${ }^{2}$ Landwirtschaftskammer Nordrhein-Westfalen, Lippstadt, Germany

${ }^{3}$ PROFUMA Spezialfutterwerke GmbH \& CO KG, Dormagen, Germany

Contact: Isabel Sand, i.sand@ktbl.de

\section{Abstract:}

Purpose: To evaluate the performance and costs of goat milk production, if it is economical, and

whether animal places have an influence on performance cost accounting.

Methods: We modelled three production processes of dairy goat farming. These only differed in stock size with the area per animal kept constant. This resulted in 125, 245, and 490 animal places.

We also kept the production characteristics constant. With these assumptions, a performancecost calculation was carried out. It included a list of performance and direct costs, investment requirements and annual building costs, operating costs and performances, costs and success factors. The data we use are from our own data collection and research.

Results: Animal places had no influence on the direct costs and direct cost free performance. However, animal places had an impact on variable costs. These increase with a decrease in animal places and thus decrease the profit margin. Direct and operating free and single-free performance increase with increasing animal places. In the same way, the operating productivity increases and the unit costs are positively affected while the price per litre goat milk decreases. For all three scenarios, the gross margin was still positive, but the direct and operating cost free and individual cost free performance was negative.

Conclusion: All three models of production processes turned out as non-economical. To cover all costs, the milk price of $€ 0.75$ per litre would have to increase by around $50 \%$ in the largest barn.

To increase profitability, direct marketing of goat's milk products could be added to milk production. Good kid marketing would also increase profitability.

Relevance: We were able to show which economic variables in the performance and cost calculation arise for the farmer in goat milk production, whether it is economical in the planning examples and where there is room for improvement. 


\title{
Economics:
}

How can the profitability of sheep and goat

farming be improved?

\section{An assessment of economic efficiency in German sheep farming - a nationwide analysis}

\author{
Stanislaus von Korn ${ }^{1}$, Stefan Völl ${ }^{2}$ and Arbeitskreis Wirtschaftlichkeit ${ }^{2}$ \\ ${ }^{1}$ Hochschule für Wirtschaft und Umwelt (HfWU), Nürtingen-Geislingen, Germany \\ ${ }^{2}$ Vereinigung Deutscher Landesschafzuchtverbände (VDL), Berlin, Germany \\ Contact: Prof. Dr. Stanislaus von Korn, Hochschule für Wirtschaft und Umwelt Nürtingen-Geislingen, \\ Institut für Angewandte Agrarforschung (IAAF), 72622 Nürtingen, Stanislaus.korn@hfwu.de
}

\section{Abstract:}

In view of the declining herd population (v. Korn 2019), the analysis of the economic situation in sheep farming is of central importance for the establishment of suitable control measures in order to be able to maintain sheep farming. Against this background, the aim of the project funded by the Landwirtschaftliche Rentenbank was to carry out a nationwide representative analysis of the current assessment of profitability in sheep farming.

For this purpose, all available data from consulting initiatives as well as from accounting and testfarm results have been researched, merged and adjusted. Thus, the most extensive data basis on sheep profitability was created with approximately 700 farm surveys from recent years. The results show large variations between regions, based mainly on different herd structures and location conditions. The deviations between the years are primarily determined by the fluctuating lamb prices. Overall, it was found that approximately $60 \%$ of total income from sheep farming ( $290 € /$ Ewe +Year) comes from public donations.

However, under the current price and cost relationships, full costs cannot be covered despite the comparatively high proportion of public funds. This means that if sheep farming is to be preserved in its multifunctionality for landscape, nature conservation, society and rural structures, suitable support instruments must also be installed in the future (EU 2018), but also consulting, training and commitment in sheep farms will be required.

\section{References:}

EU (2018). Bericht über die derzeitige Lage und die Zukunftsperspektiven der Schaf- und Ziegenhaltung in der EU. Europäisches Parlament, A8-0064/2018, März 2018

von Korn, Stanislaus (2019). Strukturen und Perspektiven der Schafhaltung, Workshop

„Zucht und Haltung von Schaf und Ziege in Deutschland“, Okt. 2019 Berlin 
Economics:

How can the profitability of sheep and goat

farming be improved?

Oral presentations

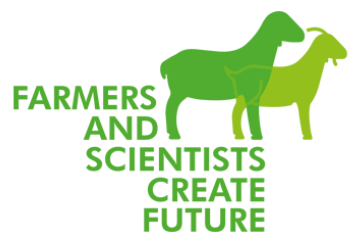

Genetic Resources

\section{The Thuringian sheep and goat premium}

\section{$\underline{\text { Adriana Schwarz }^{1}}$ and Henryk Baumbach ${ }^{2}$}

${ }^{1}$ Thuringian State Office for Environment, Mining and Nature Conservation, Weimar, Germany

${ }^{2}$ Thuringian Ministry for Environment, Energy and Nature Conservation, Erfurt, Germany

Contact: Adriana Schwarz, Thuringian State Office for Environment, Mining and Nature Conservation,

Harry-Graf-Kessler-Straße 1, 99423 Weimar, Tel: +49 361573943 595,

adriana.schwarz@tlubn.thueringen.de

\section{Abstract:}

Since 1990, the sheep population in Thuringia has decreased significantly. The total number of sheep has shrunken to less than 1/4, compared to 1989 (542,253). The fundamental change of agricultural structures after the unification and the abolition of coupled payments for sheep and goats at federal level in 2005 led to this dramatic decline.

Therefore, Thuringia has supported and initiated some initiatives to reintroduce a premium for grazing animals. Thuringia introduced its own premium for sheep and goats in 2019 (limited until 2021), which is fully financed from state resources and granted as de-minimis aid. The premium is supposed to counter the decrease of animal population, which is essential to conserve high nature value grassland in the medium term. Furthermore, the initiative aims to reintroduce coupled payments as appropriate instrument at federal level with the new CAP period.

Thuringia supports farmers with $25 €$ per animal and year. Due to the de-minimis rules, the total annual amount is limited to 6,666 € per agricultural holding. In 2019, the premium was paid to 321 farms for 47,000 animals. The total number of dams kept by these farms was about twice this number. However, due to the aid ceiling the premium was capped.

In 2019 the sheep population in Thuringia started to rise again slightly by $2 \%$ (121,900 vs. 119,500 in 2018). With this concept, Thuringia has a pioneering role in Germany, which other federal states have picked up. However, a fundamental solution has to be found at the federal level. 


\section{Economics:}

How can the profitability of sheep and goat

farming be improved?

\section{Weidewonne - bringing together lamb marketing and landscape conservation}

\section{Stefanie Schröter}

Naturstiftung David, Projekt Weidewonne, Brau, Deutschland

Contact: Heidelbergstr. 1, 06577 Braunsroda, Germany, stefanie.schroeter@naturstiftung-david.de

\section{Abstract}

Today, the main threat for the valuable dry grasslands is under-grazing, which results in matting and shrub encroachment. After German reunification, the sheep stock decreased especially in Eastern Germany. On average, $58 \%$ of the shepherd's income in Thuringia results from subsidies. However, the German lamb market is challenged by the cost-effective imports from New Zealand.

The applying project Weidewonne aims at supporting shepherds, who are also engaged in landscape conservation, by an increase of the value lamb caused by implementing direct marketing.

The brand "Weidewonne" was created for the marketing of landscape conservation lamb in the Thuringian Basin. Since 2011, quality criteria and marketing channels were developed within an EU LIFE project. Since 2017, the project is managed on behalf of the Thuringian Ministry for Environment, Energy and Nature Conservation by the foundation "Naturstiftung David" and funded by ELER.

Currently, 16 shepherds participating in the project, along with butchers, who stock "Weidewonne lamb". Regular marketing campaigns involve partners from slaughter and distribution. In March 2020, an online shop was launched. Now, customers, who have no access to "Weidewonne butchers", are able to order fresh lamb online.

The project shows that nowadays shepherds not only have issues of economical nature but also of social acceptance, bureaucracy and farm succession. In future, the Weidewonne project gains to increase its activities by fully supporting shepherds throughout Thuringia. Then it will be possible to evaluate the improvement on a statistical basis. 
Economics:

How can the profitability of sheep and goat

farming be improved?

Genetic Resources

Oral presentations

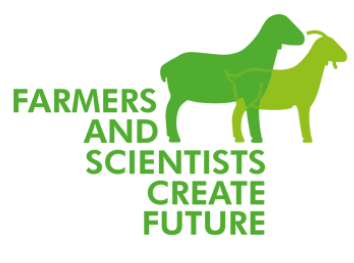

\section{Ways to improve the profitability of sheep farming with rare indigenous sheep breeds}

\section{Nathalie Ketterle $^{1}$ and Caroline Ketterle ${ }^{2}$}

${ }^{1}$ Kollektion der Vielfalt, Zell, Germany

${ }^{2}$ University of Applied Science Nürtingen-Geislingen (HfWU), Nürtingen, Germany

Contact: Nathalie Ketterle, Boßlerstr. 1, D-73119 Zell u.A., nathalie.ketterle@kollektion-der-vielfalt.de

\section{Abstract:}

The main goal is the preservation of rare indigenous sheep breeds by using their typical and natural coloured wool in traditional and modern ways, creating sustainable woollen products and selling them directly from farmgate to the consumers and therefore increase the profitability of sheep farming and preserve biodiversity.

When we started 2004, the renewable research wool was regarded as waste and it had no use at all. Instead of increasing the income of farmers, wool costs them and shearing their sheep is only done for animal welfare reasons.

Instead of throwing away an eco-friendly and sustainable fibre, we found use for the wool of our indigenous sheep breeds thereby avoiding microplastic pollution since wool is reusable and $100 \%$ biodegradable, compared to synthetical fibre.

Since 2009, we consult and support projects all over Europe to develop a whole value chain for wool and collaboratively create a local brand for woollen products from rare indigenous sheep breeds.

By selling high quality woollen products directly from "sheep to shop", the whole value chain is maxed out, increase the income of the breeders, supporting preservation of rare indigenous sheep breeds and maintaining and sustaining biodiversity and cultural heritage.

Another benefit, $5 \%$ of the weight of wool is pure organic carbon. When stored in wool, there is less carbon in the atmosphere and this mitigates climate change.

Our work contributed to agriculture and landscape conservation as well as to the promotion of old and endangered sheep breeds and the preservation of their genetic diversity. 


\section{Economics:}

How can the profitability of sheep and goat

farming be improved?

\section{Place of goat meat in human consumption in the Chlef region in Algeria}

\section{Mohamed Sadoud and Yassine Sadoud}

H. Benbouali Chlef University, BP 151, Chlef, Algeria

Contact: $m$ sadoud@yahoo.fr

\section{Abstract:}

According to FAO statistics, Algeria had around 5 million goat heads and produced 7500 tonnes of goat meat in 2017. According to Madani (2000), the goat breeds existing in Algeria are of the traditional type, the majority of which are subject only to natural selection. They are composed by animals of the local population with generally Nubian blood. In addition to local populations, there are also introduced populations, and crossed populations. The survey took place during 2019. The questionnaire was sent to 200 heads of households. The surveys comprising 24 questions targeted the usual consumers of goat meat, who were previously selected according to the difficult piedmonts and mountain areas of the Chlef region. Consumer preferences are very complex and heterogeneous and depend not only on the sensory properties of the meat, but also on psychological and socio-demographic factors. Thus, they look for freshness considered as a factor in the appreciation of the quality of a meat and for this they pay great attention to the color of the meat, which is used as an indicator of the age of the animal (Oury et al., 2009). They consider juiciness and taste as very important criteria in the choice of meat.

\section{References:}

FAO. (2017). Food and agriculture data, http://www.fao.org/faostat/en/

Madani T., 2000. Goat farming in north-eastern Algeria. Gruner L and Chabert Y (Ed). INRA and Institut de l'Elevage Pub, Tours 2000. Proceedings of the 7th Conference International on Goats, Tours (France) 15-21 / 05 / 00,351-353

Oury, M.P., Picard, B., Briand, M., Dransfield, E., Blanquet, J. P., Dumont, R. (2009). Interrelationships between meat quality traits, texture measurements and physicochemical characteristics of M. rectus abdominis from Charolais heifers. Meat Science, 83, 293-301 


\title{
Economics:
}

How can the profitability of sheep and goat

farming be improved?

\section{Impact of direct ewe support on the cost-income situation of the sheep farm}

\author{
Bence Jávor $^{1}$, András Nábrádi $^{2}$ and Sándor Kukovics ${ }^{3}$ \\ ${ }^{1}$ Hódmezőgazda Closed Corporation, Hódmezővásárhely, Hungary \\ ${ }^{2}$ University of Debrecen, Debrecen, Hungary \\ ${ }^{3}$ Sheep and Goat Products' Board and Inter-professional Organization, Várpalota, Hungary \\ Contact: Bence Jávor, Arany Sándor u. 17. Debrecen 4014 Hungary; javorbence0804@gmail.com
}

\section{Abstract:}

The basic condition for the survival of the sheep sector is that it is worth keeping sheep. This requires, in addition to the revenue generated by the products manufactured under the given condition scheme, a level of support for the services provided to the community.

To analyse the situation of domestic sheep farming, the economic database of the sector was subjected to a sensitivity analysis. Database contained data on existing sheep farms in test farm system (FADN), data from Central Statistical Office, and analyses of sectoral organizations made during the period between 2003 and 2018.

In examinations, the production value per ewe, revenues (animals, wool, milk), direct ewe support, costs (wages, feed, services, overheads), the margin contribution, and the sectoral result were analysed.

Data were processed using Microsoft Excel 2016 software package and correlation studies (Pearson's correlation calculation, covariance analysis, $\mathrm{r} 2$ test) were performed.

The results show that production costs increased at a faster rate than revenues during the period under review, and direct ewe support plays a very important role in shaping the sectoral result. In the process of this since 2012, with the increase of this support, the sectoral income per ewe has increased, which has yielded a positive result since 2014.

In conclusion, we found that at the current level of production, only direct ewe support allows for economical sheep farming. Without this, the utilised progeny rate should be improved from $85 \%$ to $150 \%$.

In addition, area-based direct payments represent the real income of a given sheep farm.

\section{References:}

Kukovics S. Sándor and Jávor, András (2010): A fejlesztés lehetőségei a juh ágazatban, JUHINNOV Platform /Development possibilities in sheep sector, JUHINNOV Platform/, K-OVI-CAP Bt. és Debreceni Egyetem AGTC, Érd-Debrecen, ISBN 978-96308-0624-4, 365 pages

Bence Jávor, András Nábrádi, Sándor Kukovics (2018): Subsidies are potential sources of profitable management - their payment between 2010 and 2016; APSTRACT Vol. 12. Number 1-2. 2018.pages 97-120. ISSN 1789-7874 


\title{
Environmental performance and climate change: \\ What do sheep and goats contribute to climate change mitigation?
}

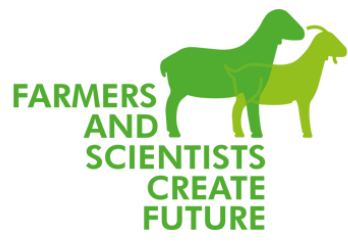

Oral presentations

\section{Adaptation to saline drinking water in goats}

\author{
Rukhsana Amin Runa ${ }^{1}$, Alexander Riek ${ }^{2}$, Lea Brinkmann ${ }^{3}$ and Martina Gerken ${ }^{3}$ \\ ${ }^{1}$ Department of Surgery and Obstetrics, Bangladesh Agricultural University, Mymensingh, Bangladesh \\ ${ }^{2}$ Institute of Animal Welfare and Animal Husbandry, Friedrich-Loeffler-Institute, Celle, Germany \\ ${ }^{3}$ Department of Animal Sciences, University of Göttingen, Göttingen, Germany \\ Contact: Dr. Alexander Riek, Institute of Animal Welfare and Animal Husbandry, Friedrich-Loeffler- \\ Institut, Dörnbergstr. 25/27, 29223 Celle, Tel: +49 51413846 160, Email: alexander.riek@fli.de
}

\section{Abstract:}

In the context of global warming, salinization of groundwater and soil is a prevalent global issue with serious consequences on animal health and production. Therefore, we investigated the capacity of goats to adjust their salt intake from saline drinking water in a free choice system. Twelve non-pregnant Boer goats were kept in individual pens for 4 weeks. In the control phase (1 week), only fresh water was supplied in five identical buckets for each pen. During the subsequent treatment phase (3 weeks), fresh tap water and four different concentrations $(0.75,1.0,1.25$, and $1.5 \% \mathrm{NaCl})$ of saline water were offered simultaneously in a free choice system. Hay, water and a mineral lick were provided ad libitum. Dry matter intake, total water intake and total sodium intake were significantly $(\mathrm{P}<0.001)$ higher during the treatment phase. All goats had a significant preference for fresh $(0 \% \mathrm{NaCl})$ over saline water. At the beginning of the simultaneous choice situation, animals did not differentiate between salt concentration of $0.75 \%$ and $1.0 \%$. However, with successive treatment, animals distinguished more sensitively between saline water concentrations and preferred the $0.75 \%$ salt concentration. The total sodium intake of goats ranged between 0.37-0.55 g/kg BM0.75 per day during the treatment phase, being 8 to 11 -fold higher than the daily requirements of sodium for body maintenance. The results suggest that goats are able to differentiate between saline water concentrations and adjust their sodium intake by quick adjustments in selfselection in a free choice system. 


\title{
Environmental performance and climate change: \\ What do sheep and goats contribute to climate change mitigation?
}

\section{Anaplasma phagocytophilum in cattle, sheep and goats in Germany - results of a systematic review of the literature}

\section{Matthias G. Wagener and Martin Ganter}

\author{
University of Veterinary Medicine Hannover, Foundation, Clinic for Swine and Small Ruminants, \\ Hannover, Germany \\ Contact: University of Veterinary Medicine Hannover, Foundation, Clinic for Swine and Small Ruminants, \\ Bischofsholer Damm 15, 30173 Hannover, Germany, matthias.gerhard.wagener@tiho-hannover.de
}

\begin{abstract}
:
Anaplasma phagocytophilum, formerly called Ehrlichia phagocytophila, is a Gram-negative, obligate intracellular bacterium that has a broad host range. Because it is transmitted by ticks and enters the neutrophil granulocytes, clinical pictures are called granulocytic anaplasmosis in dogs or humans, or tick-borne fever in ruminants. Clinical signs in small ruminants include an acute febrile reaction, abortion, depressed appetite and respiratory symptoms. Due to secondary infections a broad range of other clinical signs is also observed. Tick-borne fever in small ruminants typically played a role in northern Europe, and higher-altitude regions in southern Europe. But there are also high seroprevalences in dogs or wild ruminants in Germany. Positive samples of patients show that there is also a clinical impact of the infection in German small ruminants. A systematic literature search in three scientific databases was performed. Search terms were "Anaplasma phagocytophilum" AND "Germany" AND ("sheep" OR "goat" OR "cattle") as well as synonyms or German translations of the terms. 161 sources (without replicates) from 1920 to 2020 were found. 13 sources were identified as suitable in providing information about the status of $A$. phagocytophilum in cattle or small ruminants in Germany. Except one source all were from the last decade, 9 of them dealt with cattle, 2 with sheep, 2 with goats, 2 with mouflons. All sources containing small ruminants included more than one host species. These data show a lack of knowledge concerning this pathogen in small ruminants in Germany. Tick-borne fever in ruminants might be currently underdiagnosed and even might get a higher impact on flocks in Germany due to the climate change and the accompanying better conditions for ticks as a vector of $A$. phagocytophilum.
\end{abstract}

\section{References:}

Huhn, C., Winter, C., Wolfsperger, T., Wüppenhorst, N., Smrdel, K. S., Skuballa, J., Pfäffle, M., Petney, T., Silaghi, C., Dyachenko, V., Pantchev, N., Straubinger, R. K., Schaarschmidt-Kiener, D., Ganter, M., Aardema, M. L. and Loewenich, F. D. von (2014). Analysis of the population structure of Anaplasma phagocytophilum using multilocus sequence typing. PLoS ONE, 9(4), e93725-e93725.

Tegtmeyer, P., Ganter, M., von Loewenich, F.D. (2019). Simutaneous infection of cattle with different Anaplasma phagocytophilum variants. Ticks and Tick-borne Diseases 10, 1051-1056.

Woldehiwet, Z. (2007). Tick-borne diseases. In: Aitken I.D. ed. Diseases of Sheep. $4^{\text {th }}$ ed. Oxford, UK: Blackwell Publishing, 347355. 


\title{
Environmental performance and climate change: \\ What do sheep and goats contribute to climate change mitigation?
}

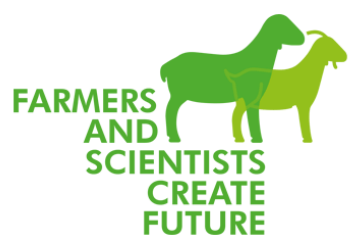

Oral presentations

\section{Opportunities to mitigate GHG emissions from sheep and goat farming in Indonesia}

\author{
Mohammad Ikhsan Shiddieqy ${ }^{1}$, Bess Tiesnamurti ${ }^{1}$ and Yeni Widiawati ${ }^{2}$ \\ ${ }^{1}$ Indonesian Center for Animal Research and Development (ICARD), Bogor, Indonesia \\ ${ }^{2}$ Indonesian Research Institute for Animal Production, (IRIAP), Ciawi, Indonesia \\ Contact: Jalan Raya Pajajaran Kav. E-59, Bogor 16151, Indonesia, (+62) 2518322185 , \\ m.ikhsan.shiddieqy@litbang.pertanian.go.id
}

\section{Abstract:}

Sheep and goat farming play an important role in the livelihoods of the farmers in Indonesia. Small ruminants farming in Indonesia is identified with limited ownership by farmers (2-7 heads/household). Farming management systems are dynamic in response to the availability of resources. Indonesia's Ministry of Agriculture is trying to boost the small ruminant population. However, an increase in small ruminant population is related to the contribution of sheep and goat to greenhouse gas (GHG) emission. The small ruminant production system is affected by climate change and contributes to global warming with GHG emissions (Marino et al., 2015). Since goats are considered more climate resilient than other ruminant species (Pragna et al., 2018), their contribution to GHG emissions is more important to highlight. This paper aims to provide an integrated overview on the opportunities to mitigate GHG emissions from sheep and goat farming in Indonesia. Beef cattle are the highest contributor of enteric $\mathrm{CH}_{4}$ (18.04 Gg CO -e or 65,12\%) among livestock's GHG (Tier 1) in the country, while goat and sheep are $2.043 \mathrm{Gg} \mathrm{CO}_{2}$-e (8.47\%) and $1.509 \mathrm{Gg} \mathrm{CO}_{2}$-e $(6,26 \%)$ in 2014, respectively. However, GHG emissions from small ruminants are significant since the population are growing $10.1 \%$ per year. GHG emissions (enteric $\mathrm{CH}_{4}$, feces $\mathrm{CH}_{4}$ and feces $\mathrm{N}_{2} \mathrm{O}$ ) from sheep using Tier 2 method are $1.693 \mathrm{Gg} \mathrm{CO}_{2}$-e in 2014 (Widiawati and Tiesnamurti, 2019). Among the various GHG mitigating strategies, our review suggests that the most effective mitigation strategies in Indonesia is through nutritional intervention, such as utilization of tropical legumes and palm kernel cake as small ruminants feed which reduce enteric $\mathrm{CH}_{4}$ production.

\section{References:}

Pragna, P., Chauhan, S.S., Sejian, V., Leury, B.J., Dunshea, F.R. (2018). Climate Change and Goat Production: Enteric Methane Emission and Its Mitigation. Animals 2018, 8(12), 235. https://doi.org/10.3390/ani8120235

Marino, R., Atzori, A.S., D’Andreac, M., Iovaned, G., Trabalza-Marinuccie, M., Rinaldi, L. (2015). Climate change: Production performance, health issues, greenhouse gas emissions and mitigation strategies in sheep and goat farming. Small Ruminant Res. Volume 135, February 2016, Pages 50-59. https://dx.doi.org/10.1016/j.smallrumres.2015.12.012

Widiawati, Y., and Tiesnamurti, B. (2019). "Sumbangan Emisi Gas Rumah Kaca dari Domba di Indonesia," in Emisi Gas Rumah Kaca dari Peternakan di Indonesia dengan Tier 2 IPCC, ed. E. Aldrian, S. Puspowardoyo, and B. Haryanto (Jakarta, LIPI Press), 57-70. 


\author{
Environmental performance and \\ climate change: \\ What do sheep and goats contribute to climate \\ change mitigation? \\ Oral presentations
}

\title{
The impact and breeding perspectives of maternal energy metabolism profiles pre- and postpartum on lamb body weight development with special regard to ewe methane emission traits
}

\author{
Jessica Reintke ${ }^{1}$, Kerstin Brügemann ${ }^{1}$, Tong Yin $^{1}$, Petra Engel ${ }^{1}$, Henrik Wagner ${ }^{2}$, Axel \\ Wehrend $^{2}$, Anja Müller ${ }^{3}$ and Sven König ${ }^{1}$ \\ ${ }^{1}$ Institute of Animal Breeding and Genetics, University of Giessen, Ludwig St. 21B, 35390 Giessen, \\ Germany \\ ${ }^{2}$ Clinic for Obstetrics, Gynaecology and Andrology of Large and Small Animals with Veterinary \\ Ambulance, University of Giessen, Frankfurter St. 106, 35392 Giessen, Germany \\ ${ }^{3}$ IDEXX Laboratories, Vet Med Labor GmbH, Im Moltengraben 65, 70806 Kornwestheim, Germany \\ Contact: Jessica Reintke, Institute of Animal Breeding and Genetics, University of Giessen, Ludwig St. 21B, \\ 35390 Giessen, Germany, Jessica.Reintke@agrar.uni-giessen.de
}

\section{Abstract:}

The profitability of sheep production strongly depends on the maternal health and feed efficiency status, and on lamb weaning performance. This study focused on intergenerational aspects and associations between maternal energy metabolism profiles with lamb body weight development. Data included repeated observations for body condition and methane (recorded via laser methane detector) traits from 330 ewes (253 Merinolandsheep, 77 Rhönsheep) postpartum, and macro-, microelement and metabolic status (blood samples) from 46 ewes pre- and postpartum. Additionally, the body weight of 629 lambs was recorded. In Merino ewes, a maternal serum magnesium level $>1.0 \mathrm{mmol} / \mathrm{L}$ at weaning was associated with an increase of $13 \%$ in lamb body weight, compared to offspring from ewes with lower serum magnesium concentration. Furthermore, copper positively affected ewe body condition at weaning in both breeds. In Rhönsheep, a sufficient selenium supply was important to optimize body condition. Moreover, high zinc level during lactation was associated with reduced methane emissions in Merino ewes and a low ß-hydroxybutyrate level contributed to decreased methane emissions in both breeds. Large methane levels of an ewe were associated with reduced lamb body weight and reduced ewe body condition. Heritabilities for methane traits were small (h2 $\leq 0.03$ ) and genetic correlations between methane emissions, ewe body condition traits and lamb body weight were mostly negative. Results indicate that the maternal mineral and metabolic status affects ewe body condition, methane emissions and lamb body weight. Furthermore, breeding on reduced methane emissions also contributes to genetic improvements of lamb weaning performance. 


\title{
EUGENA: the European genebank network for animal genetic resources
}

\author{
Fernando Tejerina Ampudia $^{1}$, Coralie Danchin-Burge ${ }^{2}$ and Sipke Joost Hiemstra ${ }^{3}$ \\ ${ }^{1}$ Ministerio de Agricultura, Pesca y Alimentación. Subdirección General de Medios de Producción \\ Ganadera. C, Almagro 33, CP28010, Madrid, Spain \\ ${ }^{2}$ Institut de l'Elevage, 149 rue de Bercy, F-75595, Paris 12, France \\ ${ }^{3}$ Centre for Genetic Resources (CGN), Wageningen University \& Research, Wageningen, Netherlands
}

\section{Abstract:}

Conservation of within and across breed genetic diversity in genebanks (ex situ) is a complementary strategy of the in situ conservation to maintain a broad genetic base for future breeding and research. It is important to safeguard farm animal genetic diversity (both local and mainstream breeds) for future generations, in particular in the global context of food and nutrition security and climate change. With reference to the achievement of Sustainable Development Goal target 2.5, the Food and Agricultural Organization of the United Nations is monitoring the number of animal genetic resources for food and agriculture secured in medium or long term conservation facilities (genebanks) (indicator 2.5.1.b).

In a recent survey developed by the ex situ Conservation Working Group of the European Regional Focal Point for Animal Genetic Resources (ERFP, https://www.animalgeneticresources.net/), a total of 125 genebanks (reproductive and/or genomic) were identified in 26 European countries. The most frequent objective as indicated by these facilities in the survey was the conservation of Animal Genetic Resources, followed by research activities and commercial use of the stored material. The results of the survey show the high interest in the establishment and development of collections for the ex situ conservation of animal genetic resources and for use in breeding, conservation and research. The European Genebank Network for AnGR (EUGENA) is a network of nationally recognized member genebanks in European countries with the aim to support the medium/long term ex situ conservation and sustainable use of AnGR, and to facilitate the implementation of the FAO Global Plan of Action at national and pan-European level. Exchange of knowledge and experiences as well as facilitating access to information about genebank collections in Europe are the main objectives of EUGENA.

Development of EUGENA was initiated by ERFP in 2016, and since then the network has grown constantly in terms of number of countries, genebanks members and information about genebank collections. Currently, EUGENA is composed of 8 genebanks from 6 different countries, which store 865.324 samples (semen, embryos, hair and blood) from 10 different species. EUGENA gathers information from 59.774 samples (59.549 semen and 226 blood) from 23 goat breeds, allocated in 4 different genebanks, and 113.805 samples (113.151 semen, 23 wool and 631 blood) from 40 sheep breeds, allocated in 4 different genebanks.

You can find more information about EUGENA at https://www.eugena-erfp.net/en/. 


\title{
Genomic characterization of selection signatures: what is the future for sustainable utilization of Ugandan goat breeds
}

\author{
$\underline{\text { Robert B. Onzima }}{ }^{1,2,4,5}$, Maulik R. Upadhyay ${ }^{1,3}$, Harmen P. Doekes ${ }^{1}$, Mirte Bosse ${ }^{1}$, Martien A. \\ M. Groenen ${ }^{1}$ and Richard P. M. A. Crooijmans ${ }^{1}$ \\ ${ }^{1}$ Animal Breeding and Genomics, Wageningen University and Research, Wageningen, Netherlands \\ ${ }^{2}$ Department of Agricultural Sciences, Faculty of Agriculture and Environmental Sciences (FAES), Muni \\ University, Arua, Uganda \\ ${ }^{3}$ Department of VeterinarySciences Agricultural Population Genomics, Ludwig-Maximilians-University \\ Munich, Germany \\ ${ }^{4}$ Department of Agricultural Sciences, Faculty of Agriculture and Environmental Sciences (FAES), Kabale \\ University, Kabale, Uganda \\ ${ }^{5}$ National Agricultural Research Organization (NARO) P O Box 295, Entebbe, Uganda \\ Contact: Department of Agricultural Sciences, Faculty of Agriculture and Environmental Sciences (FAES), \\ Muni University, P.O. Box 725, Arua, Uganda, robertonzima@gmail.com, r.onzima@muni.ac.ug
}

\section{Abstract:}

Both natural and artificial selection are among the main drivers shaping genetic variation across the genome of livestock species. Selection typically leaves signatures in the genome, which are often characterized by high genetic differentiation across breeds and/or a strong reduction in genetic diversity in regions associated with traits under intense selection pressure. We evaluated selection signatures in six Ugandan goat breeds: Boer $(\mathrm{n}=13)$, and the indigenous breeds Karamojong $(n=15)$, Kigezi $(n=29)$, Mubende $(n=29)$, Small East African $(n=29)$ and Sebei $(n=29)$. After genotyping quality control, 45,294 autosomal single nucleotide polymorphisms (SNPs) remained for further analyses. A total of 394 and 6 breed-specific putative selection signatures were identified across all breeds, based on marker-specific fixation index ( $F_{\mathrm{ST}}$-values) and haplotype differentiation (hapFLK), respectively. These regions were enriched with genes involved in signalling pathways associated directly or indirectly with environmental adaptation, such as immune response (e.g. IL1ORB and IL23A), growth and fatty acid composition (e.g. FGF9 and IGF1), and thermo-tolerance (e.g. MTOR and MAPK3). The study revealed little overlap between breeds in genomic regions under selection and generally did not display the typical classic selection signatures as expected due to the complex nature of the traits. In the Boer, candidate genes associated with production traits, such as body size and growth (e.g. GJB2 and GJA3) were identified. This study provides insights into the effects of long-term selection in Boer and indigenous Ugandan goat breeds, which are relevant for implementation of breeding programs and conservation of genetic resources, and their sustainable use and management. 


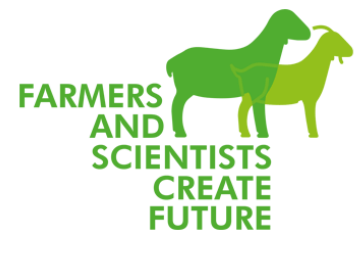

\title{
Morphological variability and geographical distribution of goat populations from Benin (West Africa)
}

\author{
Habib R. V. Whannou ${ }^{1}$, Ulriche C. Afatondji ${ }^{1}$, Dominique Demblon ${ }^{2}$, Marcel R. B. Houinato ${ }^{1}$ \\ and Luc H. Dossa ${ }^{1}$ \\ ${ }^{1}$ Faculty of Agricultural Sciences, University of Abomey-Calavi, Benin \\ ${ }^{2}$ Higher Education Institute Condorcet Province of Hainaut, Belgium \\ Contact: Faculty of Agricultural Sciences, University of Abomey-Calavi, email: raidvich27@gmail.com
}

\section{Abstract:}

Worldwide, insufficient knowledge of the genetic and phenotypic variabilities within and between local goat populations and of their suitability to diversified production environments hampers the development of programs for their rationale selection, use and management. This study explored the current geographical distribution of goat populations in Benin based on their morphology, as a first step in their genetic molecular and phenotypic characterizations. From November 2019 to February 2020, ten qualitative and twenty-six linear body measurements were taken on 2114 adult female goats in the ten phytogeographic zones that compose the three vegetation areas of Benin. Fifteen ratios were generated from the quantitative variables. The data were analyzed using generalized linear model procedures followed by multiple comparison of least square means and multivariate analytical methods, including canonical discrimination analysis and hierarchical ascendant classification. All linear body measurements significantly varied $(\mathrm{P}<0.05)$ among zones. The highest mean values of height traits were recorded in the drier zones of the Sudanian area and the lowest in humid Guineo-congolese area. In the discriminant function analysis, only $61.80 \%$ of the measured individuals were correctly classified in their district of origin by 26 measured variables and 8 ratios. The cluster procedure analysis revealed four sub-populations within the three large known goat populations. These results confirm the spatial variation of goat populations according to production areas in Benin, but also suggest that interbreeding may have taken place among animals from the different phytogeographic zones. 


\title{
Discovery of casein variants in goats using capture sequencing
}

\author{
Siham A. Rahmatalla ${ }^{1,2}$, Danny Arends ${ }^{1}$, Ammar Said Ahmed ${ }^{1}$, Lubna M. A. Hassan ${ }^{3}$, Stefan \\ Krebs $^{4}$, Monika Resissmann ${ }^{1}$ and Gudrun A. Brockmann ${ }^{1}$
}

${ }^{1}$ Albrecht Daniel Thaer-Institut für Agrar- und Gartenbauwissenschaften, Humboldt-Universität zu Berlin, Invalidenstraße 42, D-10115 Berlin, Germany

${ }^{2}$ Department of Dairy Production, Faculty of Animal Production, University of Khartoum, Shambat P.O. Box 32, 13314 Khartoum North, Sudan

${ }^{3}$ Laboratory of Functional Genome Analysis, Gene Center, University of Munich (LMU), Feodor-Lynen-

Strasse 25, 81377 Muenchen, Germany

Contact: Siham A. Rahmatalla, Albrecht Daniel Thaer-Institut für Agrar- und Gartenbauwissenschaften Humboldt-Universität zu Berlin, Invalidenstraße 42, rahmatas@hu-berlin.de

\section{Abstract:}

Genetic polymorphisms in casein genes (CSN1S1, CSN2, CSN1S2, and CSN3) are known to affect milk protein, milk composition, cheese processing properties and human digestibility (Martin et al. 2002; Selvaggi \& Tufarelli 2012; Lad et al. 2017). In this study, we investigated sequence variants in coding regions of casein genes in four Sudanese goat breeds (Nubian, Desert, Nilotic, and Taggar) and compared them with Saanen goats, Bezoar ibex, as well as Alpine and Nubian ibex. Using high-density capture sequencing 22 non-synonymous and 13 synonymous SNPs were identified, among them 11 and 7 novel SNPs, respectively. In the CSN1S1 gene, six non-synonymous (two novel) and seven synonymous SNPs (five novel), in the CSN2 gene five non-synonymous (three novel) and one synonymous SNP, in the CSN1S2 gene, six non-synonymous (four novel), and in the CSN3 gene five non-synonymous (two novel) and five synonymous (one novel) SNPs were detected. Most novel SNPs in coding regions of the casein genes were detected only in the critically endangered Nubian ibex. The identified markers for milk protein variants are additional useful tools for breed characterization, investigating biodiversity and phylogeny, and for the preservation of endangered breeds. Further research is needed to characterize these new sequence variants with respect to allele frequencies in different breeds and consequences on milk properties for human nutrition.

\section{References:}

\footnotetext{
Lad, S.S., Aparnathi, K.D., Mehta, B.M., Suresh, V. (2017). Goat Milk in Human Nutrition and Health - A Review. International Journal of Current Microbiology and Applied Sciences 6, 1781-92. doi: 10.20546/ijcmas.2017.605.194

Martin, P., Szymanowska, M., Zwierzchowski, L. \& Leroux C. (2002). The impact of genetic polymorphisms on the protein composition of ruminant milks. Reprod Nutr Dev. 42, 433-59. doi:10.1051/rnd:2002036

Selvaggi, M., Tufarelli, V. (2012). "Caseins of Goat and Sheep Milk: Analytical and Technological Aspects," in Casein: Production, Uses and Health Effects, ed. A. M. Ventimiglia, J. M. Birkenhäger (Nova Publishers), 1-26.
} 


\title{
Runs of homozygosity islands across 100 sheep and 96 goat populations reveal selection signatures
}

\author{
Wim Gorssen, Roel Meyermans, Steven Janssens and Nadine Buys
}

Department of Biosystems - Livestock Genetics - KU Leuven, Leuven, Belgium

Contact: +32 163778 24, wim.gorssen@kuleuven.be

\section{Abstract:}

Runs of homozygosity (ROH) are long stretches of homozygosity which are mainly caused by inbreeding. These $\mathrm{ROH}$ can be used for the detection of selection signatures by computing/defining ROH islands. Although there are numerous goat and sheep SNP datatesets available online, many of these data were never investigated for $\mathrm{ROH}$ (islands) and an overview of known $\mathrm{ROH}$ islands in sheep and goats is currently missing. In this study, we analysed $\mathrm{ROH}$ inferred from medium density SNP datasets in goats (96 populations; 4327 animals; Colli et al., 2018) and sheep (100 populations, 3490 animals; Sempéré et al., 2015). ROH analyses were performed using PLINK and graphically presented per population. Next, results on ROH islands per population were summarised per species. We defined $\mathrm{ROH}$ islands as SNPs with a P-value for $\mathrm{ROH}$ incidence larger than 0.999 (using standard normal z-scores), and an incidence of minimum $30 \%$.

A number of known $\mathrm{ROH}$ islands was confirmed, for example selection signatures for the myostatin gene in Texel sheep on OAR2. However, we also identified several ROH islands which were common in many populations, but with yet unknown, underlying biological mechanism. For example, fifteen sheep populations showed an ROH island on OAR6 at 37-38 $\mathrm{Mb}$ and six goat populations showed an $\mathrm{ROH}$ island on ARS12 at 35Mb. These findings may direct future studies or can serve as a reference for results in other populations or other investigations. Therefore, these results can be a valuable tool in future genetic research in sheep and goats.

\section{References:}

Colli L, Milanesi M, Talenti A, Bertolini F, Chen M, Crisà A, et al. (2018). Genome-wide SNP profiling of worldwide goat populations reveals strong partitioning of diversity and highlights 


\title{
Genetic diversity of Algerian and Turkish native sheep breeds
}

\author{
Abdelkader Ameur Ameur ${ }^{1}$, Onur Yilmaz ${ }^{2}$, Nezih Ata $^{2}$, Ibrahim Cemal ${ }^{2}$ and Semir Bechir \\ Suheil Gaouar ${ }^{3}$ \\ ${ }^{1}$ Agronomic sciences department, University of Tlemcen, Tlemcen, Algeria \\ ${ }^{2}$ Department of Animal Science, Adnan Menderes University, Aydin, Turkey \\ ${ }^{3}$ Department of Biology. University of Tlemcen, Tlemcen, Algeria \\ Contact: Ameur Ameur A., University Of Tlemcen, Department of Agronomic sciences, and Faculty life and \\ nature sciences, Email ameurabdelkader@gmail.com, Tel: +213657052803 \\ ORCID: https://orcid.org/0000-0002-7450-4311
}

\section{Abstract:}

The present study was conducted to investigate the genetic diversity and relationship of some native sheep breeds reared in Turkey and Algeria. A set of fourteen microsatellite markers was used for genotyping 240 animals from four Algerian (Hamra, Ouled Djellal, Sidaou and Tazegzawt) and four Turkish (White Karaman, South Karaman, Karacabey Merino and Kıvırcik) sheep breeds. A total of 340 alleles were observed. The mean number of alleles (Na) and the effective alleles (Ne) were, respectively, 24.29 and 10.99 with an average polymorphic information content (PIC) of 0.90. Hight genetic diversity level was inferred by observed (0.90) and expected heterozygosity (0.76). All FIS (inbreeding coefficient) values were obtained as positive and significant in all sheep breeds studied except White Karaman and Sidaou breeds. Mean value of DST, GST and HT values were found as 0.054, 0.060 and 0.91 , respectively. The mean global coefficient of gene differentiation (GST) showed that approximately $94.0 \%$ of the genetic variation was within-population. The highest number of private alleles with frequency above 5\% was observed in Ouled Djellal sheep. As a result, the eight sheep breeds studied show a distinction between them. Nevertheless, only the Algerian breed Ouled Djellal which is located near the Turkish ovine breeds in the dendrogram, this breed which introduced by the Tribes of Arabia "Benou HILAL" coming from the Middle East. However, the other breeds (Hamra, Tazagzawet and Sidaou) are native breeds of North Africa. In addition, such information provides an overview of the effect of conservation activities on breeding farms, suggesting that we should take some measures to avoid further losses of genetic diversity and minimize inbreeding represented by these breeds as soon as possible.

Keywords: Polymorphism, native sheep breeds, Turkey, Algeria, Microsatellite. 
Animal genetic resources:

Implementation of policies and support

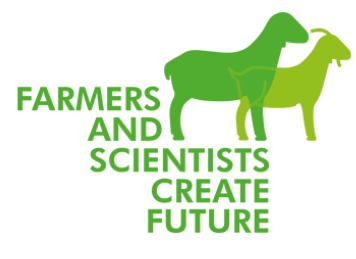

\section{The implementation of international commitments for animal genetic resources in Europe and Germany}

\section{$\underline{\text { Holger Göderz }}{ }^{1}$}

${ }^{1}$ Federal Office for Agriculture and Food, Bonn, Germany

Contact: Holger Göderz, Federal Office for Agriculture and Food, Deichmanns Aue 29, DE-53179 Bonn, Germany, holger.goederz@ble.de

\section{Abstract:}

Countries have agreed international and national commitments and strategies for the conservation and use of animal genetic resources (AnGR). Information is provided on the most relevant international commitments: the Global Plan of Action for AnGR (GPA), the Convention on Biological Diversity and the Sustainable Development Goals with a focus on the situation in Germany. In Germany, a programme for AnGR has been adopted in the year 2003. After the adoption of the GPA in the year 2007, this programme has been revised. Important actions are a continuous monitoring of all livestock breeds in Germany, the establishment of a national gene bank, the providing of public payments for the breeding of endangered breeds and project funding. In the year 2013, the national risk classification system in Germany has been revised. Since then, the number of breeds that are strongly endangered could be reduced. The stocks of the 19 endangered native sheep breeds increased. One of the success stories is the Alpines Steinschaf, which has been also facilitated by a wool marketing initiative. Its stock of breeding animals increased from 465 (2011) to 1,265 (2019). The stocks of the three native goat breeds have increased by approximately ten percent in this period. The National Programme for the Conservation and Sustainable Use of Animal Genetic Resources in Germany has proven to be suitable to increase or at least to maintain breeding stocks of endangered breeds and thus to maintain AnGR as a basis for the adaptability of livestock production. 
Animal genetic resources:

Implementation of policies and support

Genetic Resources

Oral presentations

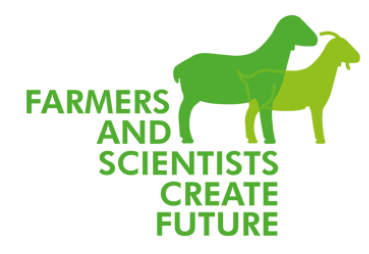

\title{
The Krainer Steinschaf in Austria - in situ conservation of an endangered breed
}

\author{
Beate Berger $^{1}$ and Barbara Soritz ${ }^{2}$
}

${ }^{1}$ AREC Raumberg-Gumpenstein, Thalheim, Austria

${ }^{2}$ Arche Austria, Austria

Contact: Beate Berger, AREC Raumberg-Gumpenstein, Institute of Organic Farming and Biodiversity of Farm Animals, Austrasse 10, 4601 Thalheim, Austria. +43(0)72424701122, beate.berger@raumberggumpenstein.at

\section{Abstract:}

The Austrian Conservation Breeding Program supports 29 breeds of farm animals. The example of the Krainer Steinschaf shows the network and different approaches necessary to analyze, rebuild and use a highly endangered breed. The Krainer Steinschaf is a small framed, nonseasonally fertile dairy sheep. The breed belongs to the cluster of rough wool breeds stemming from the Medieval Zaupelschaf and is well separated from the other endangered Austrian sheep breeds. The flock book population increased from 160 animals (1997) to 4071 animals (2020). Due to a strictly controlled mating plan based on pedigree analysis, the inbreeding rate in the active breeding population was $0,45 \%$ for 2007 and $0,4 \%$ for 2020 . The breeding organization is responsible for the breeding goals and registration of breeding animals on a genetic basis as broad as possible. A farmer driven marketing organization production systems and quality marketing schemes. Pasturing without concentrates is the main production system. On pasture, milk yield drops about two months after lambing with the onset of estrus. Twinning rate is not an issue as the ewes can lamb twice a year. For eight years, a quality program of a big food retailer brought up to 1000 lambs per year to market. Unfortunately, the program ceased because of reasons beyond control of the breeders. Now, on farm marketing is the main distribution channel. Breeding goals and marketing issues to improve the conservation of the breed are discussed. 


\title{
Animal genetic resources: \\ Implementation of policies and support
}

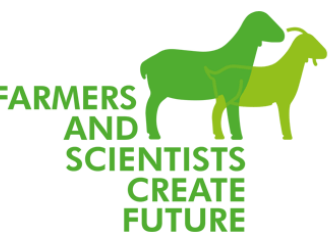

\section{Is the German White-headed Mutton Sheep an endangered breed?}

\author{
$\underline{\text { Sowah Addo }}{ }^{1}$, Stefanie Klingel ${ }^{2}$, Georg Thaller $^{3}$ and Dirk Hinrichs ${ }^{1}$ \\ ${ }^{1}$ University of Kassel, Witzenhausen, Germany \\ ${ }^{2}$ Arche Warder Zentrum für alte Haus- und Nutztierrassen e.V., Warder, Germany \\ ${ }^{3}$ Christian-Albrecht University, Kiel, Germany \\ Contact: Animal Breeding Department, University of Kassel, Nordbahnhofstr. 1a, 37213 Witzenhausen, \\ Germany; uk069108@uni-kassel.de
}

\section{Abstract:}

German White-headed Mutton is a meat type sheep classified as a monitoring population, meaning that the effective population size is between 200 and 1000, and a semen cryoconservation programme should be initiated as soon as the number of adult male animals falls below 100. Effective population size estimation for this classification is based on the number of flock book animals, being 1,912 ewes and 102 rams in 2019. In light of the availability of pedigree and marker information, the present study aimed at elucidating the diversity status of German White-headed Mutton from pedigree and genome perspectives. Our data consisted of pedigree information on 19,000 animals, and on 46 individuals genotyped at 40,753 single nucleotide polymorphism markers.

Pedigree-based inbreeding coefficient and effective population size estimates were $1.02 \%$ and 132 for the whole population, and 3.50\% and 99 for a reference subpopulation of animals born between 2012 and 2015, respectively. Estimate of average generation interval was 3.24 years. Runs of homozygosity-based inbreeding coefficient estimates varied with approximate number of ancestral generations $(G)$ i.e., $1.36 \%(G=2), 4.47 \%(G=8)$ and $11.30 \%(G=64)$. A linkage disequilibrium-based effective population size estimate was 53 at 5 generations ago. Our estimates of effective population size are above the commonly accepted minimum value of 50 (FAO, 1998). However, values below 200 imply, that the German risk classification system could be revised considering both, the method/data to estimate effective population size and the thresholds for assigning breeds to certain risk classes.

\section{Reference:}

FAO (1998). Secondary guidelines for development of national farm animal genetic resources management plans: Management of small populations at risk. url: http://www.fao.org/3/a-w9361e.pdf 


\section{Marketing situation and concepts for products of endangered local breeds of sheep and goats in Germany}

\section{Antje Feldmann and Katrin Dorkewitz}

Gesellschaft zur Erhaltung alter und gefährdeter Haustierrassen e.V. (GEH), Witzenhausen, Deutschland

Contact: Antje Feldmann, Gesellschaft zur Erhaltung alter und gefährdeter Haustierrassen e.V. (GEH);

Walburger Str. 2, 37213 Witzenhausen, E-Mail: feldmann@g-e-h.de, Tel.:+49 (0)5542-1864

\section{Abstract:}

Many local breeds of sheep and goats are on the Red List of Endangered Livestock Breeds in Germany (BLE, 2019). The project "Marketing concepts for products of endangered breeds of farm animals" (Menger et al., 2020) analyzed the current marketing situation of endangered breeds with the focus on food retailing. On the basis of questionnaires from 182 farms and an online research it became clear that the majority of the farmers sell their products via direct marketing (81\%). Wild fluctuations were found, especially in pricing. The marketing situation was mostly balanced (51.5 \%) or demand exceeded supply (33.8 \%).

Sales tests in food retailing showed that consumers are willing to pay premium prices. Sales promotion measures are able to stimulate business. Products from endangered breeds can be sold very well, especially in urban areas. Markups of $65 \%$ on goat's cheese from the Thuringian Forest Goat did not show negative effects on sales. After a period of communication methods the sales figures almost doubled, even without negative effects on the sale of other goat cheese products. There was neither a substitution nor a cannibalization effect.

The establishment of products from endangered breeds of farm animals in the food retail trade supports sustainable conservation in agricultural use. The project results enable sheep- and goat-breeders and retailers to gain an overview of the communication with the customer, the requirements of the trade and the needs of the farmer and helps them to transfer this knowledge to their own work.

\section{References:}

Bundesanstalt für Landwirtschaft und Ernährung (BLE) (2019): Einheimische Nutztierrassen in Deutschland und Rote Liste gefährdeter Nutztierrassen 2019. Online verfügbar unter

https://www.ble.de/SharedDocs/Downloads/DE/Landwirtschaft/Biologische-Vielfalt/RoteListe.html, zuletzt geprüft am 30.04 .2020

Menger, K., Feldmann, A., Dorkewitz, K., Hamm, U. (2020): Vermarktungskonzepte für Produkte gefährdeter Nutztierrassen. Online verfügbar unter: https://orgprints.org/37582/1/37582-15NA168-15NA028-geh-unikassel-feldmann-hamm-2020-

vermarktung-gefaehrdeter-nutztierrassen.pdf, zuletzt geprüft am 30.04.20 


\section{Keynote: Sheep production in Ireland - key factors influencing profitability}

\section{T.W.J Keady}

Teagasc, Athenry, Co Galway, Ireland.

Contact:Tim.Keady@teagasc.ie

\section{Abstract:}

Ireland has a population of 4.7 million people and produces enough food to feed 40 million; consequently $85 \%$ of its agricultural production is exported. Sheep production in Ireland is grass-based and lambing generally coincides with the initiation of grass growth in early March. Ireland is the fourth largest exporter, worldwide, of sheep meat and the largest net exporter in the EU. The EU is the second largest importer of sheep meat in the world, is only $85 \%$ selfsufficient in sheep meat production, and accounts for $88 \%$ of Irish sheep meat exports. The following are some key factors impacting sheep farm productivity and profitability:

1. Use of prolific ewe genotypes (e.g., Belclare X) increases annual ewe productivity by up to 0.35 lambs reared per ewe joined.

2. Mating flock replacements to lamb at 1 year of age has no negative effect on ewe productivity at 2 years of age and significantly increases ewe lifetime performance.

3. Each $0.5 \mathrm{~kg}$ increase in lamb body weight (BW) at birth increases weaning weight (100 days) by $1.5 \mathrm{~kg}$ and thus reduces age at slaughter by approximately 10 days. Optimum birth BW is the highest weight that is compatible with a live, unassisted birth that survives. The optimum birth BW for lambs born as twins and triplets is 0.93 and 0.78 that of singles.

4. Each 5-percentage-point increase in the digestibility of the grass silage offered during mid and late pregnancy increases lamb BW at birth by $0.25 \mathrm{~kg}$ and ewe BW at lambing by $6.5 \mathrm{~kg}$. Soybean meal as the dominant protein source in concentrate offered during late gestation increases lamb BW at birth by $0.3 \mathrm{~kg}$.

5. Shearing ewes at housing (mid-December) rather than early summer (May/June) increases lamb BW at birth by $0.7 \mathrm{~kg}$.

6. Leaving male lambs entire increases BW at weaning by $1.8 \mathrm{~kg}$ and reduces age at slaughter by 16 days without any negative impact on meat eating quality characteristics.

7. Lambs managed on a grazed-grass only diet can be consistently finished prior to the end of the grazing season. In a 12-year study (in which concentrate, maximum of 300 $\mathrm{g} /$ day, was only offered to lambs being reared as triplets) the mean BW gain pre weaning was 330, 271 and $279 \mathrm{~g} /$ day for lambs born and reared as singles, twins and triplets, respectively; corresponding BW weight gains from weaning to drafting for slaughter were 183, 178 and $163 \mathrm{~g} /$ day.

8. Increasing the feed value of the silage offered to lambs being finished on ensiled forage diets increases BW gain or reduces the level of concentrate supplementation required to achieve a give level performance.

9. Many swards are marginal or deficient in minerals (e.g., cobalt). Need to identify deficiency based on laboratory analyses and/or veterinary guidance. 
10. There are a number of EU-funded thematic networks (e.g., SheepNet, EuroSheep) that use a multi-actor approach to engage farmers, scientists, advisors/consultants, veterinarians etc. These networks demonstrate that solutions to many producer needs are available, either locally or worldwide, and compile reservoirs of solutions (e.g., www.sheepnet.network, www.eurosheep.network).

Sheep productivity and performance can be improved dramatically by using existing technologies and information resources, thus potentially increasing farm profitability. 


\section{Development of an animal-friendly feeding system for horned goats - preliminary results}

\section{Bianca Greiner ${ }^{1}$, Stanislaus von Korn ${ }^{1}$, Katrin Sporkmann ${ }^{2}$, Heiko Georg ${ }^{2}$, Andreas Kern ${ }^{3}$, Charlotte Lutz ${ }^{1}$ and Maren Bernau ${ }^{1}$}

${ }^{1}$ Hochschule für Wirtschaft und Umwelt Nürtingen-Geislingen, Nürtingen, Deutschland

${ }^{2}$ Thünen-Institut für Ökologischen Landbau, Westerau, Deutschland

${ }^{3}$ Bioland Erzeugerring Bayern e.V., Augsburg, Deutschland

Contact: Bianca Greiner, Hochschule für Wirtschaft und Umwelt Nürtingen-Geislingen, Institut für

Angewandte Agrarforschung, Hechingerstraße 12, 72622 Nürtingen, Phone: 07022 201-271,

bianca.greiner@hfwu.de

\section{Abstract:}

In Germany, particularly in federal state Baden-Württemberg, dairy goat farming is becoming increasingly important as an alternative source of income (Statistisches Bundesamt, 2017). In feeding dairy goats there is a need for developing concentrate feeding systems adapted for horned goats, since dehorning is forbidden in Germany (Animal welfare act, 2019). Due to their species-specific behavior, agonistic interactions and horn-induced injuries are often found, especially while competition during feed intake. Injuries affect animal well-being, animal health, and result in economic losses (Leitner et al., 2007). The project aimed to develop a functional and safe feeding system for horned goats. For further development of concentrated feeding systems, two different systems that are available for hornless goats were selected: A) the Lamking Double Box (LB) (Wasserbauer $\mathrm{GmbH}$ ) and B) the Capra Box (CB) (Dedden/Hanskamp). One of each system was installed on two different farms in Germany (together 320 goats). Both systems differ fundamentally in the way they work. LB works with a sideways swinging door, whereas $\mathrm{CB}$ works as a walk through. To evaluate the feeding system, body condition scoring as well as incidence and type of udder and body injuries were evaluated before and after installation.

A first result is the functionality of the optimized feeding system in each farm, which will be presented during the talk. Data evaluation is still ongoing to be able to give sufficient information about both feeding systems in terms of animal well-being, animal health and economics.

Funding: The project is funded within the framework of the European Innovation Partnership "Landwirtschaftliche Produktivität und Nachhaltigkeit" (EIP-AGRI). The funding measure is a measure of the "Maßnahmen- und Entwicklungsplan Ländlicher Raum Baden-Württemberg 2014-2020" (MEPL III). The project is funded by the state of Baden-Württemberg and the "Europäischer Landwirtschaftsfond für die Entwicklung des Ländlichen Raums (ELER)".

\section{References:}

\footnotetext{
Animal welfare act (2019). Tierschutzgesetz in der Fassung der Bekanntmachung vom 18. Mai 2006 (BGBl. I S. 1206, 1313), zuletzt geändert durch Art. 101 G v. 20.11.2019.

Leitner, G., Silanikove, N., Merin, U. (2007). Estimate of milk and curd yield loss of sheep and goats with and intrammamary infection and its relation to somatic cell count. Small Ruminant Research 74 (2008), 221-225. doi:10.1016/j.smallrumres.2007.02.009

Statistisches Bundesamt (Hg.) (2017) Land- und Forstwirtschaft, Fischerei - Viehhaltung der Betriebe Agrarstrukturerhebung 2016, Fachserie 3, Reihe 2.1.3
} 


\title{
Influence of housing and management on claw health of Swiss dairy goats
}

\author{
Lisa-Marie Sailer ${ }^{1}$, Joan-Bryce Burla ${ }^{1}$, Beat Wechsler ${ }^{1}$, Mirjam Holinger ${ }^{2}$, Patrik Zanolari ${ }^{3}$ and \\ Katharina Friedli ${ }^{1}$ \\ ${ }^{1}$ Federal Food Safety and Veterinary Office (FSVO), Centre for Proper Housing of Ruminants and Pigs, \\ Tänikon, Switzerland \\ ${ }^{2}$ Department of Livestock Sciences FiBL, Frick, Switzerland \\ ${ }^{3}$ University of Bern, Vetsuisse Faculty, Clinic for Ruminants, Bern, Switzerland \\ Contact: Lisa-Marie Sailer, Tänikon 1, 8356 Tänikon, Schweiz, +49 15159216779 , \\ lisa-marie.sailer@agroscope.admin.ch
}

\section{Abstract:}

Dairy goats are commonly housed on deep bedding, at least during winter periods. Due to the lack of claw horn wear on abrasive surfaces, goats have a high prevalence of overgrown wall horn. As a result, claw health and locomotion behaviour could be impaired. To evaluate claw conditions and claw lesions, data was collected on 28 dairy goat farms all over Switzerland in autumn 2018 and spring 2019. Locomotion activity and lying behaviour were recorded by means of MSR-loggers. Furthermore, management data concerning housing and claw trimming was gathered on all farms. Linear and generalized linear mixed-effects models were designed to analyze data. Almost all claws showed at least moderate or even severe wall horn overgrowth. Horn separation and sole hemorrhages turned out to be the most frequent lesions. Severe pathologies and infectious claw diseases did not occur. With severely overgrown claws the risk of developing sole hemorrhages was nearly twice as high as with moderate overgrowth. For horn separation, we could show a positive effect of education of the trimmer and of pasture at the time of data collection. Furthermore, season had a significant effect on locomotion activity and on the number of lying bouts per 24 hours. In conclusion, the goats did not seem to be impaired in their locomotion by wall horn overgrowth. However, severe wall horn overgrowth was associated with an increase in the proportion of claws with sole hemorrhages. Therefore, regular, frequent and skilled claw trimming should be propagated.

\section{References:}

Christodoulopoulos G. Foot lameness in dairy goats. Research in Veterinary Science. 2009;86(2):281-4

Hill PP, Murphy PE, Nelson AJ, Mouttotou N, Green LE, Morgan KL. Lameness and foot lesions in adult British dairy goats. The Veterinary Record. 1997;141:412-6. 
Management and animal welfare

Genetic Resources

Oral presentations

\title{
Welfare effects of introducing and separating/reintroducing individual goats
}

\author{
$\underline{\text { Antonia Patt }^{1}}$, Lorenz Gygax ${ }^{2}$, Beat Wechsler ${ }^{3}$, Edna Hillmann ${ }^{2}$ and Nina M. Keil ${ }^{3}$ \\ ${ }^{1}$ Institute of Animal Welfare and Animal Husbandry, Friedrich-Loeffler-Institut, Celle, Germany \\ ${ }^{2}$ Animal Husbandry and Ethology, Albrecht Daniel Thaer-Insitute of Agricultural and Horticultural \\ Sciences, Humboldt-Universität zu Berlin, Berlin, Germany \\ ${ }^{3}$ Centre for Proper Housing of Ruminants and Pigs, Federal Food Safety and Veterinary Office, Agroscope, \\ Ettenhausen, Switzerland \\ Contact: Antonia Patt, Dörnbergstr. 25/27, 29223 Celle, +49 51413846 150, antonia.patt@fli.de
}

\section{Abstract:}

In goat husbandry, several management procedures are associated with regrouping of animals, e.g. introduction of unfamiliar goats or temporary separation and subsequent reintegration. In two experiments, we thus aimed to quantify the effects of a) introducing (for five days) an unfamiliar goat into an established herd using both horned and hornless groups, and of b) separating (two days) and reintegrating (three days) individual goats. In both experiments, we collected data on social interactions, lying and feeding behavior, and concentrations of fecal cortisol metabolites. Data were analyzed using linear mixed-effects models. In the first experiment, introduced goats showed substantially longer lying times, shorter feeding times and elevated concentrations of fecal cortisol metabolites. Further, introduced goats received most agonistic interactions on the first day. These changes were found in all groups, but were more pronounced in horned goats. During the second experiment, we investigated whether an increased level of contact (visual and tactile) with the original group during separation could reduce the negative effects of separation and reintegration compared to only allowing for acoustic contact with the group. Separated goats showed shorter feeding times during separation and higher fecal cortisol metabolites concentrations during both periods. Increased contact during separation mitigated these effects. Both the introduction of an unfamiliar individual into established groups and the temporary separation of individuals from the rest of the groups led to clear stress responses and should thus be avoided whenever possible. If separation is unavoidable, visual and tactile contact should be permitted to mitigate adverse effects. 


\title{
Goat commercialization through increasing productivity of homestead herds in South Africa
}

\author{
Rauri Alcock ${ }^{1}$ and Marisia Geraci ${ }^{2}$ \\ ${ }^{1}$ Mdukatshani Rural Development Project, Hilton, South Africa \\ ${ }^{2}$ Heifer Project South Africa, Hillcrest, South Africa \\ Contact: khonya@yebo.co.za
}

\section{Abstract:}

The South Africa Goat Agribusiness Project (GAP) is a project aimed at commercialising goats owned by African communal farmers in rural areas in South Africa. GAP has been working for 5 years to pilot interventions to support smallholder farmers focusing on goats as this sector of the economy has never been considered commercial. It is estimated that South Africa imports a million goats from its neighbours worth 67 million euro annually. The entire market for goats in South Africa is for live sacrifice rather than for meat. Even with an urbanising and growing middle class, the demand for these animals and related cultural practices is increasing. Through a process of innovation support and learning, GAP has facilitated and captured in field work through farmer exchanges and distributed these successes to scale up the productivity across the country. Bush encroachment is destroying many grazing areas in the country and linked to successive droughts, making goat farming a successful alternative to livestock farmers in an environment where cattle are on the decline. The GAP innovations and interventions focused on low productivity experienced by smallholder women goat farmers left in charge of homes through a legacy of migrant labour system. Research in field showed that kid mortality was the biggest production loss, with losses ranging from $60-80 \%$ of kids. A pilot involving building enclosures and creep feeding kids from 2 weeks to 3 months reduced mortality to 5\%. Locally harvested plant materials were processed to feed the kids 100 grams a day. GAP also developed an energy block, with $15 \%$ protein, that farmers mix and process themselves. A health management and disease control program carried out by 260 Community Animal Health Workers who were locally recruited, unemployed youth. They were extensively trained and equipped as an independent business to support communities and their livestock. 


\title{
A topical anaesthestic wound formulation diminishes pain responses and improves wound healing of lambs at tail-docking
}

\author{
Ferrer, L.M. ${ }^{1}$, Lacasta, D. ${ }^{1}$, Ramos, J.J. ${ }^{1}$, Ortín, A. ${ }^{1}$, Tejedor, M.T. ${ }^{2}$, Castells, E. ${ }^{3}$, Ruiz de \\ Arcaute, M. ${ }^{1}$, Pérez, M. ${ }^{1}$, Rubira, I. $^{4}$ and Windsor, P.A. ${ }^{5}$ \\ ${ }^{1}$ Animal Pathology Department, Instituto Agroalimentario de Aragón-IA2 (Universidad de Zaragoza- \\ CITA), Veterinary Faculty of Zaragoza, C/Miguel Servet 177. 50013 Zaragoza, Spain \\ ${ }^{2}$ Anatomy, Embryology and Animal Genetics Department, CIBER CV (Universidad de Zaragoza-IIS), \\ Veterinary Faculty of Zaragoza, C/Miguel Servet 177. 50013 Zaragoza, Spain \\ ${ }^{3}$ Centro Clínico Veterinario, C/ Madre Genoveva Torres Morales, 8, 50006 Zaragoza, Spain \\ ${ }^{4}$ Gabinete técnico Veterinario S.L. C/ Isla conejera s/n. 50013 Zaragoza, Spain \\ ${ }^{5}$ Sydney School of Veterinary Science, The University of Sydney, Camden, NSW | 2570, Australia \\ Contact:dlacasta@unizar.es
}

\section{Abstract:}

Tail docking is a painful husbandry practice performed routinely in sheep production worldwide. We examined two different procedures for surgical tail docking; with and without general anaesthesia (GA), including the use of a topical wound gel formulation to alleviate pain and improve healing after surgery, containing local anaesthetics lignocaine and bupivacaine, with cetrimide and adrenalin (Tri-Solfen $®$; TS).

Forty-four female lambs with similar weights were recruited into four equal cohorts: Groups A and C, the tail was excised with a scalpel without anaesthesia and Groups B and D, the tail was surgically excised and stitched under GA. C and D groups were immediately treated with TS. Pain-related behaviour was assessed using a numerical rating scale (NRS) developed previously. A trained scientist blinded to treatment observed the lambs immediately (T0), 2.5h (T1) and 5h (T2) after tail docking. Following the procedure, the animals were examined daily for 15 days, with lesions photographed. This enabled analysis of wound healing after taildocking and the detection of secondary infections.

Behavioural observations identified that groups without GA (A \& C) displayed significantly less pain-related behaviours immediately after the procedure, especially if treated with TS (C). Similarly, the mean of days when animals showed no signs of wound infection was longer in the groups not undergoing GA, especially in those treated with TS.

Surgical tail-docking without GA but where wounds are immediately sprayed with TS is an affordable and welfare appropriate method of conducting tail docking in lambs, avoiding the unnecessary use of antibiotics.

\section{References:}

Lomax, S., Sheil, M. and Windsor, P.A., 2008. Impact of topical anaesthesia on pain alleviation and wound healing in lambs after mulesing. Australian Veterinary Journal 86, 159-168. DOI: 10.1111/j.1751-0813.2008.00285.x.

Lomax, S., Dickson, H., Sheil, M. and Windsor, P.A., 2010. Topical anaesthesia alleviates short-term pain of castration and tail docking in lambs. Australian Veterinary Journal 88, 67-74. DOI: 10.1111/j.1751-0813.2009.00546.x.

Orihuela. A. and Ungerfeld. R., 2019. Tail docking in sheep (Ovis aries): A review on the arguments for and against the procedure, advantages/disadvantages, methods, and new evidence to revisit the topic. Livestock Science 230, 103837. DOI: 10.1016/j.livsci.2019.103837. 


\title{
Evaluation of behavior during grazing for crossbred hair sheep in the dry Caribbean
}

\author{
Clara Rúa-Bustamante $^{1}$, Sandra C Perdomo Ayola ${ }^{1}$, Juan Zambrano-Ortiz ${ }^{1}$ and Lorena \\ Aguayo $^{2}$ \\ ${ }^{1}$ Corporación Colombiana de Investigación Agropecuaria - AGROSAVIA, CI. Motilonia, Codazzi-Cesar, \\ Colombia \\ ${ }^{2}$ Corporación Colombiana de Investigación Agropecuaria - AGROSAVIA, CI Turipaná. Cereté -Córdoba, \\ Colombia. \\ Contact: Clara Viviana Rúa-Bustamante. CI Motilonia, Agrosavia. Email: crua@agrosavia.co
}

\section{Abstract:}

The aim was to evaluate the behavior of crossbreed hair sheep, grazing under dry Caribbean agro-ecological conditions from North of Colombia. The behavior of nine males (300d) in a pasture composed of native trees, shrubs, weeds and different tropical grasses, was recorded. During four consecutive days, an instantaneous sampling was performed between 8:00 and 15:30, every $15 \mathrm{~min}$. The behavioural events recorded were grazing, eat fruit (mango), browse, resting, walking, ruminating, drinking, others. The temperature $(\mathrm{T})$ and relative humidity $(\mathrm{H})$ were stored in dataloggers. The ITH index was calculated. For the statistical analysis, three blocks were formed: morning, noon and afternoon, using SAS 9.4 statistical software. The general behavioural budget was $56.4 \%$ grazing, $12.4 \%$ eating fruit, 9.8\% browsing, $7.6 \%$ rest, $6.4 \%$ walking, $5 \%$ ruminating, $0.1 \%$ drinking, $0.1 \%$ others. Most grazing was during afternoon (44.9\%), then morning (39.8\%) and noon (15\%), where the ITH index was respectively 74.8 $\left(\mathrm{T}=23.7 \pm 0.31^{\circ} \mathrm{C}, \mathrm{RH}=100 \%\right), 74.1\left(\mathrm{~T}=23.3 \pm 0.1^{\circ} \mathrm{C}, \mathrm{RH} 100 \%\right)$ and $73,7(\mathrm{~T}=23.1 \pm$ $\left.0.17^{\circ} \mathrm{C}, \mathrm{RH} 100 \%\right)$. This could suggest that grazing frequency does not depend on this indicator. The consumption of mango (49.2\%) and browsing (49\%), was mainly in the morning. The frequency of behaviours appears to not be limited by the ITH-related variables rated within normal values. More studies are necessary to determine if the intensity of ultraviolet radiation is a factor that may be influencing the behaviour of sheep in general, and consumption specifically. 
Management and animal welfare

Poster presentations

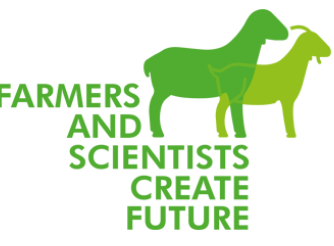

\title{
Sheep farming in marginal lands of Central Italy: recognition of common failures during shearing
}

\author{
Sebastian Alessandro Mignacca ${ }^{1}$, Claudio Forte ${ }^{1}$, Laura Vieceli ${ }^{2}$, Nigel Thompson ${ }^{3}$, Luca \\ Schillaci $^{4}$, Chiara Francesca Magistrali ${ }^{1}$ and Marco Antonini ${ }^{5}$ \\ ${ }^{1}$ Istituto Zooprofilattico Sperimentale dell'Umbria e delle Marche 'Togo Rosati', Perugia, Italy \\ ${ }^{2}$ Department of Veterinary Medicine, University of Perugia, Perugia, Italy \\ ${ }^{3}$ Biella the Wool Company, Biella, Italy \\ ${ }^{4}$ Gran Sasso e Monti della Laga Park, L'Aquila, Italy \\ ${ }^{5}$ Italian National Agency for New Technology, Energy and Sustainable Economic Development (ENEA) \\ Roma, Italy \\ Contact: [Via GB Giuliano, Catenanuova (Enna) 94010, Italy, sebastian.mignacca80@gmail.com]
}

\section{Abstract:}

Europe has a worldwide leading position in environmental and animal welfare legislation. Among other good practice recommendations, guidelines describing the recommended management of sheep shearing have been defined. "Woolfair" is a project enrolling 95 farms (approximately 18,000 heads) aimed at addressing resilience, animal welfare and competitiveness of sheep farming in marginal lands in Central Italy. Major errors observed during the shearing season of 2019 in 25 farms (approximately 5900 heads) are reported in this work.

Most of the farms showed the peculiarity of starting the shearing in March, in order to transhumate with a minimum of fleece for the highest pastures. Errors were detected in all the shearing phases. During pre-shearing, inadequate protection of animals against weather conditions was recorded in 3 out of 25 farms, non-fasted animals in 15 farms, overcrowding in 5 farms, and inadequate restraint and manipulation in 15 farms. Shearing phase revealed inadequate restraint and manipulation in 15 out of 25 farms, excessive presence of wounds in 8 farms, excessive time of shearing in 7 farms. Post-shearing management resulted in inadequate protection of animals against weather conditions in 3 farms while inadequate nutrition supplementation was recorded in 10 farms. Due to the local peculiar environment and farming systems, it does not result easy to adapt shearing good practices. During the onfarm visits, improvements to the shearing management and the link between animal welfare and wool quality have been discussed with stakeholders and easily applicable guidelines for a correct shearing procedure have been provided. 


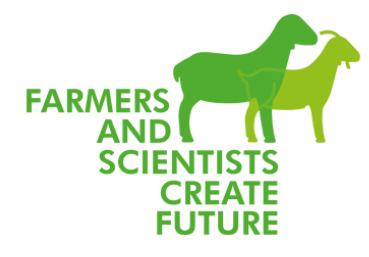

\section{Handling sheep without docking of the tail - Demonstration Project Animal Welfare}

\section{Martin Steffens}

Hesse Department of Agriculture Affairs (Landesbetrieb Landwirtschaft Hessen), Wetzlar, Germany Contact: Schanzenfeldstr. 8, 35578 Wetzlar, +49 64419289-372, martin.steffens@llh.hessen.de

\section{Abstract:}

The German Federal Ministry of Food and Agriculture supports the "Demonstration Project Animal Welfare" through the Federal Office of Agriculture and Food to give famers the opportunity to change husbandry conditions in order to improve welfare to the sheep. In total 6 farmers were chosen to keep sheep with long tails. The participants started in 2017. The docking is done in particular for hygienic reasons. Most of the breeds of sheep bred in Germany have long, woolly tails that can be very dirty. The contaminated areas can be used by various types of flies to lay their eggs or larvae and lead to so called myiasis (fly maggot infestation) in affected sheep. By shortening the tail, the above-mentioned fecal contamination can be reduced. Although scientific studies have not unanimously linked tail length and the likelihood of myiasis, blowfly infestation is one of the main reasons for tail cropping in sheep.

The keeping of uncrossed long-tailed breeds is hardly practiced in Germany. Throughout Germany, up to six companies were sought for the thematic network "No tail docking in sheep lambs" who would like to participate in this pilot project as demonstration companies over a period of two and a half years.

To handle this challenge, the improvement of all areas in the environment of the sheep e.g. food, stable management, genetics, parasite management, and much more is necessary. The Hesse Department of Agriculture Affairs, represented by Martin Steffens, was instructed by the Federal Office of Agriculture and Food to perform the advising part for these farmers and can show the results and options to handle Sheep with long tails. 
Management and animal welfare

Genetic Resources

Poster presentations

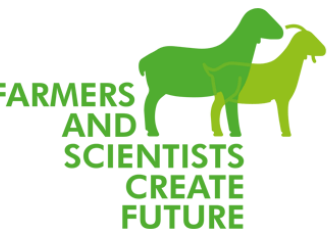

\title{
Comparison of concentrate and flour mixture digestibility results in purebred Latvian Dark-Head lambs
}

\author{
$\underline{\text { Liga Senfelde }^{1}}$, Daina Kairisa ${ }^{1}$ and Dace Barzdina ${ }^{1}$ \\ ${ }^{1}$ Latvia University of Life Sciences and Technologies, Faculty of Agriculture, Institute of Animal Science, \\ Street Liela 2, LV-3001 Jelgava, Latvia \\ Contact: Latvia University of Life Sciences and Technologies, Faculty of Agriculture, Institute of Animal
} Science, Street Liela 2, LV-3001 Jelgava, Latvia, shenfeldel@gmail.com

\section{Abstract:}

Research has been conducted to compare the efficiency of concentrate and flour mixture digestibility in lambs during fattening. Purebred Latvian Dark-Head ram lambs were used in the research. Feed were provided ad libitum for two groups: CON (concentrate and hay) and BNF (hay and flour mixture consisting of $50 \%$ beans, $25 \%$ barley and $25 \%$ oats). The mean live weight of the lambs at the start of research was $24.6 \mathrm{~kg}$ (CON) and $25.6 \mathrm{~kg}$ (BNF), with a mean age of $83 \pm 1.4$ days (CON; $\mathrm{p}<0.05$ ) and $75 \pm 1.6$ days (BNF). Feed digestibility data were recorded in three periods each for five days in week $3(\mathrm{~F}), 6(\mathrm{~S})$ and 9 (T) of the fattening when the lambs were placed in cages with a slatted wooden floor and a container with a grate under it for faecal and urine production. The average daily consumption of concentrate for CON were higher and ranged from $1.25 \pm 0.11 \mathrm{~kg}(\mathrm{~F})$ to $1.75 \pm 0.09 \mathrm{~kg}(\mathrm{~T})$. The average daily hay consumption were higher for BNF and ranged from $0.23 \pm 0.03 \mathrm{~kg}$ (F) to $0.18 \pm 0.03 \mathrm{~kg}$ (T). Higher faecal production per lamb were collected in BNF $(0.85 \pm 0.05 \mathrm{~kg}(\mathrm{~F})$ to $0.96 \pm$ $0.07 \mathrm{~kg}(\mathrm{~T}))$. The proportion of digested dry matter during the research ranged from $76.3 \%$ to $80.2 \%(\mathrm{CON})$ and from $63.1 \%$ to $77.9 \%(\mathrm{BNF})$. A faecal fraction was soft (CON) and solid (BNF). 


\section{Problems with the back teeth! A relevance for breeding sheep and goats in Germany?}

\section{Philip Christian Tegtmeyer}

Tierarztpraxis Tegtmeyer - Sheep and goat health consultancy - Langenhagen, Germany Contact: Dr. med. vet. Philip C. Tegtmeyer, Resser Str. 1a, 30855 Langenhagen, Germany, mail@tierarztpraxis-tegtmeyer.de

\section{Abstract:}

Teeth problems, particulary the defective position of molar teeth might have a considerable importance for malnutrition of sheep and goats in Germany. It is recognised in elder animals mainly.

It is generally known that the set of teeth of small ruminants wears down over the years. This might be influenced by the type of feed. Because of a following defective position of back teeth and loss of teeth sheep and goats often cannot eat adequately and fast enough. Loss of incisor teeth is a common finding in German sheep flocks. In most cases, the animals do not suffer from the loss of incisors but they are often culled. In the author's experience we have to look closer at the back teeth instead of the common practice of controlling incisors.

What kind of teeth problems can be detected? Comparable with horses, small ruminants develop sharp edges on the molar teeth caused by the chewing process. These edges often overtop the other teeth and cause mechanical irritations when animals are chewing. Often, the corresponding teeth of the other side are damaged by these edges.

The prevalence of back teeth disorders is not known. In order to get some numbers 18 skulls of preselected old ewes were examined for teeth disorders after slaughter. Eight ewes had back teeth problems which caused functional damage. In postmortem examinations and inspections of the oral cavity often massive failures of the denture can be detected. Back teeth disorders can also be detected in younger sheep. Problems can become present for example under second dentition of gimmers. The defective positions of molar teeth may advance the hypothesis that these problems are heritable. First of all, a prevalence study is needed for a real confirmation of the hypothesis.

Furthermore, research on the aspect of the hereditability has to be conducted.

\section{References:}

Erjavec, V., Crossley,D. (2010). Initial observations of cheek tooth abnormalities in sheep in Slovenia. Veterinary Record 167, 134-137

Laws, AJ., Baker, RL., Aitken, WM. (1993). The heritability of gingival crevice depths in sheep. Res Vet Sci. May;54(3):379-83.

Kaulfuß, K.H., Hoffmann, B., (2004). Erkrankungen der Kiefer und Zähne beim Schaf (Übersichtsreferat). Literaturübersicht und Ergebnisse eines Zuchtversuchs zur Brachygnathia inferior beim Ostfriesischen Milchschaf. Tierärztl. Umschau 59, 380-387. 


\title{
Effect of a topical anaesthetic formulation on viral load in lambs naturally infected with orf virus
}

\author{
Lacasta, D. ${ }^{1}$, Reina, R. ${ }^{2}$, Ramos, J.J. ${ }^{1}$, Ferrer, L.M. ${ }^{1}$, Benito, A.A. ${ }^{3}$, Tejedor, M.T. ${ }^{4}$, Martínez, \\ S. ${ }^{1}$, Ruiz, H. ${ }^{1}$, Echeverria, I. ${ }^{2}$ and Windsor, $P{ }^{5}$ \\ ${ }^{1}$ Animal Pathology Department, Instituto Agroalimentario de Aragón-IA2 (Universidad de Zaragoza- \\ CITA), Veterinary Faculty of Zaragoza, C/Miguel Servet 177. 50013 Zaragoza, Spain \\ ${ }^{2}$ Instituto de Agrobiotecnología (CSIC-Gobierno de Navarra), Av. Pamplona, 123, 31192 Mutilva Baja, \\ Navarra, Spain \\ ${ }^{3}$ Laboratorios Exopol Diagnóstico y Autovacunas, Polígono San Mateo de Gállego, Spain \\ ${ }^{4}$ Anatomy, Embryology and Animal Genetics Department, CIBER CV (Universidad de Zaragoza-IIS), \\ Veterinary Faculty of Zaragoza, C/Miguel Servet 177. 50013 Zaragoza, Spain \\ ${ }^{5}$ Sydney School of Veterinary Science, The University of Sydney, Camden, NSW | 2570, Australia \\ Contact: dlacasta@unizar.es
}

\section{Abstract:}

Orf is a highly contagious eruptive skin condition of sheep and goats. Vaccination with live orf virus is the preferred option for disease control, despite this vaccine is unavailable in many countries. Treatment of orf lesions involves standard hygiene and management of presumptive secondary infections with antibiotics. The wound dressing formulation, Tri-Solfen ${ }^{\circledR}$ (Animal Ethics Pty Ltd, Australia) offers advantages over current therapies, providing pain relief and potentially, more rapid healing of lesions. The formulation contains two local anaesthetics (lignocaine and bupivacaine), adrenalin and an antiseptic (cetramide) in a gel formulation, and creates a $\mathrm{pH}$ of $\sim 2.7$ that is potentially viricidal.

Fourteen one-month-old lambs, naturally infected with orf, were recruited from a farm during an outbreak of orf disease. The animals were selected at the early stages of the infection and divided into two cohorts: Group A $(n=11)$ treated with Tri-Solfen ${ }^{\circledR}$ and Group B $(n=3)$, a control group without treatment.

Swabs were obtained before treatment (T0) and days 1 (T1), 3 (T2) and 5 (T3) post-treatment, then submitted to direct DNA extraction and real-time PCR quantification (Exopol) or to incubation with primary tissue cultures from ovine skin fibroblasts (OSF) and T-immortalized goat embryonic fibroblasts (TIGEF). In the study conducted using quantitative PCR, no significant differences were found $(\mathrm{p}=0.722)$. However, when the viral load was assessed in OSF cell cultures, there was a significant difference $(\mathrm{p}<0.05)$ in reduction between both groups between T0 and T3.

These findings suggest that treatment of orf lesions with Tri-Solfen ${ }^{\circledR}$ reduces the viral load present in lesions.

\section{References:}

\footnotetext{
Lomax, S., Sheil, M. and Windsor, P.A., 2008. Impact of topical anaesthesia on pain alleviation and wound healing in lambs after mulesing. Australian Veterinary Journal 86, 159-168. DOI: 10.1111/j.1751-0813.2008.00285.x.

Roberts, C.D. and Windsor P.A., 2019. Innovative pain management solutions in animals may provide improved wound pain reduction during debridement in humans: An opinion informed by veterinary literature. International Wound Journal 16 (2) DOI: https://doi.org/10.1111/iwj.13129.

Spyroua, V., Valiakosb, G., 2017. Orf virus infection in sheep and goats. Veterinary Microbiology 181 (2015) 178-182. DOI: http://dx.doi.org/10.1016/j.vetmic.2015.08.010.
} 
Management and animal welfare 


\title{
Effect of a topical wound anaesthesia formulation on the cortisol and the acute phase responses of lambs undergoing tail docking.
}

\author{
Ortín, A. ${ }^{1}$, Borobia, M. ${ }^{1}$ Ramos, J.J. ${ }^{1}$, Lacasta, D. ${ }^{1}$, Ferrer, L.M. ${ }^{1}$, Tejedor, M.T. ${ }^{2}$, Ruiz, H. ${ }^{1}$, \\ Jimenez, C. ${ }^{3,4}$ and Windsor, P.A. ${ }^{1}$ \\ ${ }^{1}$ Animal Pathology Department, Instituto Agroalimentario de Aragón-IA2 (Universidad de Zaragoza- \\ CITA), Veterinary Faculty of Zaragoza, Zaragoza, Spain \\ ${ }^{2}$ Anatomy, Embryology and Animal Genetics Department, CIBER CV (Universidad de Zaragoza-IIS), \\ (Universidad de Zaragoza-CITA), Veterinary Faculty of Zaragoza, Zaragoza, Spain \\ ${ }^{3}$ Gabinete Técnico Veterinario S.L. C/ Isla conejera s/n. 50013 Zaragoza, Spain \\ 4 Sydney School of Veterinary Science, The University of Sydney, Sydney, Australia \\ Contact: Aurora Ortín, aortin@unizar.es
}

\section{Abstract:}

In this study we evaluated the effect of a topical wound gel formulation containing local anaesthetics lignocaine and bupivacaine, with cetrimide and adrenalin (Tri-Solfen ${ }^{\circledR}$; TS) on the concentrations of serum cortisol (SC) and the acute phase protein serum amyloid A (SAA) in tail-docked lambs.

Forty-four female lambs with similar weights were recruited into four equal cohorts: Groups A and $\mathrm{C}$, the tail was excised with a scalpel without anaesthesia and Groups B and D, the tail was surgically excised and stitched under general anaesthesia (GA). C and D groups were immediately sprayed with TS. Blood samples were collected before tail docking and at different time intervals post-tail excision. Concentra-tions of SC and SAA were determined using ELISA assays (Salivary Cortisol ELISA SLV-2930, DRG Diagnostics, Marburg, Germany; PHASE TM Serum Amyloid A Assay, Tridelta Development Ltd., Maynooth, Ireland). Statistical analysis was preformed using IBM SPSS statistics version 26 (2019) software (IBM, Armonk, NY, USA). SC concentration did not change significantly over time in cohorts tail-docked under GA (B \& D), but peaked at 30 min post tail removing without anaesthesia (A \& C), and treatment with TS (C) appeared to reduce this cortisol response.

In cohorts B \& D , SAA concentrations increased significantly 48 hours after tail docking, as it is expected after a noxious stimulus, but treatment with TS avoided the elevation of SAA at this time point in lambs where the tail was excised without anaesthesia.

These results appear to indicate that treatment with TS reduces cortisol and SAA responses in lambs tail docked without anaesthesia, although further research is needed to corroborate these findings.

\section{References:}

\footnotetext{
Marini, D., Colditz, I.G., Hinch, G., Petherick, J.C., Lee, C., 2017. Self-administration by consumption of flunixin in feed alleviates the pain and inflammation associated with castration and tail docking of lambs. Appl. Anim. Behav. Sci. 188, 26-33. DOI: 10.1016/j.applanim.2016.12.008.

Paull, D.R., Lee, C., Colditz, I.G., Atkinson, S.J., Fisher, A.D., 2009. The effect of a topical anaesthetic formulation, systemic flunixin and carprofen, singly or in combination, on cortisol and behavioural responses of Merino lambs to mulesing. Aust. Vet. J. 85, 98-106. DOI: $10.1111 /$ j.1 751 -0813.2009.00429.x.

Tothova C, Nagy O, Kovac G. 2014. Acute phase proteins and their use in the diagnosis of diseases in ruminants: a review. Vet. Med. 59, 163-168. DOI: 10.17221/7478-VETMED.
} 
Other topics

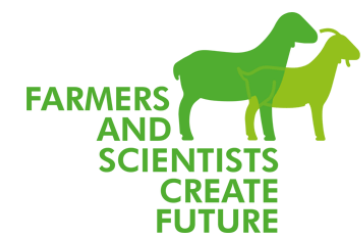

\section{Keynote: Team Sheep vs. Team Corporate - Team building and leadership training as additional income source for shepherds}

\section{Hans-Peter Etzold}

NatuerlichTeambuilding.de, Andernach, Germany

Contact: Im Rosental 23,D-56626 Andernach, peter@leadalpha.eu, spitzenplatz@gmail.com https://www.natuerlichteambuilding.de/

\section{Abstract:}

Team building activities and leadership training are additional income sources for professional shepherds. The innovative activity combines the experience of nature with immediate feedback regarding leadership and teamwork styles. With the help of a management coach and under supervision of the shepherd corporate teams lead and drive a herd of sheep and goats from A to $B$ in a touristically attractive area. While the sheep and goats are grazing during breaks, the teams reflect upon their performance and discuss the lessons learnt related to the herding of the sheep, but also their leadership styles and teamwork. The author is the pioneer of sheep herding as a team building and leadership training activity and offers this kind of activity in cooperation with local shepherds to SME and global corporations. Since 2015 he has served approx. 350 clients. Shepherds are required to have at least 500 sheep and goats in an attractive landscape preferably within one hour's drive of a major city. The shepherds are also required to consider themselves as service providers to professionals from outside the primary sector.

\section{References:}

https://www.natuerlichteambuilding.de/

https://programm.ard.de/TV/Programm/Sender/?sendung=28106372186471

Kevin Leman, William Pentak: Das Hirtenprinzip, Sieben Erfolgsrezepte guter Menschenführung, 2010. 


\title{
Other topics
}

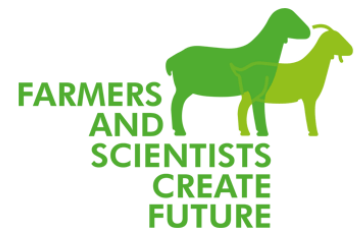

\section{Zoonotic diseases in small ruminants: risks and opportunities}

\author{
Benjamin Bauer ${ }^{1}$, Martin Runge ${ }^{2}$, Annika Wolf ${ }^{1}$, Louise Prüfer ${ }^{2}$, Laura Wiesner ${ }^{3}$, Imke \\ Steffen $^{3}$, Cornelia Silaghi ${ }^{4}$, Matthias Wagener ${ }^{1}$, Wibke Rubel ${ }^{1}$ and Martin Ganter ${ }^{1}$ \\ ${ }^{1}$ University of Veterinary Medicine Hannover, Foundation, Clinic for Swine and Small Ruminants, \\ Hannover, Germany \\ ${ }^{2}$ Lower Saxony State Office for Consumer Protection and Food Safety (LAVES), Food and Veterinary \\ Institute Braunschweig/Hannover, Hannover, Germany \\ ${ }^{3}$ University of Veterinary Medicine Hannover, Foundation, Institute for Biochemistry and Research Center \\ for Emerging Infections and Zoonoses, Hannover, Germany \\ ${ }^{4}$ Friedrich-Loeffler-Institut, Institute of Infectiology, Greifswald - Isle of Riems, Germany \\ Contact: University of Veterinary Medicine Hannover, Foundation, Clinic for Swine and Small Ruminants, \\ Bischofsholer Damm 15, 30173 Hannover, Germany; Benjamin.Bauer@tiho-hannover.de
}

\section{Abstract:}

The awareness of zoonotic diseases in small ruminants has increased within the last two decades. Most of the zoonotic pathogens cause abortion in sheep and goats (Ganter 2015). For instance, the intracellular bacteria Coxiella burnetii affected more than 4,000 people in The Netherlands from 2007 until 2011. Large dairy goat farms were responsible for this Q fever epidemic. In contrast, lambing sheep are responsible for small-scale $\mathrm{Q}$ fever epidemics across Germany. A recent study revealed a prevalence between 31.3\% and 33.8\% in German sheep flocks (Wolf et al. 2020). Main risk factors are purchases of sheep and goats and year-round lambing. An active monitoring and surveillance system followed by strategic vaccination programs in small ruminant flocks are suitable to prevent $\mathrm{Q}$ fever in humans.

Furthermore, there are several zoonotic vector-borne diseases harming small ruminants and humans alike. These are mainly transmitted either by ticks or by insects. Sheep and goats have a limited home range, are available in large numbers, are well dispersed in the environment and show a long-lasting antibody response after natural infections (Gerth et al. 1995). In consequence, small ruminants seem to be ideal sentinels for surveillance of zoonotic vectorborne pathogens like Tick-borne Encephalitis Virus (TBEV), West Nile Virus, Crimean-Congo Hemorrhagic Fever Virus and Anaplasma phagocytophilum. For instance, recent examinations of small ruminant sera determined a TBEV intra-herd prevalence of $12.5 \%$ in a goat flock. This flock is located in a non-TBEV risk area in Northern Germany and a potential new endemic area of TBEV was identified.

According to the One-Health approach, it is necessary to implement efficient measures to control zoonotic livestock diseases. However, it is also essential to increase the awareness and preparedness of the public health sector for zoonotic vector-borne diseases using small ruminants as sentinel animals.

\section{References:}

Ganter, M. (2015). Zoonotic risks from small ruminants. Vet Microbiol 181, 53-65. doi: 10.1016/j.vetmic.2015.07.015.

Gerth, H.-J., Grimshandl, D., Stage, B., Döller, G., Kunz, C. (1995). Roe deer as sentinels for endemicity of tick-borne encephalitis virus. Epidemiol Infect 115, 355-365. doi: 10.1017/S0950268800058477

Wolf, A., Prüfer, T. L., Schoneberg, C., Campe, A., Runge, M., Ganter, M., Bauer B. U. (2020). Prevalence of Coxiella burnetii in German sheep flocks and evaluation of a novel approach to detect an infection via preputial swabs at herd-level. Epidemiol Infect 148, e75. doi: 10.1017/S0950268820000679 
Other topics

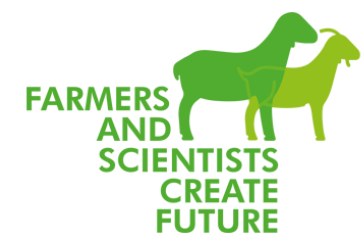

\title{
Comparative fattening and slaughter performance of four sheep breeds under practical farming conditions in northern Germany
}

\author{
Regina Roessler ${ }^{1}$, Stefanie Klingel ${ }^{2}$, Nina Ossowski ${ }^{3}$, Georg Thaller ${ }^{3}$ and Dirk Hinrichs ${ }^{1}$ \\ ${ }^{1}$ University of Kassel, Section Animal Breeding, Nordbahnhofstr. 1a, 37213 Witzenhausen, Germany \\ ${ }^{2}$ Arche Warder Zentrum für alte Haus- und Nutztierrassen e.V., Langwedeler Weg 11, 24646 Warder, \\ Germany \\ ${ }^{3}$ Christian-Albrechts-Universität zu Kiel, Section Animal Breeding and Genetics, Hermann-Rodewald- \\ Straße 6, 24118 Kiel, Germany
}

Contact: Head of Section Animal Breeding, University of Kassel, Nordbahnhofstr. 1a, 37213 Witzenhausen,dhinrichs@agrar.uni-kassel.de

\section{$\underline{\text { Abstract: }}$}

The production of lamb meat has become more important than wool production in the past decades due to changing market conditions. Therefore, the influence of breed on fattening and slaughter performance was studied in 20 Charollais, 40 German White-headed Mutton, 17 Suffolk and 13 Texel male lambs in a pasture feeding trial in Eiderstedt over a 2-month period. The aim was to identify animals that perform well under the practical farming conditions in northern Germany. Analysis of variance or Kruskal-Wallis tests were performed in R 3.6.1. Tukey-HSD test was used for pairwise comparisons of the corrected mean values. Corrections were made for the age, the liveweight or the cold carcass weight. A significant effect of breed on the fattening and slaughter performance was observed. Initial liveweight was highest in Suffolk (46.7 kg) and lowest in German White-headed Mutton $(40.4 \mathrm{~kg}$ ). The highest final liveweight (61.3 kg), carcass weight (28.1 kg warm, $26.7 \mathrm{~kg}$ cold) and daily weight gain (271 g) were observed for Charollais. Suffolk had the lowest daily weight gain $(161 \mathrm{~g} / \mathrm{d})$, and their carcass weight was nearly $2 \mathrm{~kg}$ lighter than for Charollais. However, no breed differences were observed for net daily gain. The German White-headed Mutton were genetically inferior with regard the subcutaneous fat $(0.57 \mathrm{~cm})$ and ultrasonic muscle thickness $(26.3 \mathrm{~mm})$, while Texel had similar slaughter performance than Charollais. The carcass examination showed no breed differences in the incidence of pulmonary pneumonia. In conclusion, no sheep breed was clearly superior in all the studied performance traits. 


\begin{tabular}{|c|c|c|}
\hline Genetic Resources & Other topics & $\begin{array}{l}\text { FARMERS } \\
\text { AND } \\
\text { SCIENTISTS } \\
\text { CREATE } \\
\text { FUTURE }\end{array}$ \\
\hline
\end{tabular}

\section{Udder health in dairy goats and dairy sheep in Hesse}

\section{Irene Noll}

Regional Council of Gießen, Wetzlar, Germany

Contact: Irene Noll, Schanzenfeldstr. 8, Dezernat 51.2, 35578 Wetzlar, Irene.Noll@rpgi.hessen.de

\section{Abstract:}

Since milk of small ruminants, unlike dairy cows, is largely processed on the farm itself, often as raw milk, the increased microbiological risk requires special care.

The occurrence of individual, mostly serious clinical udder diseases contrasts with a multiple of subclinical udder diseases.

In order to detect subclinical diseases, the content of somatic cells in milk can be estimated using the California Mastitis Test (CMT).

In case of a cumulative or increasing number of half-differences, half-milk samples are taken. These milk samples are sent to a recognized laboratory for cytobacteriological analysis.

In subclinical mastitis in small ruminants, coagulase-negative staphylococci are mostly found. In contrast, Staphylococcus aureus (S. aureus) is usually the triggering agent in clinical mastitis, occasionally Pasteurella multocida, Mannheimia haemolytica, Escherichia coli and pseudomonads can be found.

Since $S$. aureus can also often be detected in wounds, greater attention should also be paid to teat and udder wounds as part of a rehabilitation, as these can represent a constant reservoir of pathogens. This mainly happens when the lambs/ fawns have not yet been weaned and the dams are already being milked.

As part of the official milk hygiene monitoring, cytobacteriological total stock examinations are regularly carried out on dairy goat and dairy sheep farms in Hesse.

The results are presented. 


\section{Other topics}

\section{Goat production systems characteristics and management practices in Zambia}

\section{Kolawole Odubote}

University of Zambia, Lusaka, Zambia

Contact: Department of Biomedical Sciences, School of Veterinary Sciences, University of Zambia, Email: kola.odubote@gmail.com

\section{Abstract:}

This study was undertaken to describe goat production system characteristics and management practices in Zambia. The data collected during the Zambia 2017/2018 livestock and aquaculture census were analyzed using both, qualitative and quantitative methods. The main production system was essentially traditional and extensive with free range being the dominant feeding practices. The management practices were minimal although main purpose of keeping goats were for sale and income. The constraints to goat production were mostly on the inadequacies of the production systems and limited management practices such as disease control, management of grazing lands, feeds and feeding, theft, livestock extension services, access to water, distance to dipping facilities, access to quality breeding stock, record keeping, access to credit and market development amongst others. The study also revealed a wide array of genetic resources of local breeds, exotic breeds and crosses between and among them. However, the local-exotic crosses represented the largest single genetic group, which was a reflection of government and development organizations programmes and the farmers' desire to improve productivity through crossbreeding although indiscriminately carried out. It is therefore imperative that a holistic system approach is required to develop the goat sector in Zambia. A community based goat breeding programme to optimally utilize available genetic resources and livestock extension services to reach farmers with husbandry skills that include crop livestock integration, promotion of pasture production with high yielding fodders, management of communal grazing lands, hygienic practices, disease control and market development would be key steps to improve production and productivity. 


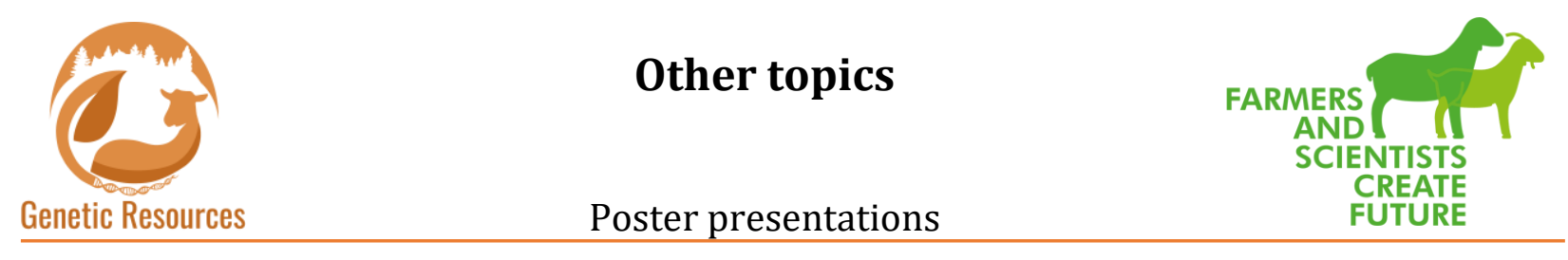

\section{Gender roles in goat production in Ogbomoso region, southwestern Nigeria}

\section{David Aderemi Ajayi, Saheed Adeyemi Busari, Comfort Oluwabori Durosinmi, Sunday Olufemi Osewa, Olusola Jolaiya and Oluwasogo Dammy Abegunrin}

National Centre for Genetic Resources and Biotechnology, Moor Plantation, Ibadan, Nigeria. Contact: Animal Genetic Resources Department, National Centre for Genetic Resources and Biotechnology, PMB 5382Moor Plantation, Ibadan, Nigeria. rhemiajayi@gmail.com Tel: +2348034073868

\section{Abstract:}

Women play important roles in livestock production in developing countries. Information on their roles in goat production activities is however not sufficiently documented in literature and hence a study was conducted to document gender roles in goat production in Ogbomoso region of southwestern Nigeria.

Data was collected by using questionnaire administered to142 purposively selected farmers who kept goats on personal information and goat production related activities.

About $51.10 \%$ of the farmers interviewed were aged 41 years and above. The breed reared by $90 \%$ of the respondents was West African Dwarf goats. Furthermore, $60 \%$ of the farmers reared the animals for meat purpose while $36 \%$ kept goats to serve as a source of income. The major constraints in goat production enterprises included lack of capital, diseases and thefts of the animals.

Majority of the farmers agreed that the roles of selection of foundation stock, pen construction, caring for sick animals, slaughtering and processing of slaughtered animals are played by men while women played leading roles in feeding, caring for young animals, cleaning of the pens and marketing of goats.

In conclusion, men play more roles than women especially in those activities requiring more energy in goat production in Ogbomoso region of southwestern Nigeria. 


\title{
Other topics
}

\section{Comparative study of some physiochemical properties in milk from Murciano Granadina goats which had, or not, been treated with antibiotics}

\author{
$\underline{\text { Laura Almela }^{1}}$, Begoña Peinado ${ }^{1}$, Sonia Galián ${ }^{1}$, Ángel Poto ${ }^{1}$, Elisa Escudero ${ }^{2}$ and Pedro \\ Marín $^{2}$ \\ ${ }^{1}$ Murcian Institute for Agricultural and Food Research and Development (IMIDA), La Alberca-Murcia, \\ Spain \\ ${ }^{2}$ Department of Pharmacology, Murcia Region, Spain \\ Contact: Laura Almela, Murcian Institute for Agricultural and Food Research and Development (IMIDA), \\ La \\ Alberca-Murcia, SPAIN. Email: laura.almela@carm.es, Telephone: +34 968366756
}

\section{Abstract:}

Some physicochemical properties have been compared in the milk from Murciano-Granadina (M-G) goats which had been given antibiotics (A) and milk from untreated goats (NA), to find out if the addition of antibiotics makes any difference in the processing of the milk.

Of the total goats in the study, 20 goats were not treated at all and 6 goats were given antibiotics. The milk collection was daily, separating milk A from milk NA. Thirty-six samples (18 A and $18 \mathrm{NA}$ ), from different days over 2 months, were analysed. Milk A and milk NA were subjected to a pasteurization process, and once cooled to $40^{\circ} \mathrm{C}$ commercial rennet was added (enzymatic coagulation). The coagulation point was timed and measured using the "buttonhole technique", checking the coagulation status every 5 seconds. The rennet and whey were separated and the following parameters were measured: whey amount, rennet weight, whey and rennet $\mathrm{pH}$, and rennet colour.

The results showed a milk A curdling time of three minutes and fourteen seconds, compared to a milk NA curdling time of three minutes and four seconds. According to the statistical comparison study, there are no significant differences between them for this variable, nor for the other variables studied. The results indicate that after the pasteurisation process there are no significant differences between the milk from those goats treated with antibiotics and those which weren't. Neither are there any observable alterations in the milk processing process. 


\title{
Goat semen collection with two different sexual stimuli
}

\author{
Begoña Peinado ${ }^{1}$, Ángel Poto ${ }^{1}$, Laura Almela ${ }^{1}$ and Sonia Galián ${ }^{1}$ \\ ${ }^{1}$ Instituto Murciano de Investigación y Desarrollo Agrario y Alimentario, La Alberca, Murcia, Spain \\ Contact: Dra. Begoña Peinado, equipo de mejora genética animal, Instituto Murciano de Investigación y \\ Desarrollo Agrario y Alimentario, 30150 La Alberca, Murcia, Spain
}

\section{Abstract:}

The aim of this work was to know if it was possible to perform semen collection from bucks of the Murciano-Granadina breed, previously trained in semen collection with females of the breed, using another male as a sexual stimulus and to determine if there are differences in their sexual behaviour, libido and seminal quality with respect to that obtained when the stimulus is a female. We compared the data from the training period of 8 bucks under one year of age with those obtained in the same bucks when they were sexually stimulated by a female or another buck. We assess the reaction time, ejaculate volume, total sperm concentration, individual sperm motility and percentage of motile sperm in each ejaculate. It was also compared if the number of rides in a morning was different. After statistical analysis of the results, we observed that the reaction time was lower once the males had been trained, but it did not differ whether the lure was another male or a female. Seminal quality was better after the training period due to the older age of the bucks, but did not show large differences in any of the parameters evaluated when using a female or a male and the number of services performed by the bucks in one morning was also the same. We conclude that the semen collection from bucks can be done using another male as a stimulus, which would avoid the repeated use of hormones to females, improving animal welfare. 


\title{
Other topics
}

\section{SIRA SMART SCALE, a milk lamb weight scale that helps to introduce maternal index in extensive meat breed breeding productivity}

\author{
Marta Gómez Segura $^{1}$, Jesús Ochoa ${ }^{2}$, Manuel Quinteiro ${ }^{3}$ and Juan Altarriba ${ }^{4}$ \\ ${ }^{1}$ ARANA, Navarra, Spain \\ ${ }^{2}$ INTIA, Navarra, Spain \\ ${ }^{3}$ Compañía de Instrumentación y Control, Alcobendas, Spain \\ ${ }^{4}$ Zaragoza Veterinary University, Zaragoza, Spain \\ Contact: Marta Gomez Segura, ARANA, Ainziburu S/N, 31170 Iza, Navarra (Spain), \\ mgomez@arana.centroiza.com
}

\section{$\underline{\text { Abstract }}$}

Raza Navarra is a North Spain extensive meat breed. After 30 years breeding to select the most prolificably maternal lines we are trying to introduce maternal index in order to improve productivity and profit.

Handling to weight milk lambs in an extensive breed means lots of problems farmers are not willing to assume. Nowadays, the sheep sector lacks financial return, it is aged and farmers are discouraged, but even then, it needs imaginative technical improvements to try to increase its profits.

Selecting ewes by their maternal index could reduce the time lambs need to reach their optimal weight to go to the market, which means costs are likely to be lower.

SIRA SMART SCALE is a milk lamb weight scale which registers individual lamb weight without farmer interaction.

It includes a camera that discriminates between one or more lambs on the scale and if they have fully stepped on it. Lambs are identified by means of an electronic ear tag so the scale registers their individual number and the date they have been weighed.

With this poster we would like to show the material, method and results obtained with SIRA SMART SCALE during 2019-2020 in several Raza Navarra herds.

\section{Results:}

During 2019, 12,642 lambs have been weighed.

Data shown below are from a single herd, where 1762 lambs where weighed (they mean 90\% of lambs born during 2019)

- On average, the lambs had 37 days of life the day of weighing.

- Results shown the average daily weight gain is 0.211 grams per day.

- The ewe age does not seem to interfere on lamb weight.

- Female lambs weight nearly a kilogram less than males at day 37 of birth.

- On average, at day 37 of birth, single born lambs weigh $1.257 \mathrm{~kg}$ more than doubles and

$1.730 \mathrm{~kg}$ more than triples, 


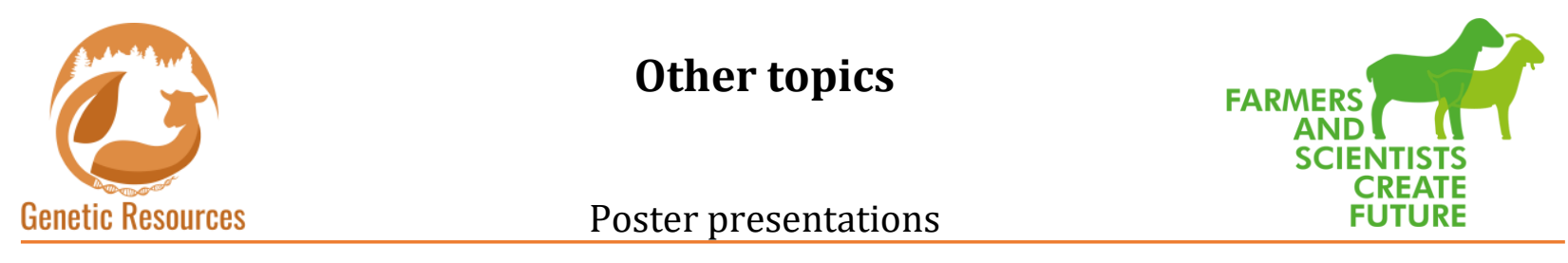

\section{Feeding dairy sheep and goats}

\section{George Christodoulopoulos}

Clinical Veterinary Medicine Dept, Faculty of Veterinary Science, University of Thessaly, Karditsa, Greece Contact: P.O. Box 199, Karditsa, GR-43131, Greece; Tel: 00306942061708; Email: gc@vet.uth.gr

\section{Abstract:}

On the farm, dairy sheep and goats are usually fed a mixture of concentrates as well as a kind of roughage. Often, the advice given by the practitioners on what quantities they should be fed is empirical. Here are our calculations which determined what quantities they should be fed. Our calculations are intended for mixtures of concentrates containing 15-17\% crude proteins and $20-25 \%$ digestive fibers; therefore the mixtures are "total mixed rations", as they are meant to feed each head over $0.5 \mathrm{~kg}$ per day (Thonney and Hogue, 2013; AHDB, 2018).

In a dairy ewe farm, the quantities of roughages (x) and concentrate mixture (y) that should be fed can be calculated using the formulas:

$\mathrm{x}=\frac{7.1 \mathrm{~L}+0.085 \mathrm{~W}-1.2 \frac{\mathrm{bW}}{\mathrm{k}}+2.85}{\mathrm{a}-\frac{\mathrm{bq}}{\mathrm{k}}}$ and $\mathrm{y}=1.2 \frac{\mathrm{W}}{\mathrm{k}}-\frac{\mathrm{q}}{\mathrm{k}} \mathrm{x}$, where $x$ and $y$ are given in $\mathrm{kg}$ of dry matter; $L$ is the daily milk yield $(\mathrm{kg}), W$ the live weight of ewe $(\mathrm{kg}), \mathrm{k}$ and $q$ the percentage of neutral detergent fibers and $a$ and $b$ the amount of metabolisable energy (ME) in the concentrates and roughage correspondently.

Since the ME of the concentrates is greater than that of the roughage, if the animals consume more roughage than the quantity calculated their ME needs will not be met. However, if the required quantities of roughage are not available, any available amount may be fed and the missing quantity may be replaced by a quantity of concentrates equivalent in ME to meet the livestock's needs.

\section{References:}

Thonney, M.L., and Hogue, D.E. (2013) Fermentable fiber for diet formulation. In Proceedings of the Cornell Nutrition Conference, Ithaca.

AHDB (2018). Feeding the ewe. A manual for consultants, vets and producers. (United Kingdom: Better Returns Programme), $64 \mathrm{p}$. 
Animal health:

Parasitology

Genetic Resources

Oral presentations

\title{
Potentials of using milk performance data as indicator for Targeted Selective Treatment in Lacaune dairy sheep in Switzerland
}

\author{
Katharina Schwarz ${ }^{1,2}$, Beat Bapst ${ }^{3}$, Mirjam Holinger ${ }^{1}$, Inga Schleip ${ }^{2}$ and Steffen Werne ${ }^{1}$ \\ ${ }^{1}$ Research Institute of Organic Agriculture (FiBL), PO Box, 5070 Frick, Switzerland \\ ${ }^{2}$ Eberswalde University for Sustainable Development, Schicklerstrasse 5, 16225 Eberswalde, Germany \\ ${ }^{3}$ Qualitas AG, Chamerstrasse 56, 6300 Zug, Switzerland \\ Contact: Steffen Werne, Ackerstrasse 113, 5070 Frick, Switzerland, email: steffen.werne@fibl.org
}

\section{Abstract:}

Anthelmintic resistance is a major threat in small ruminant farming worldwide. One approach to slow down the development of anthelmintic resistance is Targeted Selective Treatment (TST), where a part of animals is left unexposed to anthelmintic treatment and thus providing refugia for susceptible parasites. Closely linked to the successful implementation of TST is the identification of animals in need of treatment. The aim of this study was therefore to investigate the general relation between milk yield and gastrointestinal nematode infections in a Swiss Lacaune dairy sheep subpopulation and, based on this, to evaluate milk yield data as a potential TST indicator in dairy sheep. On 15 Swiss farms nematode egg excretion per gram faeces (EPG) and individual milk performance of 1159 Lacaune ewes were obtained between August and December 2019. Faeces collection and individual milk performance data were closely timerelated. Coprocultures of pooled samples were conducted to determine the proportion of Haemonchus contortus on farm level. A linear mixed model was fitted, using log-transformed EPG as dependent variable and milk yield, milk protein content, days in milk, lactation number and the proportion of $H$. contortus as fixed effects. The farm was included as random effect. The results revealed a significant relation between milk yield and EPG $(P<0,01)$, which was most pronounced in the earlier stage of lactation, indicating high yielding ewes to be less resistant to GIN infections than low yielding ewes. The results suggest therefore the possibility of using milk yield data as TST indicator in dairy sheep. 
Animal health:

Parasitology

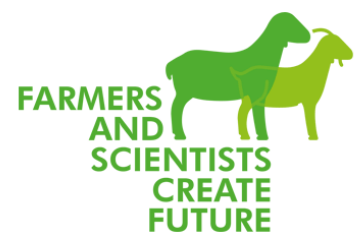

\title{
Data of Targeted Selective Treatment based on live weight gain should be used for breeding for resistance against gastrointestinal nematodes
}

\author{
Martin Ganter ${ }^{1}$, Bernd Möller ${ }^{2}$ and Inga Nolte ${ }^{1}$ \\ ${ }^{1}$ University of Veterinary Medicine Hannover, Foundation, Clinic for Swine and Small Ruminants, \\ Hannover, Germany \\ ${ }^{2}$ Institute of Farm Animal Genetics. Friedrich-Loeffler-Institute. Neustadt-Mariensee, Germany. \\ Contact: University of Veterinary Medicine Hannover, Foundation, Clinic for Swine and Small Ruminants, \\ Bischofsholer Damm 15, 30173 Hannover, Germany; Martin.Ganter@tiho-hannover.de
}

\begin{abstract}
:
The development of the FAMACHAC system (van Wyk and Bath, 2002) was a milestone in the use of Targeted Selective Treatment (TST). The transfer for non-hematophagic endoparasite populations remains a challenge (Kenyon and Jackson, 2012). In a study on adapting TST to a farm with non-hematophagic endoparasite populations daily weight gain was used as parameter for treatment of individual lambs within a group of 76 bleackheaded mouton lambs. Lambs who did not achieve the target weight were treated with ivermectine $(2 \mathrm{mg} / \mathrm{kg}$ body weight). Target weights were evaluated in the grazing season before in the same flock on the same pastures. Individual samples for faecal egg count were taken every four weeks. By reaching $45 \mathrm{~kg} \mathrm{~b}$. wt. ram lambs were slaughtered and the gut examined for gastrointestinal nematodes (GIN). Compared to a regular deworming every four weeks the number of deworming was reduced by $66.9 \%$ in male lambs and $76.6 \%$ in female lambs respectively. High rates of not treated lambs turned out. In total 36 lambs $(18=41.9 \%$ female $+18=47.4 \%$ male) remained untreated over the whole grazing season and achieved the target weights. Clinical endoparasitosis was not present. Positive effects of some lamb's treatment on gastrointestinal nematodes (GIN) on FEC in the feces of untreated lambs were observed (Nolte, 2019). The comparison with the two previous years (Trapp, 2013; Schöwerling, 2016) showed a high variability in GIN populations in the gut of the slaughter lambs. Lambs who need no anthelmintic treatment over the entire grazing season, but meet the target weight gain, should be selected as replacements. By using this as a selection criterion for breeding, an indirect selection for resistance against GIN could be achieved.
\end{abstract}

\section{References:}

Kenyon, F.\& F. Jackson (2012): Targeted flock/herd and individual ruminant treatment approaches. Veterinary Parasitology $186,10-17$.

Nolte, I. (2019): Erprobung des „Targeted Selective Treatments“ auf der Basis der Gewichtsentwicklung bzw. klinischer Scores mit makrozyklischen Laktonen zur Endoparasitenbekämpfung bei Lämmern. Tierärztliche Hochschule Hannover, Diss.

Schöwerling, J. (2016): Erprobung des "Targeted Selective Treatment" mit Levamisol zur Endoparasitenbekämpfung bei Lämmern. Tierärztliche Hochschule Hannover, Diss.

Trapp, C. (2014): Erprobung des ,Targeted Selective Treatment' zur Endoparasitenbekämpfung bei Lämmern. Tierärztliche Hochschule Hannover, Diss.

van Wyk, J.A. u. G.F. Bath (2002): The FAMACHA system for managing haemonchosis in sheep and goats by clinically identifying individual animals for treatment. Veterinary Research 33, 509-529. 
Animal health:

Parasitology

\title{
Selfmedicative behavior and tanniferous fodder plants: alteration in taste perception and feed preferences of GIN-infected Boer goats
}

\author{
Marvin Heuduck $^{1}$, Christina Strube ${ }^{2}$, Katharina Raue ${ }^{2}$, Eva Schlecht $^{1}$ and Martina Gerken ${ }^{1}$ \\ ${ }^{1}$ Georg-August-University, Goettingen, Germany \\ ${ }^{2}$ University of Veterinary Medicine, Hanover, Germany \\ Contact: Marvin Heuduck, Department of Animal Sciences, Albrecht-Thaer-Weg 3, 37075 Goettingen, \\ Tel.: +49-(0)551-3925779, marvin.heuduck@uni-goettingen.de
}

\section{Abstract:}

Nematode infections are a common thread in ruminant livestock and excessive usage of conventional anthelmintics led to emergence of resistant nematode populations. This underlines the relevance of paradigm shift towards a sustainable control approach of nematode infections.

In this study, possible changes in taste perception and in feed preferences of goats were scrutinized to prove ascertained higher feed intake of tanniferous plants by goats in case of nematode-infection.

Feed preferences of 18 Boer goats were analyzed via cafeteria-trial (12 weeks) regarding influence of changes in health status from non-infected to infected. Goats were divided in different groups: I) Non-infected + feeding-trial II) Infected + feeding-trial III) Infected without feeding-trial. The cafeteria-trial was conceptualized with pellets of tanniferous plants (leaves of sainfoin, willow, walnut, blackberry) of various tannin-contents and tannin-free hay pellets. After four weeks a mixed nematode-infection was administered to group II) and III). Besides feed intake and selection procedure, blood parameters, saliva composition and feces were analyzed on weekly basis in order to assess the course of infection and potential shifts in feed preferences due to changes of taste perception.

Analysis of trial data revealed an alteration from tannin-free (hay) and low tannin-containing feed (sainfoin) to higher tannin-contents (walnut, blackberry) in the course of infection. Results of blood, saliva and feces parameters have not yet been completely evaluated to give a more detailed overview about the effects on parasite burden and a potential altered taste perception. 


Animal health:
Parasitology
Oral presentations

\title{
Sainfoin pellets for preventive parasite control and improved protein efficiency in dairy goats
}

\author{
$\underline{\text { Steffen Werne }}{ }^{1}$, Nadine Arnold ${ }^{2}$, Erika Perler ${ }^{1}$ and Florian Leiber ${ }^{1}$ \\ ${ }^{1}$ Research Institute of Organic Agriculture FiBL, 5070 Frick, Switzerland \\ ${ }^{2}$ ZHAW Life Sciences und Facility Management, 8820 Waedenswil, Switzerland \\ Contact: Steffen Werne, Ackerstrasse 113, 5070 Frick, Switzerland, email: steffen.werne@fibl.org
}

\section{Abstract:}

Condensed tannins of the legume sainfoin (Onobrychis viciifolia) are frequently associated with beneficial effects when offered as feed to ruminants. We hypothesised that offering sainfoin to dairy goats may improve the ruminal protein-efficiency indicated by lower urea and higher protein yields in goat milk and as well may lower nematode egg extcretion (EPG). Over a period of 7 weeks, in total 20 alpine goats were fed with $700 \mathrm{~g}$ sainfoin $(n=10)$ or $700 g(n=10)$ alfalfa pellets daily. Milk protein and urea yield as well as EPG were measured regularly on individual basis. All animals were kept in one group, except for milking and pellet feeding and had access to pasture for approx. 5 hours daily. Intake from pasture or ad libitum offered hay was not determined. The concentration of condensed tannins in sainfoin and alfalfa was $4 \%$ and $0.3 \%$, respectively. Crude protein content was $18.2 \%$ for sainfoin and $20.1 \%$ for alfalfa (corrected for $100 \%$ dry matter). Repeated measurement analysis could not reveal significant differences $(\mathrm{p}=0.148)$ of the EPG between groups, even though arithmetic mean of EPG in the sainfoin group was $18 \%$ lower compared to the control group. Also the total daily milk protein $(\mathrm{p}=0.700)$ and total daily urea milk content $(\mathrm{p}=0.410)$ per animal did not differ between treatments. Other studies often report a reduced nematode egg excretion if sainfoin was administered ad libitum. As a dose dependent effect for condensed tannins is assumed, the total amount of condensed tannins in our trial might have been too low to provoke any effect. 
Animal health:

Parasitology

\title{
Coccidiosis in small ruminant's farms - case study in Trás-os-Montes (northeastern Portugal)
}

\author{
$\underline{\text { Hélder Quintas }}^{1}$, Margarida Afonso ${ }^{2}$, Daniela Silva ${ }^{3}$, Luís Cardoso ${ }^{2,5}$, Delia Lacasta ${ }^{4}$, Luis \\ Miguel Ferrer ${ }^{4}$ and Ana Patrícia Lopes ${ }^{2,5}$ \\ ${ }^{1}$ Centro de Investigação de Montanha (CIMO), Instituto Politécnico de Bragança, Campus de Santa \\ Apolónia, 5300-253 Bragança, Portugal \\ ${ }^{2}$ Departamento de Ciencias Veterinárias, Escola de Cienncias Agrárias e Veterinárias, Universidade de Trás- \\ os-Montes e Alto Douro (UTAD), Vila Real, Portugal \\ ${ }^{3}$ Segalab, Póvoa de Varzim, Portugal \\ ${ }^{4}$ Departamento de Patología Animal, Facultad de Veterinaria C/ Miguel Servet 177, 50013 Zaragoza, \\ Spain \\ ${ }^{5}$ Centro de Cieñcia Animal e Veterinária (CECAV), UTAD, Vila Real, Portugal \\ Contact: helder5tas@ipb.pt
}

\section{Abstract:}

Coccidiosis is one of the most important intestinal diseases in small ruminants and has a significant economic impact in farms over the world. The manifestations of the disease occurs mostly among young animals when submitted to stressful conditions. Thus, in improving prophylactic plans, it is necessary to understand the risk factors associated with each production system in particular. This study was carried out in the region of Trás-os- Montes (Portugal) in animals between 4 and 6 weeks of age from 46 different farms in two different years. Several factors related to the management of farms were associated with the presence of strong infections (OPG> 5 000) and isolation of pathogenic species. It is concluded that the Eimeria species with the highest prevalence in sheep was E. ovinoidalis (68.70\%) and the less prevalent $E$. intricata (13.30\%). In the case of goats, E. ninakohlyakimovae was the species with the highest prevalence (100\%) and E. alijevi (25.00\%) with the lowest. In farms where it was possible to verify a high concentration of animals near drinking spots, there were significantly ( $\mathrm{p}<0.001$ ) more strong infections. The likelihood of developing strong infections was almost 8 times higher (OR = 7.677; IC 95\%: 2.729 - 21.589) than the other farms. Moreover, in farms where antiparasitic treatments were used, the likelihood of isolating oocysts from pathogenic species of Eimeria $(\mathrm{p}=0.0065)$ was 12,17 times lower (OR $=12.167$, IC 95\%: $1.786-82.864$ ) than in the other farms. 


Animal health:
Locomotive apparatus and monitoring
Oral presentations

\section{Know how: the secret of successful lameness management}

\section{Heinz Strobel}

Schafpraxis, Stoffenried, Germany, wwww.schafpraxis.de

Contact: Dr.Heinz Strobel, Am Hopfenberg 8, D-89352 Ellzee, drheinzstrobel@t-online.de

\section{Abstract:}

Lameness still is a major problem with ecological, economical and ethical relevance on many farms (keywords: antibiotica, welfare, residues, manpower, productivity). During the last decade frustrating cycles of footrot could be broken on a fair number of farms by applying sustainable strategies. The goal was either Dichelobacter nodosus PCR negative flocks or permanent footrot control on acceptable levels $(<3 \%)$.

The evaluation of difficulties along the elimination process on farm and the results of the following monitoring clearly shows, that relapses and failures were mainly due to carelessness or wrong decisions by stocksmen in critical situations, e.g. when joining rams to the flock without quarantine or prophylactical treatment.

As a consequence, the transfer of knowledge should be intensified and optimized along with the design of protocols tailor suited for individual farms and maintained during the following observation period. It is not sufficient to replace traditional and counterproductive opinions of owners by evidence based informations. It is essential to provide a common basic knowledge to all people involved. All staff in charge of handling sheep must be able to identify risks and take appropriate measures irrespective of language barriers or hierarchies. As a result of many presentations, consultancies and stable schools a set of didactical components was created.

So knowledge on lameness can be transferred by webinars, FAQ lists, interactive courses and posters (demonstrated in this presentation). Antibiotic stewardship, animal welfare und environmental aspects make sustainable strategies indispensable on the way to effective lameness management.

\section{References:}

Strobel H, Hilke J, Spengler D, Axt H, Ganter M, Voigt K. Klaueninfektionen beim Schaf - Therapiemöglichkeiten in der tierärztlichen Praxis unter besonderer Berück sichtigung der Moderhinkebekämpfung [Claw infections in sheep - treatment options in veterinary practice, with special emphasis on ovine footrot treatment. - An update]. Tierarztl Prax Ausg G Grosstiere Nutztiere. 2018 Dec;46(6):385-398. German. doi: 10.15653/TPG-180285. Epub 2019 Jan 7. PMID: 30616280. 
Animal health:

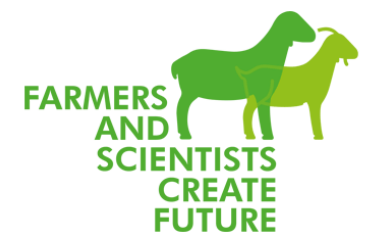

\title{
Evaluation of prevalence and risk factors associated with virulent and benign Dichelobacter nodosus in German sheep breeds
}

\author{
$\underline{\text { Julia Storms }^{1}}$, Anna Wirth ${ }^{1}$, Monia Lara Budnik ${ }^{1}$, Peter Kuhnert ${ }^{2}$, Jörg Jores ${ }^{2}$ and Ottmar \\ Distl $^{1}$ \\ ${ }^{1}$ University of Veterinary Medicine Hannover, Institute of Animal Breeding \& Genetics, Hannover, \\ Germany \\ ${ }^{2}$ University of Berne, Institute of Veterinary Bacteriology, Bern, Switzerland \\ Contact: julia.storms@tiho-hannover.de
}

\section{Abstract:}

Footrot is a contagious disease of major welfare and economic concerns in sheep worldwide. The etiological agent of ovine footrot, Dichelobacter nodosus, differs in virulence due to the subtilisin-like proteases. Two proteases, AprV2 and AprB2, determine virulent and benign strains. The thermostable AprV2 protease is required for virulence. The objectives of our study were to screen a large number of sheep breeds for $D$. nodosus strains, their clinical status and associated risk factors. Data and samples were collected from $>9000$ sheep in 200 flocks with $>20$ different breeds from all over in Germany. In addition, herd footrot history and potential risk factors for footrot were recorded. We used a competitive qRT-PCR method to detect the allelic differences TA/CG at nucleotide 661/662 in the aprV2 and aprB2 gene sequences. All sheep were examined and scored for foot and claw lesions and recorded along with breed, sex, age and previous footrot treatments. Specifity of the qRT-PCR was $>99 \%$. Sheep with underrunning footrot showed a detection rate of $96.3 \%$ for virulent strains and sheep with mild and moderate to severe interdigital dermatitis of $41.4 \%$ and $86.6 \%$. Low prevalences $(<20 \%)$ were seen in Forest sheep, East Friesian, and Skudde and moderate to high prevalences in Merinos, Leine, Bentheimer, Texel, Suffolk, Grey and White Heath ( $>40 \%)$. Risk factors by breed, season, region, flock and footrot history were analysed and will be shown. Breed and flock had the highest impact on $D$. nodosus prevalence. 


\title{
Study of antibiotic susceptibility against the main pathogens involved in fattening lambs pathology in Spain and Portugal
}

\author{
José María Bello Dronda $^{1}$ and Lorenzo Fraile Sauce ${ }^{2}$ \\ ${ }^{1}$ NANTA S.A. Ronda de Poniente,9, 28760 Tres Cantos (Madrid), Spain \\ ${ }^{2}$ Departament de Ciència Animal, ETSEA, Universitat de Lleida, Lleida, Spain \\ Contact:.jm.bello@nutreco.com
}

\section{Abstract:}

The increase of antimicrobial resistance has become a global public health problem. In the EU, reduction policies have been implemented under the "One Health" concept that implies human and animal health. The monitoring of resistance in different animal species has become a priority within the strategies of fighting against resistance.

Four hundred and twelve cases were analyzed from 2015 to 2019, coming from 121 lamb feedlot farms in Spain and Portugal. Several studies were carried out to obtain practical knowledge in order to reduce the use of antimicrobials as much as possible. Firstly, several comparative studies were carried out between samples from nasotracheal lavages and those obtained from lung tissue ("in farm examination necropsy") in order to check the suitability of this type of samples in monitoring the susceptibilities of the pathogens (Pasteurella multocida, Mannehimia haemolitica and Biberstenia threalosi) involved in respiratory problems. Secondly, another study was carried out in order to know the evolution along the years of the susceptibilities to some antibiotics of the most important pathogens (P. multocida, $M$. haemolitica, B. threalosi and Escherichia coli) involved both in respiratory and digestive diseases. Finally, a "map" of the susceptibilities of pathogens to a significant number of antibiotics available in the market were obtained.

Similar results in susceptibility were found in most of the pathogens studied comparing lavages and tissue samples. Besides, similar evolution in susceptibility of pathogens to most antibiotics checked was observed, with an increment during 2018 and 2019. In general, tetracycline (very used by oral supply) gave less susceptibility than others did. On the opposite way, amoxicillin could be an antibiotic available for further oral use.

In conclusion, the nasotracheal lavages are an efficient and valid method of taking suitable respiratory samples in practical conditions of monitoring. Besides, there is a tendency to the increment of the susceptibility of pathogens to a large part of antibiotics, in parallel to the reduction of the actual use of antimicrobials. Finally, the maps of susceptibilities provide very useful epidemiological information to be used in the strategies of antibiotic pressure reduction.

\section{References:}

González, JM et al (2016). Lamb feedlot production in Spain: Most relevant health issues. Small Ruminant Research. 142: 83:87. https://www.sciencedirect.com/science/article/abs/pii/S092144881630044XY

EUR-LEX (2017). Communication from the commission to the council and the european parliament. A European One Health Action Plan against Antimicrobial Resistance (AMR), COM/2017/0339. https://eur-lex.europa.eu/legalcontent/EN/TXT/?uri=celex:52017DC0339

Fraile, L (2013). Antimicrobial therapy in swine. A practical approach. Ed. Servet. Grupo Asis Biomedia S.L.Pages 25-43. https://store.grupoasis.com/en/swine/235-antimicrobial-therapy-in-swine-practical-approach-9788494101496.html 
Animal health:

Locomotive apparatus and monitoring

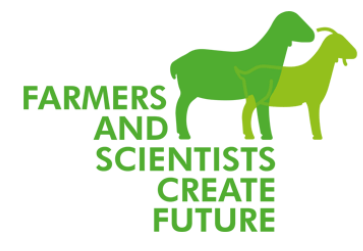

\title{
Evaluation of anthelmintic efficacy in gastrointestinal nematodes of goats raised under mountain farming conditions
}

\author{
Ioanna Poulopoulou ${ }^{1}$, Christian Lambertz ${ }^{2}$, Kunlayaphat Wuthijaree ${ }^{3}$ and Matthias Gauly ${ }^{1}$ \\ ${ }^{1}$ Faculty of Science and Technology, Free University of Bolzano, Piazza Università 5, 39100 Bolzano, Italy \\ ${ }^{2}$ Research Institute of Organic Agriculture (FiBL), Kasseler Straße 1a, 60486 Frankfurt am Main, \\ Germany \\ ${ }^{3}$ The Department of Agricultural Science, Faculty of Agriculture, Natural Resources and Environment \\ Naresuan University, 65000, Phitsanulok, Thailand \\ Contact: Ioanna Poulopoulou, Faculty of Science and Technology, Free University of Bolzano, Piazza \\ Università 5, 39100 Bolzano, Italy, E-mail: Ioanna.Poulopoulou@unibz.it
}

\section{Abstract:}

The frequent use of anthelmintics in mountain farms have led to the development of anthelmintic resistance (AR). The aim of the present study was to estimate the AR of gastrointestinal nematodes (GIN) in goats in a mountain area. On eight farms $(n=143$ animals) egg excretion (expressed as eggs per gram of faeces (EPG)) before and after routine anthelmintic treatments were used for faecal egg count reduction (FECR) tests. Either macrocyclic lactone (ML) or benzimidazole (BZ) were used as anthelmintics. On five farms (n $=135$ animals) FECR was estimated after controlled application of one of the following anthelmintics: ML, BZ (partly in combination with salicylanilide (SA)) or a combination of imidazothiazole (IT) and SA. AR was assumed if FECR and the upper confidence interval (CI) were $<95 \%$ and the 95\% confidence level < 90\%. Average EPG before anthelmintic application showed a large variation ( $E P G=751, S D=1090$ ). After treatments, $50 \%$ of the routinely ML-treated goat flocks showed adequate efficacy. FECR in all others ranged between 64 and 93\%. Under controlled anthelmintic treatments, ML had an adequate efficacy on four farms and a FECR of $88 \%$ on another one. BZ was effective on all farms. On one farm, BZ and SA had a FECR of 99\%. On two farms, IT + SA was effective and had a FECR of 91\% on a third. Low efficacy was observed in goat farms after routine and controlled treatments, which demand immediate actions to prevent further spread and development of AR. 


Animal health:
Locomotive apparatus and monitoring
Oral presentations

\section{Relevance of selenium imbalances in sheep flocks and implications for herd health management consultancy}

\section{Esther Humann-Ziehank}

LABVETCON - Laboratory Veterinary Consulting, Burgdorf, Germany

Contact: LABVETCON, Foehrenkamp 20, D-31303 Burgdorf, mail@labvetcon.de

\section{Abstract:}

Adequate nutritional supplementation of selenium is indispensable for adequate selenoprotein expression and function in animals. Germany was considered to provide low selenium in regional grown fodder causing selenium deficiency in sheep flocks as well as in wild ruminants as shown in roe deer (Humann-Ziehank et al., 2008). Marginally selenium supplemented sheep underwent ongoing selenium deprivation. Vital organs are affected by selenium deficiency attenuating functional parts of the antioxidative system. Improvement of selenium supplementation to an adequate level strongly alters serum and liver selenium concentration within 10 and 20 days, respectively, followed by a plateau (Humann-Ziehank et al., 2013a). The occurrence of selenium deficiency was demonstrated in an epidemiological study including 150 German sheep flocks. Selenium deficiency was found to be widespread in German sheep flocks. More than one third of the flocks showed relevant selenium deficiency in serum indicating the strong need to optimise the nutritional management. As it is impossible to estimate the final forage Se concentration by environmental factors only, there is a need for validation at animal level (Humann-Ziehank et al., 2013b). The best metabolic biomarker of selenium deprivation and nutritional selenium upgrade, respectively, was selenium in serum. Moreover, hepatic selenium concentrations reliably reflected the upgrade of selenium supply within days (Humann-Ziehank et al., 2013a). Factors raising suspicion of selenium imbalances are large flocks and transhumance. Stationary flocks had constantly higher mean serum selenium concentrations during the breeding, lambing and grazing period, whereas flocks practising transhumance had significant lower selenium status except during lambing (Humann-Ziehank et al., 2013b). 
Animal health:

Locomotive apparatus and monitoring

Oral presentations

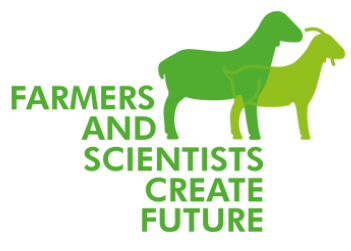

\title{
Exploiting scanning surveillance data to assess the impact of different initiatives and inform future strategies to control sheep scab
}

\author{
Eilidh Geddes ${ }^{1}$, Sibylle Mohr ${ }^{2}$, Sian Mitchell ${ }^{3}$, Sara Robertson ${ }^{4}$, Anna Brzozowska ${ }^{4}$, Stewart \\ Burgess $^{5}$ and Valentina Busin ${ }^{1}$ \\ ${ }^{1}$ School of Veterinary Medicine, University of Glasgow, 464 Bearsden Road, Glasgow, United Kingdom \\ ${ }^{2}$ Boyd Orr Centre for Population and Ecosystem Health, College of Medical, Veterinary and Life Sciences, \\ University of Glasgow, Glasgow, United Kingdom \\ ${ }^{3}$ Carmarthen Veterinary Investigation Centre, Animal and Plant Health Agency, Carmarthen, United \\ Kingdom \\ ${ }^{4}$ Surveillance Intelligence Unit, Animal and Plant Health Agency, Weybridge, Surrey, United Kingdom \\ ${ }^{5}$ Moredun Research Institute, Pentlands Science Park, Bush Loan, Edinburgh, United Kingdom \\ Contact: Valentina Busin, School of Veterinary Medicine, University of Glasgow, 464 Bearsden Road, \\ Glasgow, United Kingdom, valentina.busin@glasgow.ac.uk
}

\section{Abstract:}

Veterinary surveillance is an essential tool designed to aid decision making and a fundamental concept in food security, public health and international trade (Hoinville et al., 2013). This study aimed to investigate the use of existing scanning surveillance data for sheep scab to assess the impact of different initiatives and inform future control strategies.

The data analysed were submissions with a positive sheep scab diagnosis confirmed through identification of Psoroptes ovis mites in skin scraping in Great Britain for 2003-2018. Information were also collected on all known knowledge transfer, skills training, free testing and legislative actions (initiatives) designed to improve surveillance or decrease disease within the study period for sheep scab. First, a spatial analysis to highlight areas of concern was carried out, followed by an analysis of the effect of past initiatives on temporal patterns (Tongue et al., 2019). A total of 2,401 positive skin scrapes were recorded within the study period. The yearly distribution showed a significant downward trend in positive cases, from a peak of 277 in 2004, to 55 cases in 2015. In the study period nine initiatives occurred. Three of these initiatives had a significant effect on the number of positive cases diagnosed and this type of scheme did evoke the intended response. In conclusion, the analysis of an existing scanning surveillance source enhanced our knowledge of sheep scab by identification of areas for targeted control and offered a framework to measure the impact of future initiatives.

\section{References:}

Hoinville, L.J., Alban, L., Drewe, J.A., Gibbens, J.C., Gustafson, L., Häsler, B., Saegerman, C., Salman, M., Stärk, K.D.C. (2013). Animal Health Surveillance Terminology Final Report from Pre-ICAHS Workshop July 2013.

Tongue, S. C., Eze, J. I., Correia-Gomes, C., Brulisauer, F., Gunn, G. J. (2019). Improving the Utility of Voluntary Ovine Fallen Stock Collection and Laboratory Diagnostic Submission Data for Animal Health Surveillance Purposes: A Development Cycle. Front. Vet. Sci. 6: 487. 


\begin{tabular}{|c|c|c|}
\hline Genetic Resources & $\begin{array}{l}\text { Animal health: } \\
\text { Reproduction }\end{array}$ & $\begin{array}{l}\text { FARMERS } \\
\text { AND } \\
\text { SCIENTISTS } \\
\text { CREATE } \\
\text { FUTURE }\end{array}$ \\
\hline
\end{tabular}

\section{The trouble with the reproduction - chosen problems of the small ruminants}

\section{Henrik Wagner and Axel Wehrend}

Clinic for Obstetrics, Gynaecology and Andrology for Large and Small Animals with Veterinary Ambulance, Justus-Liebig-University Giessen

Contact: Dr. Henrik Wagner, Frankfurter Straße 106, 35392 Gießen, Phone: +49 6419938703

Mail: Henrik.W.Wagner@vetmed.uni-giessen.de

\section{Abstract:}

In breeding and keeping small ruminants, successful and safe reproduction is the basis for the financial security of the farm. In the course of the lecture, four problem areas of reproduction are to be worked out and case studies are given, which are very common in animal husbandry.

1. Low lambing rate

2. Extended lamb time

3. Weakness lambs

4. Abortions

The ram are of great importance to the clinical examination, which is unfortunately too often forgotten. As a further investigation, the ultrasonographic display of the testicles is a simple and quick diagnostic tool to better classify the breeding ability of the bucks. This technique is used too rarely at the licensing events and performance tests to assess the quality of the bucks in relation to their reproductive ability. Quarantine measures for new purchases and correct operational management (vaccination, deworming, serological examinations) are explained and their necessity discussed. Abortions continue to play a major role in small ruminants. Due to the mostly seasonal lambing, high losses occur quickly. What exactly has to be done with an abortion is with regard to securing and curtailing a possible transmission, especially in the case of zoonoses, and the possible future avoidance should be discussed.

The neonatal loss rate is always used as an index for animal welfare-related violations. This aspect is discussed in the lecture and the importance of minimizing such losses is emphasized. The veterinary care of the herds must also be critically evaluated. The density of specialist veterinarians for small ruminants can still be optimized. 
Animal health:

Reproduction

Genetic Resources

Oral presentations

\section{Coxiella burnetii on Dutch dairy sheep farms between 2006 and 2020}

\section{René van den Brom, Carlijn ter Bogt-Kappert, Erik van Engelen, Marian Aalberts and Piet Vellema}

Royal GD, Deventer, Netherlands

Contact: r.vd.brom@gdanimalheath.com

\section{Abstract:}

$\mathrm{Q}$ fever is a zoonotic disease caused by the intracellular bacterium Coxiella burnetii, which is able to infect several animal species, as well as humans. Domestic ruminants are the main animal reservoir. In small ruminants, infections mostly don't give clinical symptoms. However, abortions and stillbirths can occur, mainly during late pregnancy. Shedding of $C$. burnetii occurs in faeces, milk and mostly in placental membranes and birth fluids. During parturition of infected small ruminants, bacteria from birth products become aerosolized. Transmission to humans mainly happens through inhalation of contaminated aerosols (Maurin and Raoult, 1999).

In 2005, C. burnetii was diagnosed for the first time as cause of abortion on a dairy goat farm in the Netherlands, and between 2005 and 2010, this diagnosis was confirmed on in total 28 dairy goat and two dairy sheep farms (Van den Brom and Vellema, 2009). During this period, more than 4000 people became infected. A large package of preventive measures was implemented, mainly for dairy goat and dairy sheep farms, with the aim to reduce shedding, subsequent environmental contamination and thus human exposure to C. burnetii (Van den Brom et al., 2015), and compulsory vaccination was the most important one. Monthly bulk tank milk (BTM) surveillance, using a C. burnetii PCR, is functioning since October 2009, and has been an effective and useful tool to distinguish between $C$. burnetii excreting and nonexcreting small ruminant farms.

Vaccination of dairy sheep with phase 1 vaccine Coxevac ${ }^{\circledR}$, at a dose of $1 \mathrm{~mL}$ as prescribed for sheep since the start of compulsory vaccination, seems very effective in preventing abortion and reduction of shedding of $C$. burnetii, since no cases of abortion caused by $C$. burnetii have been confirmed after vaccination, and no $C$. burnetii shedding has been detected on dairy sheep farms after 2013 in the BTM surveillance. Antibody levels against $C$. burnetii have been high to very high since vaccination started.

We briefly present the history of Dutch dairy sheep farming, and will discuss results of implemented measures as notification, vaccination, hygiene, and surveillance, on Dutch dairy sheep farms between 2006 and 2020.

\section{References:}

Maurin M., Raoult D., 1999. Q fever. Clin. Microbiol. Rev. 12 (4), 518-553.

Van den Brom R., and Vellema P., 2009. Q fever outbreaks in small ruminants and people in the Netherlands. Small Rumin Res. 86, 74-79.

Van den Brom R., van Engelen E., Roest H.I.J., van der Hoek W., Vellema P., 2015. Coxiella burnetii infections in sheep and goats; an opionated review. Vet Microbiol. 2015 Jul 15. pii: S0378-1135(15)00273-4. doi: 10.1016/j.vetmic.2015.07.011. 


\begin{tabular}{l}
$\begin{array}{c}\text { Animal health: } \\
\text { Reproduction } \\
\text { Genetic Resources } \\
\text { Oral presentations }\end{array}$ \\
\hline
\end{tabular}

\title{
Investigation of abortions in small ruminants in Greece due to Chlamydia abortus
}

\author{
Giadinis N.D. ${ }^{1}$, Kiossis E. ${ }^{1}$, Chochlakis D. ${ }^{2}$, Lafi S.Q. ${ }^{3}$, Psaroulaki A. ${ }^{2}$, Petridou E.J. ${ }^{4}$, \\ Filippopoulos L.K. ${ }^{5}$, T. Calvo Gonzalez-Valerio ${ }^{5}$ and Massimiliano Baratelli ${ }^{5}$ \\ ${ }^{1}$ Faculty of Veterinary Medicine, Thessaloniki, GREECE \\ ${ }^{2}$ Medical School, Heraklion, GREECE \\ ${ }^{3}$ Faculty of Veterinary Medicine, Irbid, JORDAN \\ ${ }^{4}$ Faculty of Veterinary Medicine, Thessaloniki, GREECE \\ ${ }^{5}$ Laboratorios Hipra S.A., Girona, SPAIN \\ Contact: Nektarios Giadinis, Clinic of Farm Animals, Faculty of Veterinary Medicine, Aristotle University of \\ Thessaloniki, St.Voutyra 11, 54627, Thessaloniki, GREECE.E-mail: ngiadini@vet.auth.gr
}

\section{Abstract:}

Chlamydiosis due to Chlamydia abortus is one of the most common causes of abortion in small ruminant flocks worldwide. Although the causative agent is zoonotic, chlamydiosis is not a reportable disease.

Sixty abortion cases originating from different sheep flocks in Greece were investigated for Chlamydia abortus. Fetal stomach content, fetal liver, placenta or vaginal swabs were used for examinations. PCR for Chlamydia abortus gene 16S was positive in 25 out of 60 cases, while examination for gene $23 \mathrm{~S}$ was positive for 12 of them. Three samples were found doubtful. Moreover, serological investigation for Chlamydia abortus was conducted. Blood samples from 26 randomly selected sheep flocks not vaccinated against chlamydiosis were collected. From each flock, 15 to 20 blood samples were taken from adult female sheep. In total 464 blood samples were examined. One hundred and six samples were found positive (22.8\%), while 24 samples (5.24\%) were found doubtful. Also, at farm level, from the total number of 26 farms, 18 of them had positive animals (69.2\%).

In conclusion, chlamydiosis is considered a highly likely cause of sheep abortion in Greece. Therefore, vaccinations of the sheep flocks should be recommended for the prevention and control of the disease.

\section{References:}

Longbottom D. and Coulter L.J. (2003) Journal of Comparative Pathology 128 (217-244).

Longbottom D. et al. (2005) The Veterinary Journal (171) 263-275. 
Animal health:

Reproduction

Genetic Resources

Oral presentations

\title{
Ultrasound findings of common genital pathologies in small ruminants
}

\author{
Mário Balaro, Isabel Cosentino, Felipe Leal, Lucas Barbosa, Fernanda Gonçalves, Ana Beatriz \\ Carvalho, Bruno Vieira, Mirella Dias, Paula Cortat de Souza and Felipe Brandão
}

Fluminense Federal University, Niteroi, RJ, Brazil

Contact: Department of Pathology and Clinical Veterinary, Faculty of Veterinary, Fluminense Federal University, Rua Vital Brasil Filho, 64, zip code: 24320-340, Niteroi, RJ, Brazil, E-mail address: mariobalaro@id.uff.br (MFA Balaro).

\section{Abstract:}

This study reports the prevalence of some reproductive tract pathologies of small ruminants from September 2012 to February 2020 at Rio de Janeiro State, Brazil (16 extensive sheep and 10 intensive dairy goat flocks). An ultrasound device (Sonoscape S6 $\AA$, Sonoscape, Yizhe Building, Yuquan Road, Shenzhen, China) coupled to a linear transducer of $7.5 \mathrm{MHz}$ (transrectal) or $5 \mathrm{MHz}$ convex (transabdominal) were used; B-mode and Color Doppler-mode ultrasound tapes were recorded and evaluated by the same operator (MB). The chi-square test was adopted for frequency comparison $(\mathrm{P}<0.05)$. Reproductive disorders were detected in 6.5\% (216/3331) female's and 47.0\% (32/68) male's examinations. In females: hydrometra $(2.5 \%$; 83/3331), aseptic resorption of the embryo/fetus (0.9\%; 29/3331), recent embryonary/fetal death detected by the lack of heartbeat $(0.7 \% ; 23 / 3331)$, cystic endometrial hyperplasia $(0.6 \% ; 19 / 3331)$, follicular cyst $(0.5 \% ; 16 / 3331)$, hydrosalpinx $(0.3 \% ; 9 / 3331)$, luteal cyst $(0.2 \% ; 7 / 3331)$, pyometra $(0.1 \% ; 4 / 3331)$, retained placenta $(0.1 \% ; 4 / 3331)$, septic resorption $(0.09 \% ; 3 / 3331)$, endometritis $(0.06 \% ; 2 / 3331)$, macerated fetus $(0.06 \%$; $2 / 3331)$, visceral cysticercosis $(0.06 \% \% ; 2 / 3331)$ and single cases of ovarian tumor, mummified fetus, cervicitis and upper or infra-cervical abscess $(0.03 \% ; 1 / 3331)$. Ewes had significantly fewer reproductive disorders than does (3.9\%; 65/1647 vs. 8.9\%; 151/1684 $\mathrm{P}<0.05)$. In males: testicular microlithiasis $(33.8 \% ; 23 / 68)$, testicular degeneration $(4.4 \%$; $3 / 68)$, varicocele $(2.9 \% ; 2 / 68)$ and single cases of testicular tumor, hydrocele, cryptorchidism and inguinal hernia $(1.5 \% ; 1 / 68)$. No differences between rams $(43.4 \% ; 23 / 53)$ and bucks $(60.0 \% ; 9 / 15)$ were found. In conclusion, does have significantly more reproductive tract disorders than ewes. Ultrasonography provides clinically useful information relating to diagnosis, prognosis, and therapeutics.

\section{References:}

\footnotetext{
Descôteaux, L.; Gnemmi, G.; Colloton, J. (2010). Practical Atlas of Ruminant and Camelid Reproductive Ultrasonography (United States of America: Wiley-Blackwell), 244p.

Gouletsou, P.G. (2017). Ultrasonographic examination of the scrotal contents in rams. Small Ruminant Research 152, $100-106$. doi: 10.1016/j.smallrumres.2016.12.022

Scott, P. (2016). Practical Use of Ultrasound Scan in Small Ruminant Medicine and Surgery. Veterinary Clinics of North America: Food Animal Practice 32,181- 205. doi: 10.1016/j.cvfa.2015.09.008
} 


$\begin{array}{cc}\begin{array}{c}\text { Animal health: } \\ \text { Reproduction } \\ \text { Oral presentations }\end{array} \\ \text { Genetic Resources } & \text { FARMERS } \\ \text { AND SCIENTISTS } \\ \text { CREATE } \\ \text { FUTURE }\end{array}$

\title{
Chronic Mycotoxicosis in a dairy goat farm in Brazil
}

\author{
Paula Renata Cortat ${ }^{1}$, Felipe Seabra Cardoso Leal ${ }^{1}$, Helena Gomes Ferreira Pinto ${ }^{1}$, Caroline \\ Brito Dos Santos ${ }^{2}$, Mirela Balistrieri Dias ${ }^{1}$, Bruno Ribeiro Vieira ${ }^{1}$, Felipe Zandonadi Brandãoㄹ, \\ Claudia Del Fava ${ }^{2}$, Luiz Antonio Moura Keller ${ }^{1}$ and Mário Felipe Alvarez Balaro ${ }^{1}$ \\ ${ }^{1}$ Fluminense Federal University, Niteroi, RJ, Brazil. \\ ${ }^{2}$ Pathological Anatomy Laboratory, Biological Institute, São Paulo, SP, Brazil
}

Contact: Department of Pathology and Clinical Veterinary, Faculty of Veterinary, Fluminense Federal University, Rua Vital Brasil Filho, 64, zip code: 24320-340, Niteroi, RJ, Brazil, E-mail address: mariobalaro@id.uff.br (MFA Balaro)

\section{Abstract:}

Mycotoxicosis is a disease caused by distinct mycotoxins. This study aimed to describe a case of chronic mycotoxicosis in a dairy goat flock kept under an intensive system in Minas Gerais, Brazil. Lactating goats presented history of drop in milk production and weight loss in the past six months with abortion and premature births. Twelve goats showed thinness (BCS $=2$ ), pale mucous membranes and mild dehydration at clinical examination. Blood samples and feces were collected for the whole blood count, biochemistry and coproparasitological exam. Due to the poor quality of cornmeal, samples were collected for mycotoxicological analysis. Goats showed mild anemia $(\mathrm{Hb} \sim 22 \%)$, platelet aggregate, thrombocytosis $(\sim 1.2 \times 105 / \mu \mathrm{L})$, reversal of the neutrophil/lymphocyte ratio $(\sim 1.2)$, hyperproteinemia $(\sim 7.5 \mathrm{~g} / \mathrm{dL})$ with hypoalbuminemia $(\sim 2.7 \mathrm{~g} / \mathrm{dL})$ and hyperglobulinemia $(\sim 4.8 \mathrm{~g} / \mathrm{dL})$. The average egg per gram of feces count was low ( $\sim 625$ e.p.g.). Hemoparasites were not detected. In cornmeal samples were detected average of $354.5 \mu \mathrm{g} / \mathrm{Kg}$ Aflatoxins (AFs), $2300 \mu \mathrm{g} / \mathrm{Kg}$ Fumonisins (FUMO), 2165 $\mu \mathrm{g} / \mathrm{Kg}$ zearalenone (ZEA) and $3325 \mu \mathrm{g} / \mathrm{Kg}$ Deoxynivalenol (DON). From an euthanized goat, it was found anemia, generalized anasarca, severe ascites, and decreased liver size in the necropsy exam. Histopathological report revealed lobular center degeneration and liver necrosis with nephrosis and cerebral cortical spongiosis discreet. Microscopic lesions were suggestive of fumonisin action. In conclusion, the chronic mycotoxicosis diagnosis was based in clinical, pathological, and toxicological findings. Therefore, the importance of purchase ingredients from reputable suppliers with quality assurance for the feed formulation is emphasized to avoid mycotoxicosis and other disorders.

\section{References:}

Gallo, A., Giuberti, G., Frisvad, J., Bertuzzi, T., \& Nielsen, K. (2015). Review on Mycotoxin Issues in Ruminants: Occurrence in Forages, Effects of Mycotoxin Ingestion on Health Status and Animal Performance and Practical Strategies to Counteract Their Negative Effects. Toxins 7(8), 3057-3111. doi:10.3390/toxins7083057.

Gutleb, A. C., Caloni, F., Giraud, F., Cortinovis, C., Pizzo, F., Hoffmann, L., Bohn, T., Pasquali, M. (2015). Detection of multiple mycotoxin occurrences in soy animal feed by traditional mycological identification combined with molecular species identification. Toxicology Reports 2, 275-279.doi:10.1016/j.toxrep.2015.01.006

Völkel, I, Merker E. S., Czerny, C. (2011). The Carry-Over of Mycotoxins in Products of Animal Origin with Special Regard to Its Implications for the European Food Safety Legislation. Food and Nutrition Sciences. 02. 852-867. doi:10.4236/fns.2011.28117 


\title{
Outbreak of abomasal bloat in kid goats due to Clostridium ventriculi and Clostridium perfringens type A
}

\author{
Fernanda Martins Gonçalves ${ }^{1}$, Felipe Seabra Cardoso Leal ${ }^{1}$, Isabel Oliveira Cosentino ${ }^{1}$, Júlia \\ Alves Vignoli ${ }^{1}$, Nathalia Xavier da Silva ${ }^{1}$, Alessandra Figueiredo de Castro Nassar ${ }^{2}$, Simone \\ Miyashiro $^{2}$, Nathalie Costa da Cunha ${ }^{1}$, Claudia Del Fava ${ }^{3}$ and Mario Felipe Alvarez Balaro ${ }^{1}$ \\ ${ }^{1}$ Fluminense Federal University, Niteroi, RJ, Brazil \\ ${ }^{2}$ General Bacteriology Laboratory, Biological Institute, São Paulo, SP, Brazil \\ ${ }^{3}$ Pathological Anatomy Laboratory, Biological Institute, São Paulo, SP, Brazil \\ Contact: Department of Pathology and Clinical Veterinary, Faculty of Veterinary, Fluminense Federal \\ University, Rua Vital Brasil Filho, 64, zip code: 24320-340, Niteroi, RJ, Brazil, E-mail address: \\ mariobalaro@id.uff.br (MFA Balaro)
}

\section{Abstract:}

This study aimed to describe an outbreak of abomasal bloat in kid goats and its clinical, pathological, microbiological, molecular, and epidemiological characteristics. The kidding season presented an increased mortality of kid goats with a history of abdominal bloating, dullness, and death. Clinical examinations were carried out, and biological samples from necropsied kids $(n=11)$ were collected for pathological, microbiological, and molecular diagnosis. Likewise, an epidemiological survey was carried out to verify possible associated factors related to the disorder. The main necropsy findings were dehydration, pale mucosa, ascites, abomasal and intestinal meteorism and congestion, emphysematous abomasitis, and consolidation of lung's cranial areas. Through staining techniques for cytological evaluations of the abomasum, it was possible to identify Gram positive bacteria, coccoid, with a cuboid shape suggestive of Clostridium ventriculi, Gram positive bacilli suggestive of Clostridium perfringens and ovoid basophilic yeasts compatible with Saccharomyces cerevisiae. By anaerobic culture and molecular tests, $C$. ventriculi and $C$. perfringens type A were confirmed. The main histopathological findings were cholangiohepatitis, nephrosis, emphysematous abomasitis, hyalinization of the gastric and intestinal walls, gastroenteritis, intestinal thromboembolism, pulmonary edema, and non-purulent pneumonia, overall suggesting a systemic enterotoxaemia picture. There was a final mortality rate of $24.4 \%$ (20/82). Regarding the possible associated factors, the erroneous use of the milk replacer associated with inadequate kid management was verified. Among the prophylactic measures, hygiene care, proper use of milk replacer, vaccination plan containing $C$. perfringens alpha toxoid associated with a good colostrum management were suggested.

\section{References:}

Burgstaller, J.; Wittek, T.; Smith, G.W. (2017). Invited review: Abomasal emptying in calves and its potential influence on gastrointestinal disease. Journal of Dairy Science 100, 17-35. https://doi.org/10.3168/jds.2016-10949.

DeBey, B.M.; Blanchard, P.C.; Durfee, P.T. (1996). Abomasal bloat associated with Sarcina-like bacteria in goat kids. Journal of the American Veterinary Medical Association 209, 1468-1469.

Vatn, S.; Tranulis, M.A.; Hofshagen, M. (2000). Sarcina-like bacteria, Clostridium fallax and Clostridium sordellii in lambs with abomasal bloat, haemorrhage and ulcers. Journal of comparative pathology 122, 193-200. 


Animal health:
Genetic Resources
Poster presentations

\title{
Teaching vet students on sheep and goat farming: Brazilian experience
}

\author{
Mário Balaro, Lucas Barbosa, Fernanda Gonçalves, Ana Beatriz Carvalho, Marta Maria da \\ Costa, Bruno Vieira, Bruna Figueiredo, Mirella Dias, Paula Cortat de Souza and Felipe \\ Brandão
}

Fluminense Federal University, Niterói, RJ, Brazil

Contact: Department of Pathology and Clinical Veterinary, Faculty of Veterinary, Fluminense Federal University, Rua Vital Brasil Filho, 64, zip code: 24320-340, Niteroi, RJ, Brazil, E-mail address: mariobalaro@id.uff.br (MFA Balaro)

\section{Abstract:}

The Group of Study, Research and Extension in Goats and Sheep (GEPECO) aims to provide training for vet students in sheep and goat farming and to boost the consolidation and profitability of the small ruminant sector in Brazil. To reach such goals, the GEPECO is composed by undergraduate and postgraduate vet students, coordinated by lectures from the Veterinary School of the Universidade Federal Fluminense. Students develop initial skills in the sheep and goat unit of the Farm School and later they practice their learning along the extension actions in private farms assisted by the group. Throughout the semester, GEPECO holds meetings at the Farm School and, at each one, a new subject is presented to vet students. During this period of time, they are taught and debate about learned techniques. In each semester, the subjects are (1) facilities, ambience and animal welfare; (2) sustainable parasite management and vaccination protocols; (3) nutrition and pasture management; (4) reproductive management; (5) animal health and main surgical procedures; (6) data control and animal improvement; and (7) breeding and profitability. Prior to visiting a private farm, the group discusses about the procedures to be performed. All visits are guided by a postgraduate vet student or lecture that deals with the farmer and performs the activities with all students involved. In conclusion, the GEPECO join forces in skills development and professional insertion for future vet practitioners in sheep and goat farming and promoting profitability to farmers, as well as keeping people in rural zones.

\section{References:}

Bachynsky, E.A, DAle, V.H.M., Kinnison, T., GAzzard, J., Baillie, S. A. (2013). Survey of the opinions of recent veterinary graduates and employers regarding early career business skills. Veterinary Record 172, 604. doi: 10.1136/vr.101376. Collins, H. (1998). Veterinary education and role-based learning. Synerg.

Pollott G.; Wilson, R.T. (2009). Sheep and goats for diverse products and profits. Rome: Food and Agriculture Organization of United Nations - FAO Diversification booklet n. 9, 42p. 


\section{Computed tomography and magnetic resonance imaging in the diagnosis and follow-up of chronic Coenurosis in sheep (with spontaneous remission of clinical signs)}

Pérez, M. ${ }^{1}$, Climent, M. $^{2}$, De Miguel, R. ${ }^{1}$, Ortíz, M.T. ${ }^{1}$, Magdalena, A. ${ }^{1}$, Castells, E. ${ }^{3}$, Escudero, A. $^{1}$ and Ferrer, L.M. ${ }^{1}$

${ }^{1}$ Animal Pathology Department, Instituto Agroalimentario de Aragón-IA2 (Universidad de ZaragozaCITA), Veterinary Faculty of Zaragoza, C/Miguel Servet 177, 50013 Zaragoza, Spain

${ }^{2}$ Anatomy, Embryology and Animal Genetics Department, Veterinary Faculty of Zaragoza, C/Miguel Servet 177, 50013 Zaragoza, Spain

${ }^{3}$ Centro Clínico Veterinario, C/ Madre Genoveva Torres Morales, 8, 50006 Zaragoza, Spain

Contact: mariaperezb3@hotmail.com

\section{Abstract:}

Coenurosis is a condition caused by Coenurus cerebralis, the larval stage of Taenia multiceps, and causes enormous economic losses in husbandry production. C. cerebralis develops in the central nervous system of sheep and usually have an acute and chronic form of the disease, being the former caused by larval migration and the later by intracranial parasitic cyst development.

Five adult young sheep presenting neurological clinical signs were referred to the Clinical Ruminant Service of the University of Zaragoza. A clinical examination revealed circling, frequent bleating, separation from the flock and visual impairment. Computed tomography (CT) scan evinced the presence of intracranial single fluid-filled cystic structures. Diagnosis of chronic coenurosis was stablished and confirmed at the postmortem evaluation.

One of the referred animals, being pregnant, was hospitalized until she raised the lamb. Surprisingly, the symptoms remitted spontaneously in the absence of any specific treatment. CT demonstrated a marked retraction and increased consistency of the parasitic cyst. Additionally, magnetic resonance imaging (MRI) was carried out in order to study the type of tissue that had replaced the cyst fluid and revealed a pericystic infiltration of encephalic tissue, characterized by histopathology as fibroblastic tissue with a diffuse lymphoplasmacytic infiltrate.

CT and MRI allow proper localisation and measurements of the larval cyst as well as nondeniable information on the damage of adjacent nervous structures, which can be really useful in the development of new therapeutical approaches for this and other intracranial conditions of sheep.

\section{References:}

Gonzalo-Orden, J.M., Díez, A., Altónaga, J.R., Gonzalo, J.M., Orden, M. A.,2005. Computed tomographic findings in ovine coenurosis. Veterinary Radiology \& Ultrasound. 40, 441-444. Doi: 10.1111/j.1740-8261.1999.tb00372.x

Sanna, E., Careddu, G. M., Manunta, M. L., Masala, G., Columbano, N., Muzzetto, P., Muzzeto, P., 2007. Cerebral Cenurosis in Sheep: An Even Present Pathology. Veterinary Research Communications. 31, 331-333. Doi: 10.1007/s11259-007-0106-4

Tena, A., De Miguel, R., Castells, E., Escudero, A., Lacasta, D., 2020. Chronic coenurosis in sheep: spontaneous remission of clinical signs and role of CT and MRI in the diagnosis and follow-up. Veterinary Record Case Reports. 8:e001092, 1-3. Doi: 10.1136/vetreccr-2020-001092 
Animal health:

\title{
Vitamin E in the diet of lactating goats: bioavailability and influence on the passive immunity of kids
}

\author{
Mercedes Roncero-Díaz ${ }^{1}$, Begoña Panea ${ }^{2}$, María de Guía Córdoba ${ }^{3}$, Anastasio Argüello ${ }^{4}$ and \\ María J. Alcalde ${ }^{1}$ \\ ${ }^{1}$ University de Sevilla, Seville, Spain \\ ${ }^{2}$ Centro de Investigación y Tecnología Agroalimentaria de Aragón (CITA), Instituto Agroalimentario de \\ Aragón - IA2 (CITA-Universidad de Zaragoza), Zaragoza, Spain \\ ${ }^{3}$ University of Extremadura, Badajoz, Spain \\ ${ }^{4}$ University of Las Palmas de Gran Canaria, Las Palmas (Canarias), Spain
}

Contact: Maria J. Alcalde: Department of Agricultural and Forestry Science, University de Seville, Ctra, Utrera km. 1, 41013 Seville, Spain, email: aldea@us.es

\section{Abstract:}

A total of 30 male single-birth kids from the Payoya breed were used. During the trial, kids were only fed natural milk without any dietetic complement and remained stabled. Two batches of fifteen animals each were established according to the feeding systems of their dams: cultivated meadow (CM) and total mixed ration (TMR). The immunoregulatory potential of the different forms of vitamin $\mathrm{E}$ (natural/synthetic) provided to the kid through maternal diets (CM and TMR, respectively) was evaluated during lactation. Then, $\alpha$-tocopherol was quantified in the plasma of goats and their kids using high-performance liquid chromatography (HPLC). Additionally, the kidney fat of the kids was weighed. Correlation analysis and ANOVA with maternal diet as the principal effect were performed using the SPSS statistical package.

The health of a new-born is influenced by its nutritional level and hence influences visceral fat (Gall 1982). Therefore, kidney fat can be a good indicator of a kid's health and immunity. Colostrum and milk provide vitamin $\mathrm{E}$ that stimulates the immune system and is essential for the health of the new-born (Przybylska et al. 2007).

Positive correlations are noted between the plasma concentrations of $\alpha$-tocopherol in goats and their kids and between the plasma $\alpha$-tocopherol in kids and the weight of kidney fat $(r=0.606$, $\mathrm{p}<0.001 ; \mathrm{r}=0.335, \mathrm{p}=0.013$, respectively).

The increased bioavailability of natural vitamin E (Debier et al., 2005) from the diet of CM goats influences the health status of their kids [more kidney fat $(\mathrm{p}<0.001)$, and compared with TMR kids, results in a higher plasma tocopherol concentration $(\mathrm{p}<0.001)]$.

\section{References:}

Debier C.; Larondelle Y. (2005). Vitamins A and E: metabolism, roles and transfer to offspring. British Journal of Nutrition, 93 (2): 153-174.

Gall, CF (1982). Carcass composition. In Third International Conference on Goat Production and Disease. Dairy Goat Journal Publication Pgs. 472-487.

Przybylska, J, Albera, E and Kankofer, M (2007). Antioxidants in bovine colostrum. Reproduction in Domestic Animals 42, pgs 402-409. 


\title{
Use of thermography for the diagnosis of chronic proliferative rhinitis in sheep and its application in the differential diagnosis of the first case affecting the dorsal and medial turbinate
}

\author{
Ceresuela, C. ${ }^{1}$, López-Tamayo, S. ${ }^{1}$, Bueso, J.P. ${ }^{2}$, Alzuguren, O. $^{3}$, Rodríguez, A. ${ }^{1}$, Figueras, L ${ }^{4}$ \\ and Ferrer, L.M ${ }^{1}$ \\ ${ }^{1}$ Animal Pathology Department, Instituto Agroalimentario de Aragón-IA2 (Universidad de Zaragoza- \\ CITA), Veterinary Faculty of Zaragoza, C/Miguel Servet 177. 50013 Zaragoza, Spain \\ ${ }^{2}$ Laboratorio Agroambiental de Aragón, Montañana, Zaragoza, Spain \\ ${ }^{3}$ Laboratorios Exopol Diagnóstico y Atovacunas S.L., Polígono de San Mateo de Gállego, Zaragoza, Spain \\ ${ }^{4}$ Gabinete Técnico Veterinario S.L., C/ Isla Conejera s/n, Zaragoza, Spain \\ Contact: vet.ceresuela@gmail.com
}

\begin{abstract}
:
Chronic proliferative rhinitis (CPR) is an upper respiratory tract disease of sheep associated with Salmonella enterica subsp. diarizonae serotype 61:k:1:5:(7). It affects the ventral nasal turbinate and sometimes the proliferative tissue can be seen emerging from the nostril.

In the following case, the animal affected was an ewe with a severely bilateral inflammatory process of the upper respiratory tract. The thermal imaging camera revealed an increase in the temperature of both nasal cavities and the hottest area in the middle part of the nose, which corresponded with the area of the swollen dorsal turbinate. The medial localization of the affection, exhibited by thermography, directed the diagnosis towards CPR and Enzootic Nasal Adenocarcinoma (a tumoral disease which affects the ethmoidal area).

The post-mortem examination confirmed the CPR diagnosis and revealed inflammation of the ventral nasal turbinates, and, for the first time, of the dorsal and medial ones of both nasal cavities, coinciding with the images obtained by thermography.

To date, in all the descriptions made of CPR the ventral turbinate was always affected and only minor changes were observed in dorsal turbinate or ethmoidal area. The affection of the dorsal and medial turbinates here described shows how this bacterium could deepen and damage more internal structures of the respiratory tract. This was easily observed by thermography, which helped to locate the affection and facilitated the diagnosis, proving to be a useful resource for clinical diagnosis of upper respiratory tract diseases of sheep.
\end{abstract}

\section{References:}

López-Tamayo, S., Rubira, I., De las Heras, M., Castells, E., Lacasta, D. (2020) Use of thermography for the diagnosis of chronic proliferative rhinitis in sheep and its application in the differential diagnosis of the first case affecting the dorsal turbinate. Veterinary Record Case Reports 8: e001070. doi: 10.1136/vetreccr-2020-001070

Lacasta, D., et al. (2012). Chronic Proliferative Rhinitis associated with Salmonella enterica subspecies diarizonae serovar 61:k:1,5, (7) in Sheep in Spain. Elsevier Vol. 147, 406-409. doi: 10.1016/j.jepa.2012.03.004.

Lacasta, D., et al. (2017). Experimental infection with Salmonella enterica subsp. diarizonae serotype 61:k:1,5,(7) in sheep: Study of cell mediated immune response. Small Ruminant Research 149 (28-33). doi: 0.1016/j.smallrumres.2017.01.011. 


Animal health:
Genetic Resources
Poster presentations

\title{
Valvular endocarditis in small ruminants: case reports
}

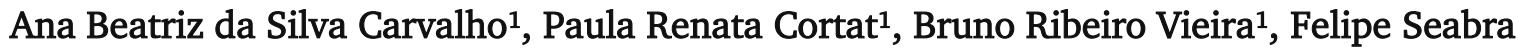 \\ Cardoso Leal ${ }^{1}$, Isabel Oliveira Cosentino ${ }^{1}$, Caroline Brito Dos Santos ${ }^{2}$, Fernanda Martins \\ Gonçalves $^{1}$, Mirela Balistrieri Dias ${ }^{1}$, Claudia Del Fava ${ }^{2}$ and Mário Felipe Alvarez Balaro ${ }^{1}$ \\ ${ }^{1}$ Fluminense Federal University, Niteroi, RJ, Brazil \\ ${ }^{2}$ Pathological Anatomy Laboratory, Biological Institute, São Paulo, SP, Brazil \\ Contact: Department of Pathology and Clinical Veterinary, Faculty of Veterinary, Fluminense Federal \\ University, Rua Vital Brasil Filho, 64, zip code: 24320-340, Niteroi, RJ, Brazil, E-mail address: \\ mariobalaro@id.uff.br (MFA Balaro)
}

\section{Abstract:}

Endocarditis is the inflammation of the endocardium, which might be located on the heart wall and/or on the valve. This study aimed to describe two cases of valvular endocarditis in small ruminants located in Rio de Janeiro, Brazil. The first case occurred in a Saanen lactating goat (five-years-old), kept under intensive system. At the ultrasound scan for pregnancy diagnosis, a large amount of free anechoic fluid was found. The animal underwent a daily treatment with furosemide $(2.5 \mathrm{mg} / \mathrm{kg})$ but died two weeks later due to an acute respiratory distress. Postmortem examination revealed yellowish friable masses adhered to leaflets that compound the tricuspid valve, as well as intense ascites, hepatomegaly, congestion and pulmonary edema. Histopathological report revealed in the mass adhered to the valve, there was a focus of neutrophilic infiltration and Splendore-Hoeppli phenomenon, compatible with bacterial and mycotic valvular endocarditis. The second case occurred in a crossbred hair sheep (three-yearsold) kept under semi-intensive system that died under suspicion of previous fight and cervical trauma. At necropsy, a friable mass was found in the tricuspid, diffuse whitish lesions on the epicardium and myocardium (suggestive of infarction), pale ocular conjunctiva, great amount of Haemonchus sp. within the abomasum, enlarged lung with diffuse congestion and whitish multifocal lesions on kidneys. In both cases, endocarditis may have been secondary to chronic bacteremia, such as pneumonia, subacute ruminal acidosis (SARA), periodontitis and others. Therefore, the diagnosis of valvular endocarditis is important to relate to other primary causes that can affect flock productivity and establish prophylactic measures.

\section{References:}

Buczinski, S., Tsuka, T., Tharwat, M. (2012). The diagnostic criteria used in bovine bacterial endocarditis: a meta-analysis of 460 published cases from 1973 to 2011. Veterinary Journal, 193, 349-357. doi: 10.1016/j.tvjl.2012.02.012

Radostitis, O.M., Gay, C.C., Hinchcliff, K.W., Constable, P.D. (2016). Veterinary Medicine - A Textbook of the Diseases of Cattle, Horses, Sheep, Pigs and Goats. (London: Saunders Ltd.). 2278 p. 


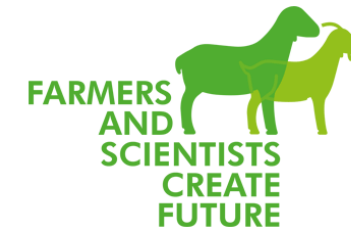

\title{
Malignant neoplasms in sheep and goats in Sicily
}

\author{
Sebastian Alessandro Mignacca ${ }^{1}$, Sandro Bevacqua ${ }^{2}$, Flavia Stassi ${ }^{2}$, Benedetta Amato $^{3}$, \\ Colombino Elena ${ }^{4}$, Vincenzo Di Marco Lo Presti ${ }^{3}$ and Maria Teresa Capucchio ${ }^{4}$ \\ ${ }^{1}$ Veterinary practitioner, Enna, Italy \\ ${ }^{2}$ Veterinary practitioner, Palermo, Italy \\ ${ }^{3}$ Istituto Zooprofilattico Sperimentale della Sicilia "A.Mirri", Barcellona P.G., Italy \\ ${ }^{4}$ Department of Veterinary Sciences, University of Torino, Turin, Italy \\ Contact: Via GB Giuliano, Catenanuova (Enna) 94010, Italy, sebastian.mignacca80@gmail.com
}

\section{Abstract:}

Tumors in small ruminants are generally rare, even if their incidence is quite different in the literature. Viruses (Papillomavirus and Jaagsiekte Sheep Retrovirus), chemical and physical agents are considered potential etiological agents. The authors reported the tumors observed during their diagnostic activity in Sicily (Italy) from January 2009 to May 2020.

Neoplasms were collected at the slaughterhouse, during necropsies or surgeries from adult animals of both sexes mainly belonged to local breeds. Gross and histological investigations were performed.

A total of 226 malignant neoplasms were detected (sheep: 159; goats: 67). Particularly, in sheep 122 squamous cell carcinomas (SCC), 27 ovine pulmonary carcinomas (OPA), 4 intestinal adenocarcinomas, 2 lymphomas, 1 melanoma, 1 mesothelioma, 1 cholangiocarcinoma and 1 anaplastic carcinoma were observed. In goats 59 SCC, 6 melanomas, and 2 sarcomas were reported.

SCC were most frequently reported followed by OPA. The high incidence of SCC permits to hypothesize that Papillomavirus could play a role in the carcinogenesis. However, its role remains to be clarified as its presence is inconstant. In authors' opinion small ruminants tumours are underestimated and an increased surveillance is recommended because these species could represent interesting animal models in comparative medicine and valid environmental bio-indicators.

\section{References:}

Mignacca S.A., Zoccola R., Monnier M., Costa M., Colombino E., Goria M., Capucchio M.T. (2018) Papillomavirus (OAPV3) in tumori cutanei ovini in Sicilia: Lesioni anatomo-patologiche e indagine biomolecolare. In Proceedings of XVIII National Congress S.I.Di.L.V., Perugia (Italy). 115-116

Mignacca S.A., Biasibetti E., Spuria L., Amato B., Di Marco Lo Presti V., and Capucchio M.T. (2016). Cutaneous tumors in small ruminants: UV ray exposure and Papillomavirus infection as potential risk factors. In Proceedings of IX World Cancer Congress, Shanghai (China). 366

Mignacca S.A., Capucchio M.T, Biasibetti E., Guarneri G., Milone S., Marchisotta A., Amato B., and Di Marco Lo Presti V. (2015). Three cases of melanoma in small ruminants: clinical symptoms and pathological results. Small Rumin Res. 126, 25-27 
Animal health:

\title{
Efficacy of a stabulogen vaccine for Streptococcus dysgalactiae-induced dermatitis in sheep
}

\author{
Sebastian Alessandro Mignacca ${ }^{1}$, Lorella Ciccarello ${ }^{2}$, Salvatore Di Bella ${ }^{2}$, Vincenzo Di Marco \\ Lo Presti ${ }^{3}$ and Gavino Marogna ${ }^{4}$ \\ ${ }^{1}$ Veterinary practitioner, Enna, Italy \\ ${ }^{2}$ Azienda Sanitaria Provinciale Palermo, Italy \\ ${ }^{3}$ Istituto Zooprofilattico Sperimentale della Sicilia “A.Mirri”, Barcellona P.G., Italy \\ ${ }^{4}$ Istituto Zooprofilattico Sperimentale della Sardegna "G. Pegreffi", Sassari, Italy \\ Contact: Via GB Giuliano, Catenanuova (Enna) 94010, Italy, sebastian.mignacca80@gmail.com
}

\section{Abstract:}

Streptococcus dysgalactiae has been reported to be the cause of several infections in farm animals, fishes and humans. In small ruminants, it has been associated with bacteremia, meningoencephalitis, mastitis, omphalophlebitis, polyarthritis and dermatitis. $S$. dysgalactiae has also been isolated from reproductive tract discharges and tonsils of healthy ruminants.

The authors described outbreaks of dermatitis in sheep by $S$. dysgalactiae and its treatment with a stabulogen vaccine in flocks in Sicily (Italy).

Outbreaks occur during winter season, a couple of weeks after a new purchase of ewes, in $10 \%$ of animals of 4 semi-extensively flocks (1300 adults in total) reared in the same pastures. The animals showed hemorrhagic-necrotic dermatitis to the udder, limbs and head. Swabs from lesions were collected and submitted for conventional bacteriological and virological tests. Samples tested positive only for $S$. dysgalactiae. A stabulogen inactivated vaccine was set up following the national guidelines. In particular, colonies were inactivated with formaldehyde, and aluminum hydroxide was used as adjuvant. It was calculated that the suspension contained around $109 \mathrm{UFC} / \mathrm{ml}$ of $S$. dysgalactiae.

Sheep were subcutaneously inoculated with $2 \mathrm{ml}$ of vaccine, without showing adverse effects after administration, and treatments were repeated after 1, 6, 12, 18 and 24 months. Ameliorative effects had already been registrated in over $40 \%$ of the affected animals after the first inoculation, and complete recovery in the third year was observed.

Authors want to point out that the use of stabulogen vaccine represents a valid, quick and safe procedure for many diseases in farm animals. In the meantime, its use is authorized in symptomatic animals decreasing the use of antibiotics.

\section{References:}

Abdelsalam M., Asheg A., Eissa A.E. (2013) Streptococcus dysgalactiae: An emerging pathogen of fishes and mammals. International Journal of Veterinary Science and Medicine, 1, 1-6.

Agnello S., Stancanelli A., Amato B., Campo F., Di Marco Lo Presti V., Mignacca S.A. (2016) Artrite da Streptococcus dysgalactiae in capretti in Sicilia: descrizione di un focolaio. In Proceedings of XXII National Congress S.I.P.A.O.C., Cuneo (Italy). 132.

Lacasta D., Ferrer L.M., Ramos J.J., Loste A., Bueso J.P. (2008) Digestive pathway of infection in Streptococcus dysgalactiae polyarthritis in lambs. Small. Rum. Res., 78, 202-205. 


\title{
Study of the use of bronchoalveolar lavage as an in vivo diagnostic method to detect clinical pulmonary Maedi Visna
}

\author{
Magdalena, A. ${ }^{1}$, Menjón, A. ${ }^{1}$, de las Heras, M. ${ }^{1}$, Borobia, M. ${ }^{1}$, Arnal, JL. ${ }^{2}$, Elorza, J. ${ }^{1}$ and \\ Lacasta, D. ${ }^{1}$ \\ ${ }^{1}$ Animal Pathology Department, Instituto Agroalimentario de Aragón-IA2 (Universidad de Zaragoza- \\ CITA), Veterinary Faculty of Zaragoza, Zaragoza, Spain \\ ${ }^{2}$ Exopol diagnóstico y autovacunas, S.L. Polígono San Mateo de Gállego, Zaragoza, Spain
}

Contact: albimag@yahoo.es

\section{Abstract:}

Maedi-Visna virus (MVV) is a lentivirus that infects sheep causing a multi-systemic and slow progressive syndrome, inducing a chronic inflammation of the lung, mammary gland, central nervous system and joints. It causes relevant economic losses worldwide, and due to the lack of vaccines and treatments, a suitable diagnosis is decisive to develop control programs.

The main objective of this study was to evaluate the usefulness of the molecular study of bronchoalveolar lavages using PCR techniques to improve the in vivo diagnosis of the pulmonary form of MVV. In order to investigate the efficacy of this diagnostic method, the MV compatible lung lesions found after the necropsy of the studied animals were analyzed, and lung tissue samples were also collected to perform a molecular diagnosis of the MVV.

One hundred and fifty-five culled sheep were analyzed at the Ruminant Clinic Service of the University of Zaragoza, Spain. At necropsies, 19 of the lungs presented compatible MV lesions $(12.25 \%)$. The lesions associated with the disease were lung enlargement, general greyish discolouration, increased size of mediastinal lymph nodes and grey subpleural dots.

Regarding bronchoalveolar lavages, 15 of the 19 lungs with MV compatible lesions (78.94\%) were MVV-positive by PCR. Therefore, this technique is revealed as a suitable, little invasive and innovative in vivo diagnostic method of MV, with a positive predictive value of $82.40 \%$ and a negative predictive value of $96.00 \%$, both related to the presence of macroscopic lesions.

\section{References:}

Blacklaws, B. A., 2012. Small ruminant lentiviruses: immunopathogenesis of visna-maedi and caprine arthritis and encephalitis virus. Comparative immunology, microbiology and infectious diseases, 35(3), 259-269. DOI: 10.1016/j.cimid.2011.12.003.

Herrmann-Hoesing, L. M. (2010). Diagnostic assays used to control small ruminant lentiviruses. Journal of veterinary diagnostic investigation, 22(6), 843-855. DOI: 10.1177/104063871002200602.

Luján, L., Pérez, M., de Andrés, D., and Reina, R. (2019). Pulmonary lentivirus infection in sheep. Small Ruminant Research, 181, 87-90. DOI: 10.1016/j.smallrumres.2019.05.006. 


Animal health:
Genetic Resources
Poster presentations

\title{
Abdominal perforation in ewes due to fetal maceration
}

\author{
Sebastian Alessandro Mignacca ${ }^{1}$, Benedetta Amato $^{2}$, Vincenzo Di Marco Lo Presti ${ }^{2}$, Gaetano \\ Guarneri $^{3}$ and Maria Costa ${ }^{1}$ \\ ${ }^{1}$ Veterinary practitioner, Enna, Italy \\ ${ }^{2}$ Istituto Zooprofilattico Sperimentale della Sicilia “A.Mirri”, Barcellona P.G., Italy \\ ${ }^{3}$ Azienda Sanitaria Provinciale, Palermo, Italy \\ Contact: Via GB Giuliano, Catenanuova (Enna) 94010, Italy, sebastian.mignacca80@gmail.com
}

\section{Abstract:}

Fetus retention is considered a complication of pregnancy and has been described both in domestic animals and in human. Mummification and maceration of the fetus are the two typical conditions of this pathology which can lead to death of the dam. When the mother remains alive for a longer period, the macerated fetal bones can perforate the uterus generating also peritonitis and fistulas with other organs.

The authors describe the clinical symptoms and pathological findings in two ewes with fetal retention that caused uterine fistula with perforation of the abdominal wall.

Both animals were cross-bread and were reared in two different small farms. Ewes were judged pregnant by owners and had a pregnancy extension of several months without showing any apparent previous signs of dystocia. They appeared in good general condition but with progressive weight loss. The bottom part of the abdomen was swollen and with some small holes that let out necrotic fragments of macerated fetus. No vaginal discharges were observed and palpation confirmed the presence of a hard and cold mass in the abdomen. Due to the poor prognosis, ewes were culled. Fistulous channels from the uterus were opened to the outside, perimetrium adhered to the surrounding organs through extended fibrous connections, and severe chronic endometritis with two retained macerated fetuses were observed in each sheep. This paper increases the clinical records in this species, and the authors add that Veterinary Practitioners should take into account that these conditions, although exceptional, can occur.

\section{References:}

Drost M. (2007) Complication during gestation in the cow. Theriogenology. 68, 487-491.

Lefebvre R.C. (2015) Fetal mummification in the major domestic species: current perspectives on causes and management. Veterinary Medicine: Research and Reports. 6 233-244. 


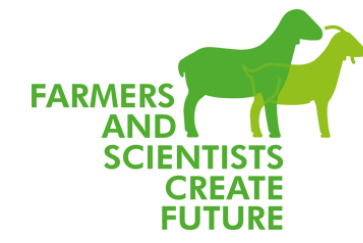

\title{
Ozonized oil can be used for topical treatment of sheep affected by Contagious Ecthyma
}

\author{
Helena Gomes Ferreira Pinto몬 Lucas De Figueiredo Cardoso Barbosa ${ }^{1}$, Mariana Santos \\ Ribeiro ${ }^{1}$, Bruna Ramalho Rigaud de Figueiredo ${ }^{1}$, Marta Maria Campos Pereira da Costa ${ }^{1}$, \\ Caroline Brito Dos Santos ${ }^{2}$, Claudia Del Fava ${ }^{2}$ and Mário Felipe Alvarez Balaro ${ }^{1}$ \\ ${ }^{1}$ Fluminense Federal University, Niteroi, RJ, Brazil \\ ${ }^{2}$ Biological Institute, São Paulo, SP, Brazil \\ Contact:Department of Pathology and Clinical Veterinary, Faculty of Veterinary, Fluminense Federal \\ University, Rua Vital Brasil Filho, 64, zip code: 24320-340, Niteroi, RJ, Brazil, E-mail address: \\ mariobalaro@id.uff.br (MFA Balaro)
}

\section{Abstract:}

Sunflower oil is ozonized directly by the flow of the gas (ozone), which reacts with the linoleic acid present forming hydrogen peroxide (antimicrobial, anti-inflammatory). Thus, the objective of the study was to test ozonized oil in cases of Contagious Ecthyma, in sheep located in Brazil's farm. A total of four adults Santa Ines ewes ( $2.9 \pm 0.5$ years old, BCS: $3.0 \pm 0.2$ ) with similar pattern of lesion were organized in two groups to compare different topical treatments: G1 treated with 1\% iodine, and G2 treated with ozonated sunflower oil, daily, for 2 consecutive weeks. From each ewe, skin biopsies were collected for histopathology evaluation and bacteriological and fungal culture, before, during and after treatments. First cultures performed showed the presence of opportunist infection by Candida sp., Staphylococcus coagulase negative and Yersinia sp., not shown in other collections. In the first biopsy, all tissues had ulcers and inflammation. In the second biopsy, both groups presented half of animals with complete tissue re-epithelialization and the other half in an intermediate process. In the third biopsy, all animals had tissues totally re-epithelialized. In the clinical analysis, the G1 still had crusts after one week of treatment, differently from G2, which no longer formed crusts at this moment. It can be concluded that both treatments were effective for the treatment. Nevertheless, ozonized oil facilitated the employee's work by the lower formation of crusts over the healing period, as well as avoiding tissue dryness (different from iodine), with greater safety for ocular and oral regions.

\section{References:}

Jandui E.; Nóbrega Jr.; et al. (2008). Contagious ecthyma in sheep and goats in the semiarid of Paraiba, Brazil. Pesquisa Veterinária Brasileira 28, 135-139.

Salles, M.W.S.; et al. (1992). Contagiousecthyma (PustularDermatitis) ofsheep. Ciência Rural 22, 319-324.

Travagli, V.; Zanardi, I.; Valacchi, G.; Bocci, V. (2010). Ozone and ozonated oils in skin diseases: a review. Mediators of inflammation. https://doi.org/10.1155/2010/610418 


\title{
Structures of and prospects for sheep and goat farming, sustainability \\ Oral presentations
}

\section{Sustainability assessment of sheep and goat production systems in peri- urban areas of southern Benin (West Africa)}

\author{
$\underline{\text { Bossima Ivan Koura }}^{1}$, Esteban Henoc Medenou $^{2}$, Fifame Panine Yassegoungbe ${ }^{2}$, Ulriche Cossi \\ Afatondji $^{2}$ and Luc Hippolyte Dossa ${ }^{2}$ \\ ${ }^{1}$ School of Animal Production, National University of Agriculture, Porto-Novo, Benin \\ ${ }^{2}$ Faculty of Agricultural Science, University of Abomey-Calavi, Abomey-Calavi, Benin \\ Contact: School of Animal Production, National University of Agriculture, BP 43 Ketou, Benin, e-mail: \\ kouraivan@gmail.com
}

\section{Abstract:}

A study was carried out in southern Benin with the aims to understand sheep and goat farmers' resilience strategies face to climate change and urbanization, to assess the sustainability of their production systems and assist them in increasing their animals' performances. Individual interviews were conducted with 125 small ruminant farmers, using a questionnaire which included questions on their socioeconomic characteristics and farming practices. The farms were typified using the categorical principal component analysis followed by a Two-Step cluster analysis. Subsequently, the French IDEA (Farm Sustainability Indicators) method was adapted to local production conditions and used to assess the agro-ecological, socio-territorial and economic sustainability of the obtained farm types. Six small ruminant farm types were identified as follows: Goat only (36.80\%), Sheep only (12\%), Sheep-goat (8.80\%), Mixed sheep-goat-crop (12.80\%), Mixed sheep-crop (5.60\%) and Mixed goat-crop (24\%). As perceived by the respondents, rapid urbanization, agricultural expansion and climate variability affect negatively the availability of grazing areas (76\%), biomass production in grasslands (98\%), animals' access to forage (97\%) and animal growth. Farmers' coping strategies included adoption of free scavenging systems (94\%) and feed supplementation with agro-processing by-products (82\%) or tree fodders (64\%). The agro-ecological and economic sustainability components scores varied ( $\mathrm{p} \leq 0.05)$ across farm types. The Mixed sheep-goatcrop farm type obtained the highest $(\mathrm{p} \leq 0.001)$ total sustainability score $(149.88)$ whereas the lowest score (122.09) was obtained by Goat only farm type. These results highlight the importance of farm activities diversification in enhancing the sustainability of smallholder small ruminant farms.

Key words: Climate variability, diversification, resilience, small ruminant, smallholder, urbanization 


\title{
Structures of and prospects for sheep and goat farming, sustainability
}

\section{Characteristics of goat transhumance and its benefits for environmental sustainability}

\author{
$\underline{\text { Sezen Ocak Yetișgin }}^{1}$ and Hasan Alp Şahin ${ }^{1}$ \\ ${ }^{1}$ Ondokuz Mayss University, Department of Animal Science, Samsun, Turkey \\ Contact: Sezen Ocak Yetisgin, Ondokuz Mayıs University, Faculty of Agriculture, Department of Animal \\ Science- 55139 Samsun, Turkey; sezenocak1@gmail.com; +905322151989
}

\begin{abstract}
:
Transhumance- seasonal migration of livestock and human, is a dynamic production strategy between spatial and temporal environments in many parts of the world. Beyond their benefits to the ecosystem, they face various challenges at different scales around the globe. The origins of transhumance in Turkey dates back to the Neolithic period, and today- two different transhumance systems are present in Turkey (sheep and goat transhumance). This type of production is an historical and traditional strategy to the climatic changes and inaccessibility. In addition to its cultural significance they have an important role on maintaining cultural landscapes and ecosystem services. Transhumance practice in Turkey has been affected by many factors resulting with a dramatic decline of the herders although they shaped for more than 1000 years the ecosystem in the mountainous areas and contributed economically to the livelihoods. In this paper we will focus on goat transhumance, an ancient transhumance system where Turkish herders for centuries move with their goats from Mediterranean lowlands where they winter, to the central Anatolian highlands for rich summer grazing areas. For this aim, a qualitative research approach with in depth-face to face interviews was used to interview 26 transhumant families from the same community named" Sarıkeçili". Participant observation was conducted in the research area during one year by spending a week /month in order to observe the daily routines. The aim was to characterize their spatial-temporal movement patterns, contemporary production practices and ecosystem services they provide. Land use/cover information for 1990 and 2018 was analyzed by Geographic Information Systems (GIS) and Remote Sensing (UA) systems. According to the results, shrublands and natural grasslands have decreased during the study period, \%13.9 and 8.2, respectively while urban \& industrial areas and agriculture lands increased \%87 and 10, respectively. Number of herders were decreased $134,7 \%$ in the last 30 years. Transhumance abandonment caused a significant reduction in shrublands and natural grasslands. Considering biodiversity and ecosystem sustainability, it is already a critical issue in the Mediterranean region of Turkey and affecting a whole system.
\end{abstract}




\section{Structures of and prospects for sheep and goat farming, sustainability \\ Oral presentations}

\section{What policy and future do sheep and goats need in Iran?}

\section{Farhad Mirzaei}

Animal Science Research Institute of Iran, Karaj, Iran

Contact: farmir2001@gmail.com

\section{Abstract:}

Livestock agriculture in Iran covers over $40 \%$ of the agricultural activities. Sheep and goat production is one of the oldest productions in the country as it is considered the origin sheep and goat domestication in the world. Currently, more than $57 \%$ of the available animal units in the country are sheep and goats (mostly sheep and goats are together). Desertification, deforestation, water shortage, erosion, low efficiency, output, and illiterate small farmers are the typical Iranian shepherds' obstacles. Currently it has more than 44 million sheep and 19 million goats. Iranian sheep and goat are providing an important part of the demand for red meat at about 321000 tons and 93000 tons in 2018 respectively as a main product, but considerable production of milk, wool and hair too. Utilization of pastures, crops' post-harvest and agricultural wastes in small ruminants' feed, which are not mainly used for other livestock, and the taste of sheep and goats meat, and various delicious food made of their products are a part of the necessity of their production, development and stability across the country. More than 20 native breeds of these small ruminants are going to be threatened by socio - ecological issues in addition to economic challenges that it is discussed in this paper. It also covers different production systems and their problems solving how the present situation can be overcome to maintain and sustain sheep and goat driven hundred thousand livelihoods presently. Another purpose of this study is to analyze the factors that influence and determine accessible needs and appropriate policies for the sustainable future of sheep and goat production systems. The results of the study will explain that the condition factors (natural resources, human resources, infrastructure and technology) were the most important factors in increasing of the hopefulness of nomads and villagers to prevent critical effects on animalbased food security, if they move on their jobs. Therefore, more attention is required from the government and non-governmental organizations for handling this trend to the well-managed and right direction.

\section{References:}

\footnotetext{
Valizadeh,R.(2010). Iranian sheep and goat industry at a glance, Ferdowsi University of Mashhad, P.O. Box: 91775-1163, Mashhad, Iran.

Kamalzadeh, A., Rajabbaigy, M. \& Kiasat, A. (2008). Livestock Production Systems and Trends in Livestock Industry in Iran. Journal of Agriculture \& Social Sciences. 04: 183-88.

Statistical Center of Iran, annual report. (2019).
} 


\title{
Structures of and prospects for sheep and goat farming, sustainability
}

\section{Evaluation of dried citrus pulp based total mixed ration (TMR) for mutton (goat) production}

\author{
Abdur Rahman $^{1}$, Huma Kalsoom ${ }^{1}$, Sadia Khanum ${ }^{1}$ and Muhammad Sajid ${ }^{2}$ \\ ${ }^{1}$ Department of Animal Sciences, University of Veterinary and Animal Sciences, Jhang Campus, 35200, \\ Pakistan \\ ${ }^{2}$ Department of Pathobiology, University of Veterinary and Animal Sciences, Jhang Campus, 35200, \\ Pakistan \\ Contact: abdurrehman@uvas.edu.pk, Tel: +92-346-4607300
}

\section{Abstract:}

Pakistan contributes about $7 \%$ of mutton production, ranked $3^{\text {rd }}$ in goat rearing countries in the world after China and India. In Pakistan per capita consumption of animal protein is 17 grams compared to 27 grams in developed countries. Pakistan rank at $30^{\text {th }}$ number among 163 nations with food security. Mutton need and demand will be overwhelmingly increasing in coming years and it needs attention to enhance its efficient production. The major factor in cost effective production is feeding. The use of non-conventional feed resources, like citrus pulp waste as a replacement of energy and protein feeds may support the economical farming. In current study, a total of 12 bucks were divided into 4 groups each having 3 animals and fed total mixed ration for 90 days including 7 days as adaptation. Rations were formulated having dried citrus pulp at $0 \%$ (control), 10\%, 15\% and 20\% replacing corn, respectively. Performance parameters including feed intake, body weight gain, feed conversion ratio, hematological and serological parameters were evaluated. Results showed non-significant differences between all the treatment groups as compared to control group, which revealed that dried citrus pulp have equal potential to corn grains as an energy rich concentrate. In conclusion, dried citrus pulp has shown no adverse impact on buck health, proving that dried citrus pulp can replace corn grains in goat feeding and disposed in better way avoiding environmental pollution.

Keywords: Mutton production, Citrus pulp, Non-conventional feed resources 


\title{
Structures of and prospects for sheep and goat farming, sustainability
}

\section{Growth response of West African Dwarf sheep fed detoxified neem (Azadirachta indica) seed cake diets}

\author{
$\underline{\text { David Aderemi Ajayi }^{1} \text { and Micheal Kolawole Adewumi }}{ }^{2}$ \\ ${ }^{1}$ National Centre for Genetic Resources and Biotechnology, Moor Plantation, Ibadan, Nigeria \\ ${ }^{2}$ Department of Animal Science, University of Ibadan, Ibadan, Nigeria \\ Contact: Department of Animal Genetic Resources, National Centre for Genetic Resources and \\ Biotechnology, PMB 5382Moor Plantation, Ibadan, Nigeria, rhemiajayi@gmail.com, +2348034073868
}

\section{Abstract:}

Neem seed cake has potential to replace expensive soyabean meal in livestock diets but requires the removal of toxic bitter triterpenoids. Utilisation of detoxified neem seed cake in ruminant feeding has not been adequately documented, hence, performance of West African Dwarf sheep fed detoxified neem seed cake-based diets were assessed.

The neem seed cake was subjected to be either water-washing, sodium hydroxide-soaking, ammoniation or sun-curing. Six diets were formulated: I (20\% soyabean meal, control), II (raw neem seed cake), while the detoxified cakes were used to replace soyabean meal in four concentrate diets: III (water-washed), IV (sodium hydroxide-soaked), V (ammoniated) and VI (sun-cured). In a completely randomised design, thirty-six West African Dwarf sheep were randomly allotted to the six treatments with six replicates per treatment and were fed basal Guinea grass and experimental diets in ratio 70:30 for 105 days. Dry matter intake, crude protein intake, feed conversion ratio and daily weight changes were recorded. Data were analysed using ANOVA at $\alpha_{0.05}$.

The dry matter intake ranged from $218.14 \pm 29.23$ (II) to $330.69 \pm 7.74 \mathrm{~g} /$ day (V). The feed conversion ratio in sheep fed treated neem seed cake diets were similar to the control and better than raw neem seed cake diet, while daily weight changes in treatments I (54.95 g/day) and V (51.28 g/day) were higher than others. The crude protein intake was 39.00, 25.46, $37.06,35.16,32.27$ and $31.39 \mathrm{~g} /$ day for treatments I to VI respectively.

Ammoniated neem seed cake supplemented diet supports best performance in sheep growth response. 


\section{Structures of and prospects for sheep and goat farming, sustainability}

\section{Precision in shoats selection using telomeres}

\section{Mercy Mulandi, Rawlynce Bett and Joseph Jung'a}

University of Nairobi, Nairobi, Kenya

Contact: mercykabondo@gmail.com, +254700649328

\section{Abstract:}

Time wastage in the farm due to 'unseen' genetic and health disorders contributes to economic losses and high levels of methane, this occurs due to unprecise selection criteria. The heritable nature, correlation between lifespan, genetic diseases to telomere length is of great impact to the selection of suitable sheep in early life stages. Sheep and goat telomere length is heritable making it a possible parameter for selection. Telomeres are protective structures at the end of chromosomes that maintain the integrity of the genome by ensuring that chromosomes are not recognised as sites of DNA damage. This study followed the telomere measurement guidelines as described by Cawthon, 2002. We conducted two seperate PCRs simultaneously, a Telomere PCR and a Single copy gene (beta-2-microglobulin (B2M) PCR for all samples. This was as such in order to get the ratio between the two as the average telomere length is usually presented as the amount of single copy gene, which is a constant to the amount of telomeric DNA. B2M was used as it has been previously used in soay sheep and freshian cattle telomere dynamics experiments and has shown stable qPCR results.

The fluorescence thresholds were different across all samples. The single gene copy had an average of 2.081 while the TEL gene had an average of 2.123. The lengths are shorter for animals with lower growth rates, lower milk production, more disease manifestations and more reproductive disorders like abortions. The telomeres are longer for animals described to have a better quality life.

\section{References:}

Blackburn EH (2005) Telomeres and telomerase:their mechanisms of action and the effects of altering their functions.

Blackburn, E. \& Gall, J. A (1978).Tandemly Repeated Sequence at the Termini of Extrachromosomal Ribbosomal RNA Genes in Tetrahymena.

Blackburn, E. H. (1991). Structure and function of telomeres. 


\title{
Structures of and prospects for sheep and goat farming, sustainability
}

\section{Milk composition of Chusca goat (Capra aeagrus hircus) in husbandry extensive environment in the dry forest of the Southern of Ecuador}

\author{
Edgar Lenin Aguirre ${ }^{1}$, Ramiro Armijos ${ }^{1}$, Miriam Puchaicela $^{2}$, Belén Gahona ${ }^{2}$, Priscila Pineda ${ }^{2}$ \\ and Juan Pablo Riofrio ${ }^{2}$ \\ ${ }^{1}$ Agricultural Faculty, Veterinary Medicine and Zootechnics School, National University of Loja-Ecuador \\ ${ }^{2}$ Graduation Students in Veterinary Medicine and Zootechnics, National University of Loja-Ecuador \\ Contact: Av. Pio Jaramillo, Ciudadela "La Argelia", Loja city, Ecuador-South America, Telf. +593- \\ 986448562,edgar.aguirre@unl.edu.ec, leninaguirrer@yahoo.es
}

\begin{abstract}
:
The goat "Chusca Lojana", which is found in the tropical zone of the Dry Forest of the Province of Loja-Ecuador, where $73 \%$ of the goat population of the nationwide is found in this place. Is important to study the productive characteristics and the milk quality of this population, because this genetic resource represents a valuable socio-economic element for the habitants of this region. Production and milk quality of 198 goats managed extensively and from different herds were evaluated. For this, 4 periodic visits were made, where production was recorded at the different stages of lactation and milk samples were taken for analysis using Lactoscan Milk Analizer. It was determined that $64 \%$ has a globular udder, $93 \%$ have pigmented nipples, the productive life curve increases in third calving and reaches its peak in fourth, and then declines $\left(\mathrm{R}^{2}=0.82\right)$. Lactation duration is $140 \pm 20$ days, lactation curve follows a two period mobile trend, showing two peaks, one higher (30 days) and another of less intensity between 120-150 days coinciding with the post-weaning period, the mean production day is $390 \pm 231 \mathrm{ml}$. Both production and composition of milk, it is statistically affected by the place husbandry, calving number, lactation stage $(\mathrm{P}<0.05)$ and the biotype $(\mathrm{P}<0.1)$. The milk composition of this goat presents $5.5 \pm 1.9 \%$ Fat, $8.2 \pm 0.83 \%$ NFS, $13.7 \pm 2.1 \%$ Total Solids, $4.5 \pm 0.47 \%$ Lactose, $3 \pm 0.3 \%$ Protein, $0.68 \pm 0.07 \%$ Mineral Salts and $6.7 \pm 0.26 \mathrm{PH}$. With the information obtained from this study, those animals with a tendency to produce quality milk can be standardized for the purposes of selection, management and multiplication.
\end{abstract}

\section{References:}

Djebly, I., Ameur-Ameur, A., Gaouar, S. (2020). General characteristics of goat milk cheese (Feta) in the region of Tlemcen, Algeria. Genet. Biodiv. J, 4(2), 60-73. Available at: http://ojs.univ-tlemcen.dz/index.php/GABJ/article/view/760. 


\title{
Structures of and prospects for sheep and goat farming, sustainability
}

\section{In vitro assessment of the larval exsheathment inhibition of extracts of Lentinula edodes (Shiitake) against Haemonchus contortus $\left(\mathrm{L}_{3}\right)$}

\author{
Tania María Rodríguez-Barrera, ${ }^{1,2}$, Jetzabelt Ambrosio-Bautista ${ }^{3}$, Maura Téllez-Téllez $^{2}$, José E. \\ Sánchez $^{4}$, Gloria Sarahí Castañeda-Ramírez ${ }^{1}$, María de Lourdes Acosta-Urdapilleta ${ }^{2}$ and \\ Liliana Aguilar-Marcelino ${ }^{1}$
}

${ }^{1}$ Centro Nacional de Investigación Disciplinaria en Salud Animal e Inocuidad, INIFAP, Km 11 Carretera Federal Cuernavaca-Cuautla, No. 8534, Col. Progreso, Jiutepec, Morelos, México, C.P. 62550

${ }^{2}$ Centro de Investigaciones Biológicas, Universidad Autónoma del Estado de Morelos, Av. Universidad No. 1001, Col Chamilpa Cuernavaca, Morelos, México, C.P. 62209

${ }^{3}$ Facultad de Medicina Veterinaria y Zootecnia, Universidad Mesoamericana, Privada de la Soledad No. 311, Puebla de Zaragoza, México, C.P. 45575

${ }^{4}$ El Colegio de la Frontera Sur, Apdo. Postal 36, Tapachula, Chiapas, México, C.P. 30700

Contact: Dr Liliana Aguilar-Marcelino, aguilar.liliana@inifap.gob.mx, Phone: +52 7773192860 ext. 121

\section{Abstract:}

Livestock is one of the most important economic activities in Mexico, is a profitable sector that guarantees the production and supply of food. This sector is affected by parasites such as gastrointestinal nematodes. One of the main ones is the nematode $H$. contortus, this etiological agent is considered the cause of diseases that afflict small ruminants. An alternative to this problem is the edible mushroom $L$. edodes, which is a natural antagonist of parasitic nematodes of sheep (Al-ani et al., 2020; Pineda-Alegría et al., 2020). The objective of the present study was the determination of anthelmintic activity in vitro was carried out with the larval unsheath inhibition test. This study used the larval exsheathment test, which is based on measuring the inhibitory capacity of unsheathing using $\mathrm{L}_{3} \mathrm{H}$. contortus to interrupt the life cycle. Statistical analysis based on determining the percentage of inhibition of the unsheathing larvae $\mathrm{L}_{3} H$. contortus with the formula: percentage of unsheathing $=\left(\mathrm{L}_{3}\right.$ larvae without sheath)/(larvae with sheath + larvae without sheath) $\mathrm{x} 100$. The results of the five concentrations of the extract $(150,312.5,625,1250$ and $2500 \mu \mathrm{g} / \mathrm{mL})$ were evaluated with one-way ANOVA comparing means. The results show that a $L$. edodes obtained a percentage of $100 \%$ inhibition of larval unsheathing at a concentration of $2500 \mu \mathrm{g} / \mathrm{mL}$. In conclusion, the extract of $L$. edodes can be used as a sustainable integral control method in the livestock area. The present study was financed by the National Problems, CONACYT, project number 9342634372.

\section{References:}

Al-ani, L. Khalil, T., Aguilar-Marcelino, L., Fiorotti, J., Sharma, S., Sharif M., Furtado E.L., Wijayawardene N.N., Herrera-Estrella A. (2020). Biological Control Agents and Their Importance for Plant Health. In: Microbial Services in Restoration Ecology.

(Eds) Singh J.S., Raj Vimal S. Elsevier. U.S.A. p 42. doi.org/10.1016/B978-0-12-819978-7.00002-6

Pineda-Alegría, J.A., Sánchez, J.E., González-Cortázar, M., Von Son-de Fernex, E., González-Garduño, R., Mendoza-de Gives, P., Zamilpa A., Aguilar-Marcelino, L. (2020). In vitro nematocidal activity of commercial fatty acids and $\beta$-sitosterol against Haemonchus contortus. Journal of Helminthology, 94(135): 1-4. doi.org/10.1017/S0022149X20000152 


\title{
Structures of and prospects for sheep and goat farming, sustainability
}

\section{In vitro assessment of the larval exsheathment inhibition of extracts of edible mushroom Pleurotus djamor against Haemonchus contortus $\left(\mathrm{L}_{3}\right)$}

\author{
Jaime Cristóbal Hernández-Rodríguez ${ }^{1,2}$, Jetzabelt Ambrosio-Bautista ${ }^{4}$, Ivan Flores-Pérez ${ }^{2}$, \\ Juan Felipe de Jesús Torres-Acosta ${ }^{3}$, Gloria Sarahí Castañeda-Ramírez ${ }^{1}$, Claudia Hallal- \\ Calleros and Liliana Aguilar-Marcelino ${ }^{1}$ \\ ${ }^{1}$ Centro Nacional de Investigación Disciplinaria en Salud Animal e Inocuidad, INIFAP, Km 11 Carretera \\ Federal Cuernavaca-Cuautla, No. 8534, Col. Progreso, Jiutepec, Morelos, México, C.P. 62550 \\ ${ }^{2}$ Facultad de Ciencias Agropecuarias, Universidad Autónoma del Estado de Morelos, Av. Universidad 1001, \\ Col. Chamilpa, Cuernavaca, Morelos, Mexico, C.P. 62209 \\ ${ }^{3}$ Facultad de Medicina Veterinaria y Zootecnia, Universidad Autónoma de Yucatán, Km 15.5 Carretera \\ Mérida-Xmatkuil, CP 97100, Mérida, Yucatán, México \\ ${ }^{4}$ Facultad de Medicina Veterinaria y Zootecnia, Universidad Mesoamericana, Privada de la Soledad No. \\ 311, Puebla de Zaragoza, México, C.P. 45575
}

Contact: Dr Liliana Aguilar-Marcelino, aguilar.liliana@inifap.gob.mx, Phone: +52 7773192860 ext. 121

\section{Abstract:}

In the present study, it was carried out in vitro assessment of the larval exsheathment inhibition of extracts of Pleurotus djamor against Haemonchus contortus (L3). They were used in series 6 $(n=4)$. Series 1, (control group) contained PBS pH 7.4; series 2) 150,3$) 312.5,4) 625,5$ ) $1250,6) 2500 \mu \mathrm{g} / \mathrm{mL}$ of extract. The chlorine concentration was determined to induce the larvae exsheathment of an extra series of PBS (control group), the concentrations of chlorine (sodium hypochlorite (4.0 to 6.0\%) and sodium hydroxide (0.002-0.10\%) ) were: $20,30,40$, 45 and $60 \mu \mathrm{L}$ (Chan et al., 2017). It is taken in $50 \mu \mathrm{L}$ of each concentration of the extract and placed on the slide. To add chlorine solution to induce larvae, select and the number of sheathed and unsheathed larvae that were observed at each concentration $(0,20,40$, and 60 minutes). The following formula is used to determine the inhibition percentage of exsheathment (ID) at 60 min for each extract: exsheathment \% = (larvae L3 without sheath) / (larvae with sheath + larvae without sheath) x 100. ID\% = 100- exsheathment. ANOVA and the media comparison test were performed. The percentage of inhibition of larval exsheathment presented by the P. djamor extract was $100 \%$ at a concentration of $2,500 \mu \mathrm{g} / \mathrm{mL}$, $99.2 \%$ at the concentration of $1,250 \mu \mathrm{g} / \mathrm{mL}, 60.4 \%$ at a concentration of $625 \mu \mathrm{g} / \mathrm{mL}, 8.2$ with a concentration of $312.5 \mu \mathrm{g} / \mathrm{mL}, 2.6$ with a concentration of $150 \mu \mathrm{g} / \mathrm{mL}$. The present study was financed by the National Problems, CONACYT, project number 9342634372.

\section{References:}

Chan-Pérez, J.I., Torres-Acosta, J.F.J., Sandoval-Castro, C.A., CastañedaRamírez, G.S., Vilarem G., Mathieu, C., Hoste, H. 2017. Susceptibility of ten Haemonchus contortus isolates from different geographical origins towards acetone:water extracts of polyphenolrich plants. Part 2: infective Larvae. Vet Parasitol 240:11-16. doi: 10.1016/j.vetpar.2017.04.023 